\title{
The effectiveness of injections in cuffdisorders and improvement of diagnostics
}

Citation for published version (APA):

Penning, L. I. F. (2015). The effectiveness of injections in cuffdisorders and improvement of diagnostics.

[Doctoral Thesis, Maastricht University]. Maastricht University. https://doi.org/10.26481/dis.20151118/p

Document status and date:

Published: 01/01/2015

DOI:

10.26481/dis.20151118lp

Document Version:

Publisher's PDF, also known as Version of record

\section{Please check the document version of this publication:}

- A submitted manuscript is the version of the article upon submission and before peer-review. There can be important differences between the submitted version and the official published version of record.

People interested in the research are advised to contact the author for the final version of the publication, or visit the DOI to the publisher's website.

- The final author version and the galley proof are versions of the publication after peer review.

- The final published version features the final layout of the paper including the volume, issue and page numbers.

Link to publication

\footnotetext{
General rights rights.

- You may freely distribute the URL identifying the publication in the public portal. please follow below link for the End User Agreement:

www.umlib.nl/taverne-license

Take down policy

If you believe that this document breaches copyright please contact us at:

repository@maastrichtuniversity.nl

providing details and we will investigate your claim.
}

Copyright and moral rights for the publications made accessible in the public portal are retained by the authors and/or other copyright owners and it is a condition of accessing publications that users recognise and abide by the legal requirements associated with these

- Users may download and print one copy of any publication from the public portal for the purpose of private study or research.

- You may not further distribute the material or use it for any profit-making activity or commercial gain

If the publication is distributed under the terms of Article $25 \mathrm{fa}$ of the Dutch Copyright Act, indicated by the "Taverne" license above, 

The effectiveness of injections in cuffdisorders and improvement of diagnostics

Ludo I.F. Penning 
Colophon

Author:

Ludo I.F. Penning

Cover design en lay-out: Miranda Dood, Mirakels Ontwerp

Printing:

Gildeprint - The Netherlands

ISBN:

978-90-824414-0-6

The publication of this thesis was kindly supported by:

Nederlandse Orthopedische Vereniging

Stichting OrthoResearch Nijmegen

Stichting Kliniek en Wetenschap Orthopedie Maastricht

(CLudo I.F. Penning, 2015

All rights reserved. No part of this publication may be reproduced or transmitted in any form by any means, without permission of the author. 


\section{The effectiveness of injections in cuffdisorders and improvement of diagnostics}

\section{PROEFSCHRIFT}

ter verkrijging van de graad van doctor aan

de Universiteit Maastricht, op gezag van de Rector Magnificus, Prof. dr. L.L.G. Soete volgens het besluit van het College van Decanen, in het openbaar te verdedigen op woensdag 18 november 2015 om 12:00 uur

door

Ludo Ivar Folmer Penning 


\section{Promotiecommissie:}

\section{Promotores:}

Prof. dr. G.H.I.M. Walenkamp

Prof. dr. R.A. de Bie

\section{Beoordelingscommissie:}

Prof. dr. A.E.R.C.H. Boonen (voorzitter)

Prof. dr. G.J. Dinant

Dr. J.J.X.R. Geraets, Fysiotherapie Schaesberg, Landgraaf

Prof. dr. G.J.M.G. van der Heijden, Academisch Centrum Tandheelkunde Amsterdam

Prof. dr. M. van Kleef 



\section{Table of Contents}

$\begin{array}{lll}\text { Chapter } 1 \text { General introduction } & \text { p.10 }\end{array}$

Chapter 2 The effectiveness of injections of hyaluronic acid p.24 or corticosteroid in patients with subacromial impingement: a three-arm randomised controlled trial.

Penning L.I.F., de Bie R.A., Walenkamp G.H.I.M. J Bone Joint Surg Br. 2012 Sep;94(9):1246-52.

Chapter 3 Subacromial triamcinolone acetonide, hyaluronic acid and saline injections for shoulder pain an RCT investigating the effectiveness in the first days.

Penning L.I.F., de Bie R.A., Walenkamp G.H.I.M.

BMC Musculoskelet Disord. 2014 Oct 23;15(1):352.

Chapter 4 Empty can and drop arm tests for cuff rupture: Improved specificity after subacromial injection Penning L.I.F., de Bie R.A., Leffers P., Weijers R.E., Walenkamp G.H.I.M. Accepted: Acta Orthopaedica Belgica 2015.

Chapter 5 Painful shoulder movement in the frontal plane, a gradation of the painful arc

Penning L.I.F., de Bie R.A., Walenkamp G.H.I.M.

Chapter 6 Reliability study of the sonographic measurement of the acromiohumeral distance in symptomatic patients. Pijls B.G., Kok F.P., Penning L.I.F., Guldemond N.A., Arens H.J. J Clin Ultrasound. 2010 Mar-Apr;38(3):128-34. 
Chapter 7 Reproducibility of a 3-dimensional gyroscope in p.118 measuring shoulder anteflexion and abduction.

Penning L.I.F., Guldemond N.A., de Bie R.A.,

Walenkamp G.H.I.M.

BMC Musculoskelet Disord. 2012 Jul 30;13:135.

Chapter 8 General discussion

p.138

Chapter 9 Summary / Nederlandse samenvatting

p.152

Acknowledgements

p.166

Curriculum Vitae

p.171

Valorisation

p.172 


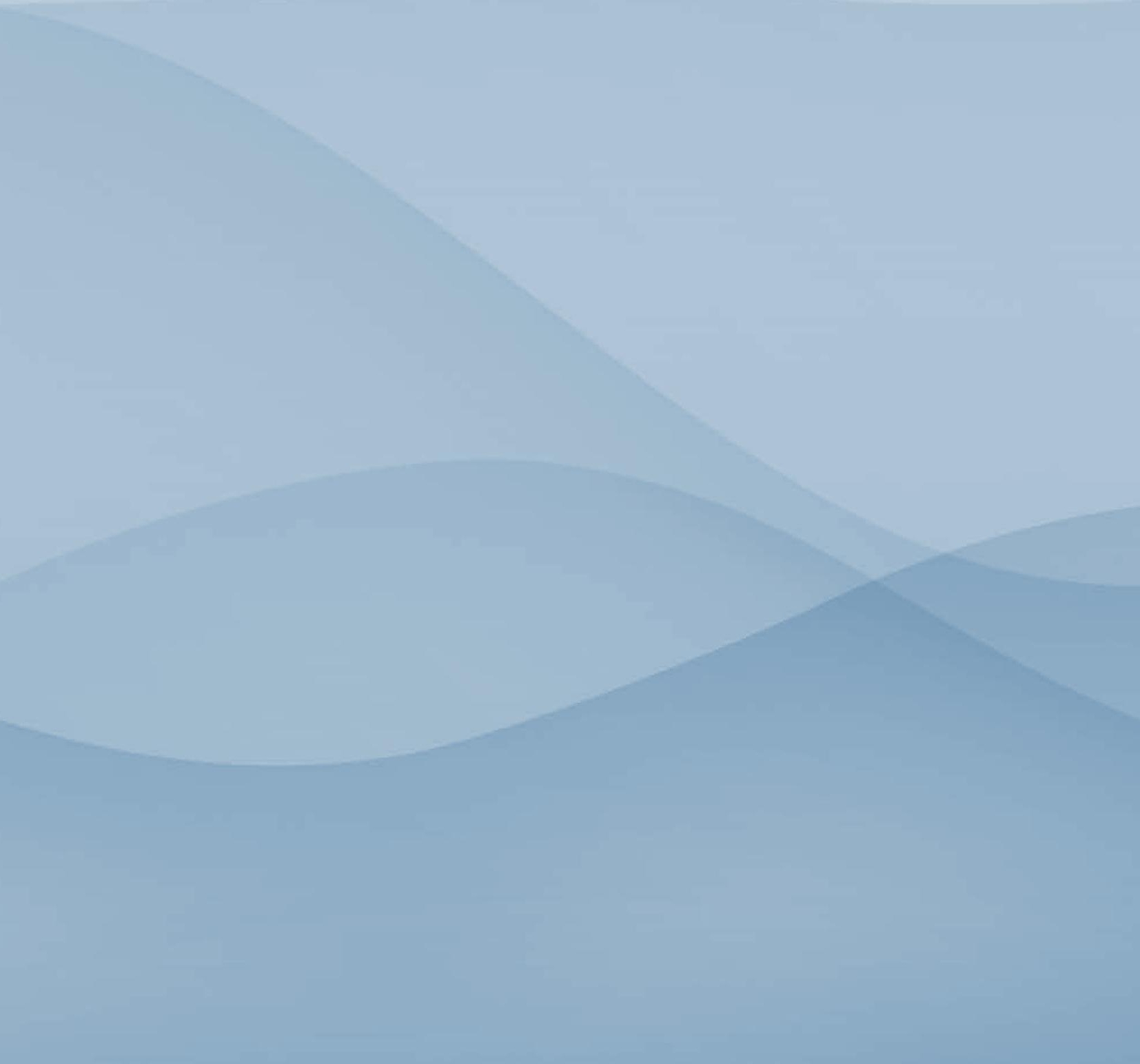


Chapter 1

General introduction 


\section{General introduction}

Shoulder complaints are frequently encountered in the general population, the incidence rates range from 0.9 - $2.5 \%$. In General Practice incidence rates range from $1.2-2.5 \% .^{(1-3)}$ The Incidence rate of shoulder complaints in Orthopedic practice in the Netherlands in 2012 is estimated at $9 \%{ }^{(4)}$

Most complaints consist of pain in the upper arm and deltoid region, sometimes accompanied by stiffness. ${ }^{(5,6)}$ Although a majority of these complaints is treated in General practice, approximately $17 \%$ of patients will be referred to secondary care. Secondary care is defined as physiotherapy, orthopedic surgery or rheumatology. ${ }^{(7)}$

There is a variety of causes and sources of shoulder disorders. A rather large group consists of subacromial localized shoulder complaints. In secondary care subacromial complaints account for $36 \%$ of the cases. ${ }^{(8)}$ Although these complaints were traditionally explained based on an anatomical subacromial impingement ${ }^{(9)}$ there is a tendency to describe the complaints as subacromial pain. ${ }^{(10)}$ Subacromial complaints are therefore only partly the result of an impingement of the bursa and rotator cuff. In general the impingement is the result of a decreased acromiohumeral distance. A number of causes have been described for the subacromial pain syndrome; calcified tendonitis, osteoarthritic osteophytes, micro instability and overuse. ${ }^{(11)}$ Further stages of the impingement as well as genetic predisposition and wear and tear lead to degeneration of the cuff causing pain. $(10,12,13)$

Some patients with a tendonitis will develop a calcified tendonitis and the accompanying pain will give rise to changes in the movement pattern of the shoulder. ${ }^{(14,15)}$

In case of osteoarthritis of the acromioclavicular joint caudally localized osteophytes can induce a subacromial bursitis, or irritate the cuff. ${ }^{(16)}$ Long lasting complaints lead to thinning and degeneration of the cuff. ${ }^{(17,18)}$

In young patients presenting with a subacromial bursitis, this can be secondary to an unstable shoulder. Repetitive microtraumatic stresses placed on the anterior shoulder capsule can cause a micro instability. This micro instability can worsen injuries such as rotator cuff tendonitis, internal impingement and SLAP lesions. ${ }^{(19-21)}$ 
Another cause for impingement is scapular dyskinesia, based on the changed movement pattern of the scapula. In dyskinesia an increase and altered tilt of the scapula leads to a relative narrowing of the subacromial space. The narrowing of the subacromial space gives an impingement of the cuff and bursa. Repeated impingement will lead to a subacromial bursitis. In case of long lasting bursitis or tendonitis, there is a risk for development of degeneration of the cuff and rupture of the cuff. ${ }^{(22,23)}$

Most patients presenting with a subacromial bursitis will have pain in the deltoid muscle region ranging from its origin at the clavicle and acromion process and scapular spine to its insertion at the middle part of the humerus, especially during overhead activities. During physical examination most patients have a painful arc between 90 and 140 degrees of abduction in the frontal plane. The patients present with normal exorotation and endorotation. In some patients endorotation is painful and limited. ${ }^{(24-26)}$

Approximately half of shoulder complaints presented in primary care is self-limiting and will not be seen in secondary care. ${ }^{(3)}$ The treatment regimen for shoulder complaints is mainly based on the duration of complaints. At first complaints will be treated with acetaminophen (paracetamol) or NSAID's (Non-steroidal Anti Inflammatory Drugs). In case of longer lasting complaints patients will be treated with physical therapy and / or subacromial injections. ${ }^{(10,27)}$

The treatment regimen in primary care in the Dutch setting is largely based on the amount and duration of complaints. Differentiation concerning the cause of complaints is restricted to shoulder complaints with limited passive range of motion, shoulder complaints with painful abduction, without limited passive range of motion and shoulder complaints without limited passive range of motion and without painful abduction. This diagnostic strategy is based upon the assumption that General Practitioners are not able to make a further differentiation using information from history taking and physical examination. ${ }^{(27)}$

A thorough history and physical examination however can aid in further differentiation of many common shoulder complaints. ${ }^{(28,29)}$

In case of long lasting complaints the risk of developing cuff pathology is large ${ }^{(12)}$ therefore there is a need for further differentiation of complaints. 
Patients with shoulder complaints in primary and secondary care probably only differ concerning the duration of complaints. The type and presentation of complaints are the same. Therefore, for both care settings the approach should be the same and should consist of thorough history taking and extensive physical examination. Although injections are primarily used for treatment they can also be used as a diagnostic tool. ${ }^{(9,30)}$ Based on the result of the injection a further differentiation has to be made. In recent years there is a tendency for early use of diagnostic imaging, in both secondary and primary care. ${ }^{(31)}$ Ultrasound findings, however, do not always correlate with the result of subacromial injections. ${ }^{(32)}$

A number of tests have been developed to discriminate the different causes and sources of shoulder complaints. They showed a rather limited sensitivity and specificity. ${ }^{(26,33-35)} \mathrm{A}$ number of studies that have investigated the applicability of shoulder tests advocate the use of multiple tests instead of the use of single tests. Single tests lack sufficient power to differentiate between the cause and source of shoulder complaints. ${ }^{(36,37)}$

In case of subacromial pain not responding to non-invasive conservative treatment, a cuff rupture should be excluded as a cause for the complaints. As previously described the sensitivity and specificity of single shoulder tests is limited. Combination of tests is advocated. In this perspective the result of subacromial injection should be combined with the result of other clinical tests. So the subacromial injection is used for both treatment and diagnosis. The pain reducing effect of the injection is interpreted according to the Neer test ${ }^{(9)}$ and therefore of value for diagnosis and prognosis. ${ }^{(38)}$ The result of this Neer test can be combined with the other performed shoulder tests. The interpretation of the combined test results will lead to a better differentiation in the type of shoulder complaint with higher sensitivity and specificity.

When conservative non-invasive treatment fails most physicians in both primary and secondary care will treat the shoulder complaints with a subacromial injection. ${ }^{10}$, ${ }^{27,39-41)}$ The majority of injections will be blindly placed based on anatomical landmarks, from a dorsal or lateral approach. Several studies have investigated the use of ultrasound for subacromial injections. ${ }^{(41-44)}$ Cadaver studies showed an accuracy of $80-91 \%$ of subacromial placed injections, when administered by experienced physicians. ${ }^{(45,46)}$ 
Although there seem to be difficulties in accurate placement of subacromial injections in some studies, another study showed effectiveness of corticosteroid injections irrespective of accurate placement. ${ }^{(44)}$

The corticosteroids tend to work fast, already during the first days after administration. $(40,47)$ The subacromial injection is the treatment of first choice for subacromial pain after adequate conservative noninvasive treatment.

Based on the profile of the effect of treatment, corticosteroid injections are used on a wide scale.

There are no good directions on how to use these injections, concerning the frequency of administration, type $\mathrm{e}^{(48)}$ and dose of corticosteroid and injection site $\mathrm{e}^{(41)}$. Limited is known about the effect of repetition of corticosteroid injections. ${ }^{(49,50)}$ Most guidelines advocate to repeat the corticosteroid injections in case of successful reduction of pain ${ }^{(10,}$ $27,50,51)$ In the recently published guideline for subacromial pain syndrome, the maximum number of injections was set at four to six injections per year. ${ }^{(52)}$ The maximum number of repeated injections is largely based on the effect of corticosteroids on cuff tissue as investigated in animal studies. ${ }^{(53,54)}$ As far as we know there are no studies that have investigated the number of repetitions of subacromial injections.

A number of studies concerning the effect of corticosteroids on tendon tissue were reviewed ${ }^{(55)}$, based on the result there is a tendency to discourage the use of corticosteroids. The main reason is based on possible early deterioration of the cuff tissue. The number of reported corticosteroid induced cuff ruptures seems to be limited and animal studies show the regenerative effect of cuff tissue after corticosteroid injection. ${ }^{(53)}$

Subacromial corticosteroid injections are mostly administered in combination with a local anesthetic. The effectiveness of subacromial corticosteroid injections has been investigated in a number of studies. ${ }^{(56-59)}$ Only a few studies have compared injections with corticosteroids and local anesthetic to local anesthetic alone. ${ }^{(58,60,61)}$

Hyaluronic acid is an anionic, non-sulfated glycosaminoglycan. It is found throughout the body in neural, connective and epithelial tissue. It is believed to have lubricant and anti-inflammatory effects. A few studies have investigated the effect of hyaluronic acid 
injections in case of subacromial complaints. In these studies improvement in pain was shown. ${ }^{(62-67)}$

In this thesis we describe the results of a three arm RCT performed to investigate the effectiveness of shoulder injections. We compared corticosteroid injections with local anesthetic and hyaluronic acid injections with local anesthetic to injections with local anesthetic and saline (sodium chloride).

Although a number of clinical tests can be applied to differentiate between various shoulder complaints, there still are some difficulties in the interpretation of these tests. For this thesis we have performed several studies addressing a diagnostic approach in shoulder complaints. In two studies we mainly focused at simple test strategies for the diagnosis of a cuff rupture. In a third study we focused on the reproducibility of a device measuring abduction and anteflection movement. In a fourth study we describe a proposed classification system for gradation of a painful arc.

One of the aims of this thesis was to develop a simple deployable diagnostic and treatment strategy for both first and second line healthcare.

\section{Questions and aims in this thesis:}

\section{Therapy:}

1. What is the effectiveness of subacromial injections in subacromial impingement with respect to patient perceived pain, disability and function and is there a difference between corticosteroid injections and hyaluronic acid?

2. Do injections with a combination of hyaluronic acid and lidocaine give a better reduction in pain, disability and function than injections in which a placebo is combined with lidocaine?

3. Do injections with a combination of a corticosteroid and lidocaine give a better reduction in pain, disability and function than injections in which a placebo is combined with lidocaine?

4. Is there an accumulative effect of repeated injections with corticosteroids?

5. What is the optimum number of repetitions of subacromial injections? 


\section{Diagnosis:}

6. Can the diagnostic and clinical value of the empty can and drop arm test for cuff disorders be improved by combining this test with a subacromial injection with lidocaine?

7. What is the diagnostic value of a gradation of the painful arc in subacromial impingement?

8. To what extent differ the observations of the acromio-humeral distance on ultrasound between experienced and non-experienced observers?

9. What is the reproducibility of measuring anteflexion and abduction with a 3 dimensional gyroscope?

10. What could be a new strategy for the diagnosis and treatment of subacromial complaints based on the studies performed for this thesis?

In chapter 2 we describe the results of a 3-arm RCT investigating the effectiveness of subacromial injections of hyaluronic acid and corticosteroids compared to a placebo.

In chapter 3 we describe the effectiveness of subacromial injections in the first days after administration.

In chapter 4 we report the results of the combination of single shoulder tests.

In chapter 5 we describe the possible diagnostic value of gradation of a painful arc in shoulder complaints.

In chapter 6 we report the results of a reliability study investigating the sonographic measurement of acromiohumeral distance in symptomatic patients.

In chapter 7 we report the reproducibility of a 3-dimensional gyroscope measuring ante flection and abduction. 


\section{References}

1. Luime, J.J., et al., Prevalence and incidence of shoulder pain in the general population; a systematic review. Scand J Rheumatol, 2004. 33(2): p. 73-81.

2. van der Windt, D.A., et al., Shoulder disorders in general practice: incidence, patient characteristics, and management. Ann Rheum Dis, 1995. 54(12): p. 959-64.

3. Greving, K., et al., Incidence, prevalence, and consultation rates of shoulder complaints in general practice. Scandinavian Journal of Rheumatology, 2012. 41(2): p. 150-155.

4. DBC Onderhoud. 2015; Available from: http://www.dbcinformatiesysteem.nl/.

5. van der Heijden, G.J., Shoulder disorders: a state-of-the-art review. Baillieres Best Pract Res Clin Rheumatol, 1999. 13(2): p. 287-309.

6. Huisstede, B.M., et al., Multidisciplinary consensus on the terminology and classification of complaints of the arm, neck and/or shoulder. Occup Environ Med, 2007. 64(5): p. 313-9.

7. Linsell, L., et al., Prevalence and incidence of adults consulting for shoulder conditions in UK primary care; patterns of diagnosis and referral. Rheumatology (Oxford), 2006. 45(2): p. 215-21.

8. Juel, N.G. and B. Natvig, Shoulder diagnoses in secondary care, a one year cohort. BMC Musculoskelet Disord, 2014. 15: p. 89.

9. Neer, C.S., 2nd, Impingement lesions. Clin Orthop Relat Res, 1983(173): p. 70-7.

10. Diercks, R., et al., Guideline for diagnosis and treatment of subacromial pain syndrome: a multidisciplinary review by the Dutch Orthopaedic Association. Acta Orthop, 2014. 85(3): p. 314-22.

11. Michener, L.A., P.W. McClure, and A.R. Karduna, Anatomical and biomechanical mechanisms of subacromial impingement syndrome. Clinical Biomechanics, 2003. 18(5): p. 369-379.

12. Keener, J.D., et al., A Prospective Evaluation of Survivorship of Asymptomatic Degenerative Rotator Cuff Tears. Vol. 97. 2015. 89-98.

13. McFarland, E.G., et al., Impingement is not impingement: the case for calling it "Rotator Cuff Disease". Muscles Ligaments Tendons J, 2013. 3(3): p. 196-200.

14. Krasny, C., et al., Ultrasound-guided needling combined with shock-wave therapy for the treatment of calcifying tendonitis of the shoulder. Journal of Bone \& Joint Surgery, British Volume, 2005. 87-B(4): p. 501-507. 
15. Khan, Y., et al., The Painful Shoulder: Shoulder Impingement Syndrome. The Open Orthopaedics Journal, 2013. 7: p. 347-351.

16. Klonz, A. and D. Loitz, [The acromioclavicular joint]. Der Unfallchirurg, 2005. 108(12): p. 1049-58, quiz 1059.

17. Neviaser, A., N. Andarawis-Puri, and E. Flatow, Basic mechanisms of tendon fatigue damage. Journal of Shoulder and Elbow Surgery, 2012. 21(2): p. 158-163.

18. Lohr, J.F. and H.K. Uhthoff, [Epidemiology and pathophysiology of rotator cuff tears]. Orthopade, 2007. 36(9): p. 788-95.

19. Reinold, M.M. and A.S. Curtis, MICROINSTABILITY OF THE SHOULDER IN THE OVERHEAD ATHLETE. International Journal of Sports Physical Therapy, 2013. 8(5): p. 601-616.

20. Nordenson, U., et al., Minor or occult shoulder instability: an intra-articular pathology presenting with extra-articular subacromial impingement symptoms. Knee Surg Sports Traumatol Arthrosc, 2011. 19(9): p. 1570-5.

21. Ellenbecker, T.S. and A. Cools, Rehabilitation of shoulder impingement syndrome and rotator cuff injuries: an evidence-based review. Br J Sports Med, 2010. 44(5): p. 319-27.

22. Kibler, W.B. and J. McMullen, Scapular dyskinesis and its relation to shoulder pain. J Am Acad Orthop Surg, 2003. 11(2): p. 142-51.

23. Kibler, W.B., et al., Clinical implications of scapular dyskinesis in shoulder injury: the 2013 consensus statement from the 'scapular summit'. British Journal of Sports Medicine, 2013. 47(14): p. 877-885.

24. O'Kane, J.W. and B.G. Toresdahl, The evidenced-based shoulder evaluation. Curr Sports Med Rep, 2014. 13(5): p. 307-13.

25. Hermans, J., et al., Does this patient with shoulder pain have rotator cuff disease?: The Rational Clinical Examination systematic review. JAMA, 2013. 310(8): p. 837-47.

26. Calis, M., et al., Diagnostic values of clinical diagnostic tests in subacromial impingement syndrome. Ann Rheum Dis, 2000. 59(1): p. 44-7.

27. Winters JC, v.d.W.D., Spinnewijn WEM, De Jogh AC, Van der Heijden GJMG, Buis PAJ, Boeke AJP, Feleus A, Geraedts JJXR NHG-Standaard Schouderklachten. Huisarts en Wetenschap, 2008. 51(11): p. 555-565.

28. Holmes, R.E., W.R. Barfield, and S.K. Woolf, Clinical evaluation of nonarthritic shoulder pain: diagnosis and treatment. Phys Sportsmed, 2015: p. 1-7. 
29. Braman, J.P., et al., Shoulder impingement revisited: evolution of diagnostic understanding in orthopedic surgery and physical therapy. Med Biol Eng Comput, 2014. 52(3): p. 211-9.

30. Singh, H.P., S.S. Mehta, and R. Pandey, A preoperative scoring system to select patients for arthroscopic subacromial decompression. J Shoulder Elbow Surg, 2014. 23(9): p. 1251-6.

31. Ottenheijm, R.P., et al., Ultrasound imaging for tailored treatment of patients with acute shoulder pain. Ann Fam Med, 2015. 13(1): p. 53-5.

32. Bouju, Y., et al., Do subacromial ultrasonography findings predict efficacy of intra-bursal injection? Prospective study in 39 patients. Orthop Traumatol Surg Res, 2014. 100(8 Suppl): p. S361-4.

33. Luime, J., Diagnostic evaluation of shoulder pain: a systematic review on the accuracy of signs and symptoms related to rotator cuff disorders. $\mathrm{PhD}$ thesis: Shoulder complaints; the occurence, course and diagnosis. 2004, Rotterdam, The Netherlands.

34. Park, H.B., et al., Diagnostic accuracy of clinical tests for the different degrees of subacromial impingement syndrome. J Bone Joint Surg Am, 2005. 87(7): p. 1446-55.

35. Hegedus, E.J., et al., Physical examination tests of the shoulder: a systematic review with meta-analysis of individual tests. Br J Sports Med, 2008. 42(2): p. 80-92; discussion 92.

36. Hanchard, N.C., et al., Physical tests for shoulder impingements and local lesions of bursa, tendon or labrum that may accompany impingement. Cochrane Database Syst Rev, 2013. 4: p. CD007427.

37. Biederwolf, N.E., A proposed evidence-based shoulder special testing examination algorithm: clinical utility based on a systematic review of the literature. Int J Sports Phys Ther, 2013. 8(4): p. 427-40.

38. Mair, S.D., et al., Can the impingement test predict outcome after arthroscopic subacromial decompression? Journal of Shoulder and Elbow Surgery, 2004. 13(2): p. 150-153.

39. Green, S., et al., Systematic review of randomised controlled trials of interventions for painful shoulder: selection criteria, outcome assessment, and efficacy. Bmj, 1998. 316(7128): p. 354-60.

40. Coombes, B.K., L. Bisset, and B. Vicenzino, Efficacy and safety of corticosteroid injections and other injections for management of tendinopathy: a systematic review of randomised controlled trials. Lancet, 2010. 376(9754): p. 1751-67.

41. Marder, R.A., et al., Injection of the subacromial bursa in patients with rotator cuff syndrome: a prospective, randomized study comparing the effectiveness of different routes. J Bone Joint Surg Am, 2012. 94(16): p. 1442-7. 
42. Henkus, H.E., et al., The accuracy of subacromial injections: a prospective randomized magnetic resonance imaging study. Arthroscopy, 2006. 22(3): p. 277-82.

43. Bloom, J.E., et al., Image-guided versus blind glucocorticoid injection for shoulder pain. Cochrane Database Syst Rev, 2012. 8: p. CD009147.

44. Ekeberg, O.M., et al., Subacromial ultrasound guided or systemic steroid injection for rotator cuff disease: randomised double blind study. BMJ, 2009. 338: p. a3112.

45. Partington, P.F. and G.H. Broome, Diagnostic injection around the shoulder: hit and miss? A cadaveric study of injection accuracy. J Shoulder Elbow Surg, 1998. 7(2): p. 147-50.

46. Hanchard, N., et al., Accuracy and dispersal of subacromial and glenohumeral injections in cadavers. J Rheumatol, 2006. 33(6): p. 1143-6.

47. Lewis, M., et al., Local steroid injections for tennis elbow: does the pain get worse before it gets better?: Results from a randomized controlled trial. Clin J Pain, 2005. 21(4): p. 330-4.

48. Chavez-Lopez, M.A., et al., Methylprednisolone versus triamcinolone in painful shoulder using ultrasound-guided injection. Mod Rheumatol, 2009. 19(2): p. 147-50.

49. Bhatia, M., et al., Correlation between rotator cuff tears and repeated subacromial steroid injections: a case-controlled study. Ann R Coll Surg Engl, 2009. 91(5): p. 414-6.

50. Gaujoux-Viala, C., M. Dougados, and L. Gossec, Efficacy and safety of steroid injections for shoulder and elbow tendonitis: a meta-analysis of randomised controlled trials. Ann Rheum Dis, 2009. 68(12): p. 1843-9.

51. Buchbinder, R., S. Green, and J.M. Youd, Corticosteroid injections for shoulder pain. Cochrane Database Syst Rev, 2003(1): p. CD004016.

52. Diercks, R. Diagnostiek en behandeling van het subacromiaal pijnsyndroom. 2013 Available from: http://richtlijnendatabase.nl/richtlijn/saps/conservatieve_behandeling van_saps.html\#overwegingen.

53. Mikolyzk, D.K., et al., Effect of Corticosteroids on the Biomechanical Strength of Rat Rotator Cuff Tendon. The Journal of Bone \& Joint Surgery, 2009. 91(5): p. 1172-1180.

54. Wei, A.S., et al., The effect of corticosteroid on collagen expression in injured rotator cuff tendon. J Bone Joint Surg Am, 2006. 88(6): p. 1331-8.

55. Dean, B.J.F., et al., The risks and benefits of glucocorticoid treatment for tendinopathy: A systematic review of the effects of local glucocorticoid on tendon. Seminars in Arthritis and Rheumatism, (0).

56. Crawshaw, D.P., et al., Exercise therapy after corticosteroid injection for moderate to severe shoulder pain: large pragmatic randomised trial. Bmj. 340: p. c3037. 
57. Blair, B., et al., Efficacy of Injections of Corticosteroids for Subacromial Impingement Syndrome. J Bone Joint Surg Am, 1996. 78(11): p. 1685-9.

58. Alvarez, C.M., et al., A prospective, double-blind, randomized clinical trial comparing subacromial injection of betamethasone and xylocaine to xylocaine alone in chronic rotator cuff tendinosis. Am J Sports Med, 2005. 33(2): p. 255-62.

59. Gruson, K.I., D.E. Ruchelsman, and J.D. Zuckerman, Subacromial corticosteroid injections. J Shoulder Elbow Surg, 2008. 17(1 Suppl): p. 118S-130S.

60. Vecchio, P.C., B.L. Hazleman, and R.H. King, A double-blind trial comparing subacromial methylprednisolone and lignocaine in acute rotator cuff tendinitis. $\mathrm{Br}$ J Rheumatol, 1993. 32(8): p. 743-5.

61. Plafki, C., et al., Local anaesthetic injection with and without corticosteroids for subacromial impingement syndrome. Int Orthop, 2000. 24(1): p. 40-2.

62. Shibata, Y., et al., Clinical evaluation of sodium hyaluronate for the treatment of patients with rotator cuff tear. J Shoulder Elbow Surg, 2001. 10(3): p. 209-16.

63. Itokazu, M. and T. Matsunaga, Clinical evaluation of high-molecular-weight sodium hyaluronate for the treatment of patients with periarthritis of the shoulder. Clin Ther, 1995. 17(5): p. 946-55.

64. Iwata, H., Pharmacologic and clinical aspects of intraarticular injection of hyaluronate. Clin Orthop Relat Res, 1993(289): p. 285-91.

65. Funk, L., Hyaluronan vs steroid injections for subacromial impingement of the shoulder. Osteoarthritis Cartilage, 2005. 13(suppl A).

66. Chou, W.Y., et al., Effect of sodium hyaluronate treatment on rotator cuff lesions without complete tears: a randomized, double-blind, placebo-controlled study. J Shoulder Elbow Surg, 2010. 19(4): p. 557-63.

67. Merolla, G., P. Bianchi, and G. Porcellini, Ultrasound-guided subacromial injections of sodium hyaluronate for the management of rotator cuff tendinopathy: a prospective comparative study with rehabilitation therapy. Musculoskelet Surg, 2013. 97 Suppl 1: p. 49-56. 


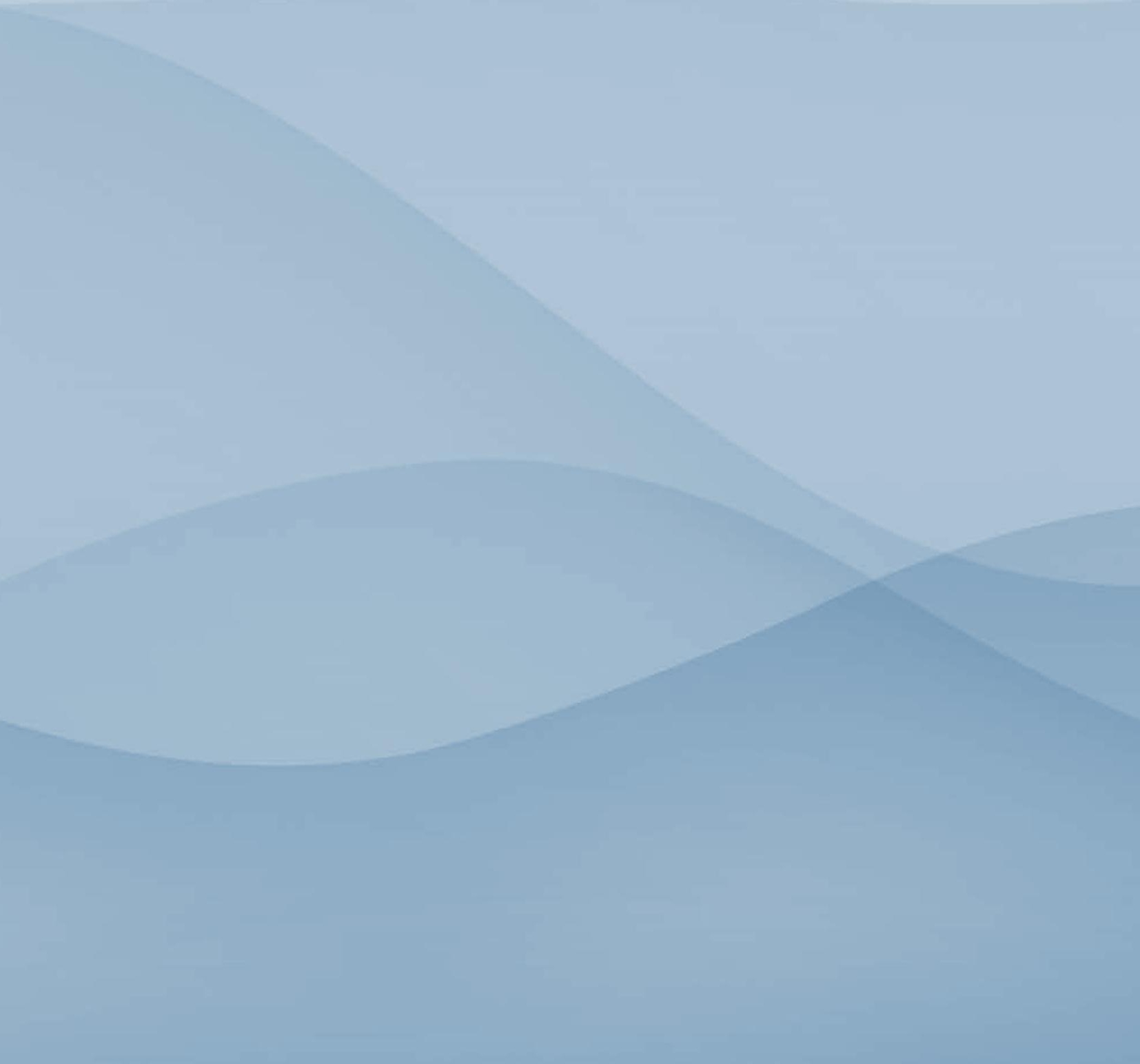




\section{Chapter 2}

The effectiveness of injections

of hyaluronic acid or

corticosteroid in patients with

subacromial impingement:

a three arm randomised trial

Penning L.I.F.

de Bie R.A.

Walenkamp G.H.I.M.

Journal of Bone and Joint Br 2012;94-B:1246-1252. 


\section{Abstract}

A total of 159 patients ( 84 women and 75 men, mean age of 53 (20 to 87)) with subacromial impingement were randomised to treatment with subacromial injections using lidocaine with one of hyaluronic acid (51 patients), corticosteroid (53 patients) or placebo (55 patients). Patients were followed up for 26 weeks. The primary outcome was pain on a visual analogue score (VAS), and secondary outcomes included the Constant Murley score, shoulder pain score, functional mobility score, shoulder disability questionnaire and pain- specific disability score. The different outcome measures showed similar results. After three, six and 12 weeks corticosteroid injections were superior to hyaluronic acid injections and only at six weeks significantly better than placebo injections. The mean short-term reduction in pain on the VAS score at 12 weeks was 7\% (SD 2.7; 97.5\% confidence interval (CI) 0.207 to $1.55 ; \mathrm{p}=0.084$ ) in the hyaluronic acid group, $28 \%$ (SD 2.8; $97.5 \%$ CI 1.86 to $3.65 ; \mathrm{p}<0.001$ ) in the corticosteroid group and $23 \%$ (SD 3.23; $97.5 \%$ CI 1.25 to $3.26 ; \mathrm{p}<0.001)$ in the placebo group. At 26 weeks there was a reduction in pain in $63 \%$ ( 32 of 51 ) of patients in the hyaluronic acid group, $72 \%$ ( 38 of 53 ) of those in the corticosteroid group and 69\% (38 of 55) of those in the placebo group.

We were not able to show a convincing benefit from hyaluronic acid injections compared with corticosteroid or placebo injections. Corticosteroid injections produced a significant reduction in pain in the short term (three to 12 weeks), but in the long term the placebo injection produced the best results. 
Shoulder disorders are common in general practice, with an incidence of 12 to 25 per 1000 per year ${ }^{(1,2)}$ and a prevalence in the general population in The Netherlands of $17 \%{ }^{(3)}$ They involve pain in the upper arm and deltoid region and stiffness that interferes with daily activities. ${ }^{(4)}$ The Dutch General Practitioner Guidelines (NHG Guideline) of $1999^{(5)}$ for treatment consists of acetaminophen (paracetamol) or low-dose nonsteroidal anti-inflammatory drugs (NSAIDs) in the first three to six weeks. When pain relief is insufficient, an injection with a combination of corticosteroid and lidocaine is generally recommended and, if necessary, repeated. These guidelines differentiate between subacromial and intra-articular pain, depending on whether there is limitation of rotation. If the latter is observed the pain is considered to be intra-articular, and the injection is given into the joint. If there is a painful arc, the subacromial bursa is considered to be involved and is injected. ${ }^{(5)}$ A more recent version of the guidelines (2008) also recommends physiotherapy or manipulative therapy. ${ }^{(6)}$ Crawshaw et $\mathrm{al}^{(7)}$ recently reported that physiotherapy combined with subacromial injections gives better results than each separately.

A number of clinical trials are reported in which subacromial corticosteroid injections were studied. ${ }^{(7-11)}$ In only three of these were corticosteroids and local anaesthetic compared with local anaesthetic alone. ${ }^{(11-13)}$ The results of only two trials were statistically pooled in a Cochrane review because of variations in methodological quality and outcome measures in the other trials. For rotator cuff disease the pooled results suggested a small benefit of subacromial corticosteroid injection over placebo at four weeks. ${ }^{(14)} \mathrm{A}$ few studies have shown improvement in pain and function following the subacromial injection of hyaluronic acid alone. ${ }^{(15-18)}$ Hyaluronic acid is thought to serve as a lubricant ${ }^{(19)}$ and is reported to have an anti-inflammatory effect. ${ }^{(20)}$

In this study we investigated the hypothesis that the addition of either hyaluronic acid or corticosteroid to lidocaine would produce a mean reduction in pain of $70 \%$ after 26 weeks, compared with $50 \%$ in the placebo group. 


\section{Patients and Methods}

The trial had ethical approval. Patients were recruited for this study from the department of orthopaedic surgery and local general practitioner practices. Eligible patients were over 18 years of age and had pain in the shoulder, either at rest or on movement. The diagnosis of impingement was made clinically without the routine use of ultrasound. All presented with a painful arc, with or without abnormal scapulohumeral movement. Exclusion criteria included: pain for less than six weeks; injection with corticosteroids in the preceding three months; flexion of $<100^{\circ}$ in the frontal plane; external rotation limited by $>50 \%$ compared with the opposite side; allergy to lidocaine, steroids or hyaluronic acid; pregnancy or suspected pregnancy; dementia; prior infection of the shoulder joints; tumour; osteoporosis; rheumatoid arthritis according to the American College of Rheumatology (ACR) criteria ${ }^{(21)}$; referred pain, such as from the neck; an associated neurological disorder; polymyalgia; ankylosing spondylitis as diagnosed using the modified New York (NY) criteria ${ }^{(22)}$; whiplash injury; previous fractures or surgery on the shoulder, upper limb, neck or thorax; and behavioural, cognitive or psychiatric disorders. Patients unable to complete Dutch questionnaires independently or reluctant to adhere to the allocated treatment or to complete follow-up were also excluded.

A total of 222 patients were referred with subacromial impingement; 63 were excluded due to reluctance to complete questionnaires in seven, reluctance to receive a placebo injection in ten, failure to meet the inclusion criteria in 25 , and other reasons in 21 . This left 159 patients in the study group (Fig. 1). There were 75 men and 84 women with a mean age of 53 years (20 to 87 ).

\section{Randomisation}

Patients were randomised blindly into three treatment groups. An independent statistician $(\mathrm{FK})$ generated a random numbers list which, by permutation of random blocks, block size 9, was balanced for treatments within strata. Strata were based on age ( $<40$ years versus $>40$ years). After selection and baseline assessment, consecutive numbered opaque envelopes of the appropriate stratum were opened by one of several independent trial nurses. 
Figure 1 - Randomisation of patients and patiënt flow in the trial

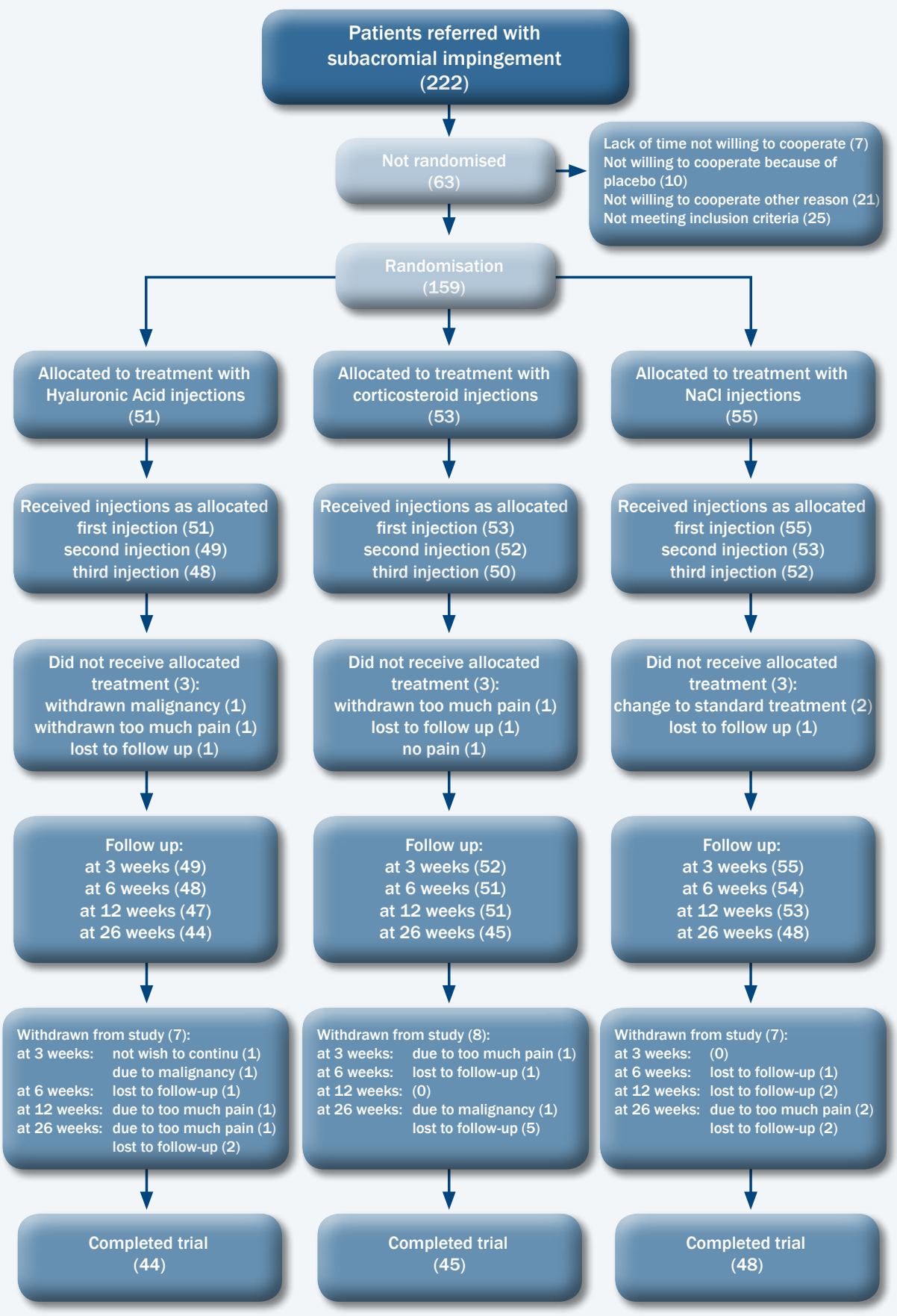




\section{Interventions}

Treatment consisted of subacromial injection with either: a mixture of $8 \mathrm{ml}$ lidocaine $1 \%$ and $2 \mathrm{ml}$ hyaluronic acid (Ostenil) (TRB CHEMEDICA, Haar/ München, Germany) (group A); a mixture of $8 \mathrm{ml}$ lidocaine $1 \%$ with $2 \mathrm{ml}$ triamcinolone acetonide $10 \mathrm{mg} /$ $\mathrm{ml}$ (group B); or a mixture of $8 \mathrm{ml}$ lidocaine $1 \%$ with $2 \mathrm{ml} \mathrm{NaCl} \mathrm{0.9 \%} \mathrm{(placebo;} \mathrm{group}$ C). Injections were repeated, if necessary, after three and six weeks. In case of complete resolution of pain, no further injections were given.

Injections were administered via a dorsolateral approach through the interval just beneath the dorsal acromial edge, with the patient sitting up. ${ }^{(23)}$ The injection site was marked and disinfected with iodine, or with chlorhexidine solution in case of known allergy. No associated treatment was allowed for 12 weeks. Self-medication with paracetamol (acetaminophen) was allowed and recorded.

\section{Characteristics of patients}

A total of 51 patients were randomised into group A, 53 into group B and 55 into group C. The baseline characteristics of each group are given in Table I. After randomisation only the use of non-steroidal anti-inflammatory drugs (NSAIDs) prior to the trial differed significantly ( $p=0.003$, ANOVA). Patients in group $C$ used the most NSAIDs. However, a multivariate linear regression analysis showed that this variable was of no influence $(p=0.894)$. After entering the trial patients were asked not to use NSAIDs but to use acetaminophen instead, in accordance with the trial protocol (Table I).

Table 1 - Baseline characteristics

\begin{tabular}{|c|c|c|c|}
\hline & $\begin{array}{l}\text { Hyaluronic acid } \\
\qquad(n=51)\end{array}$ & $\begin{array}{l}\text { Corticosteroid injection } \\
\qquad(n=53)\end{array}$ & $\begin{array}{l}\text { Placebo } \\
n=55)\end{array}$ \\
\hline Male:female & $24: 27$ & $27: 26$ & $24: 31$ \\
\hline Mean (SD) age (yrs) & $53(12)$ & $52(9)$ & $54(11)$ \\
\hline Dominant side affected (n, \%) & $30(59)$ & $30(57)$ & $29(53)$ \\
\hline \multicolumn{4}{|l|}{ Duration of complaints (n, \%) } \\
\hline 6 weeks & $4(8)$ & $3(6)$ & $4(7)$ \\
\hline 9 weeks & $1(2)$ & $3(6)$ & $4(7)$ \\
\hline 12 weeks & $6(12)$ & $9(17)$ & $7(13)$ \\
\hline 26 weeks & $4(8)$ & $5(9)$ & $1(2)$ \\
\hline$>26$ weeks & $35(69)$ & $33(62)$ & $39(71)$ \\
\hline
\end{tabular}




\begin{tabular}{|c|c|c|c|}
\hline \multicolumn{4}{|l|}{ Sick leave and duration ( $\mathrm{n}, \%)$} \\
\hline On sick leave & $9(18)$ & $12(23)$ & $8(15)$ \\
\hline$<6$ weeks & $4(8)$ & $2(4)$ & $2(4)$ \\
\hline 6 weeks & - & $1(2)$ & $1(2)$ \\
\hline 9 weeks & - & $1(2)$ & $1(2)$ \\
\hline 12 weeks & $2(4)$ & $2(4)$ & $2(4)$ \\
\hline 26 weeks & $1(2)$ & $1(2)$ & - \\
\hline$>26$ weeks & $2(4)$ & $5(9)$ & $2(4)$ \\
\hline Symptoms during sports (n, \%) & $32(63)$ & $30(57)$ & $28(57)$ \\
\hline Symptoms while at work (n, \%) & $48(94)$ & $45(83)$ & $49(89)$ \\
\hline \multicolumn{4}{|l|}{ Previous treatment $(\mathrm{n}, \%)$} \\
\hline Physiotherapy & $16(31)$ & $17(32)$ & $12(22)$ \\
\hline Corticosteroid injection & $15(29)$ & $16(30)$ & $12(22)$ \\
\hline Analgesics (NSAID*) & $6(12)$ & $7(13)$ & $18(33)$ \\
\hline Other treatment & $1(2)$ & $1(2)$ & $1(2)$ \\
\hline No treatment & $13(25)$ & $12(23)$ & $12(22)$ \\
\hline Previous episode (n, \%) & $15(29)$ & $13(25)$ & $14(26)$ \\
\hline Mean (SD) duration & $51.9(68.9)$ & $55.9(102.4)$ & $40.1(62.2)$ \\
\hline \multicolumn{4}{|l|}{ Comorbidity (n, \%) } \\
\hline Diabetes & $5(9.8)$ & $3(5.7)$ & $3(5.5)$ \\
\hline Cardiovascular disease & $12(24)$ & $19(35.8)$ & $18(32.7)$ \\
\hline \multicolumn{4}{|l|}{ Mean outcome measures ${ }^{\dagger}$} \\
\hline VAS & 6.1 & 5.8 & 5.9 \\
\hline Constant score & 71.4 & 76.6 & 74 \\
\hline SDQ & 74.9 & 71.7 & 73.7 \\
\hline Shoulder pain score & 21.6 & 20.3 & 20.7 \\
\hline FMT & 13.0 & 11.6 & 11.6 \\
\hline PSD-main complaint VAS score & 6.0 & 5.9 & 6.1 \\
\hline \multicolumn{4}{|c|}{ Mean range of movement (passive value) $\left({ }^{\circ}\right)$} \\
\hline Flexion in frontal plane & $168(173)$ & $173(173)$ & $167(170)$ \\
\hline Extension & $76(77)$ & $77(77)$ & $77(78)$ \\
\hline Abduction & $161(169)$ & $172(172)$ & $166(168)$ \\
\hline Adduction & $87(89)$ & $88(88)$ & $89(89)$ \\
\hline External rotation & $75(75)$ & $76(77)$ & $76(77)$ \\
\hline Internal rotation & $88(88)$ & 89 (89) & $87(89)$ \\
\hline
\end{tabular}




\section{Outcome assessment}

The primary outcome measure was pain as measured on a horizontal $10 \mathrm{~cm}$ visual analogue scale (VAS) (0, no pain to 10 , severe pain) and was expressed as the proportion of patients indicating a reduction in or resolution of pain. ${ }^{(24)}$ Secondary outcome measures were a painful arc; range of movement; the Constant shoulder score ${ }^{(25)}$; patient-specific disability $^{(26)}$; shoulder disability questionnaire ${ }^{(27)}$; shoulder pain score; and functional mobility test. ${ }^{(28)}$ The Constant shoulder score is a validated system with subjective (pain and daily activities) and objective (range of movement and power) assessments in a ratio of 35\%:65\%. It is designed to provide a full functional assessment applicable to different shoulder conditions. ${ }^{(25,29,30)}$ The patient-specific disability instrument measures the functional status of the patient, who selects three to five disabilities in the field of physical activity, that limit their daily or weekly activities. It uses a VAS. ${ }^{(26)}$ The shoulder disability questionnaire is a functional questionnaire for pain and/or limitation of movement of the shoulder. The past 24 hours are assessed through 16 questions that can be answered with either yes, no, or not applicable. ${ }^{(27)}$ The shoulder pain score consists of six questions about pain and uses a 101 numerical rating scale (NRS 101). It has proved useful for following the course of disorder of the shoulder over time and giving an indication of when the patient is cured. ${ }^{(31)}$ The functional mobility test is a standardised motor test in patients with painful shoulder joint disorders. ${ }^{(4,28)}$

\section{Blinding}

A specially trained physician (LIFP) administered the injections, and both physician and patients were blinded to the contents of the syringe. In order to achieve an effective blinded injection a 19 gauge 1.5 inch needle and a $10 \mathrm{ml}$ syringe were used to prevent patients identifying the difference in viscosity of the administered solutions. An independent trial nurse filled and masked the syringes with black adhesive tape, and was thus responsible for the blinding procedure.

Inclusion, follow-up assessments and data analysis were blinded for allocated treatment.

Statistical analysis. Assuming a reduction in pain of 70\% (SD 35) on the VAS in the intervention groups and a minimum reduction in pain of $50 \%$ on a $10 \mathrm{~cm}$ VAS in the placebo group, with a $=0.05$ and a power $(1-\mathrm{P})$ of $80 \%$, a total of 48 patients per group 
were needed; in order to allow for a dropout rate of $10 \%$, we planned to enroll 53 patients per group.

All data analyses were carried out according to a pre- established plan. First, data were tested for normality. Secondly, a missing values analysis was performed. Based on the outcome of this analysis it was decided to carry forward last observations in case of loss to follow-up or withdrawal. For all other missing data a mean trend substitution was performed. Clinical data were assessed according to the intention-to-treat principle; differences between groups with $95 \%$ confidence intervals (CI) were calculated for each of the clinical outcome measures using analysis of variance (ANOVA), with all statistical analyses conducted using the SPSS software v17.0 (SPSS Inc., Chicago, Illinois). The influence of prognostic variables and baseline differences for outcome measures was assessed in a multivariate linear regression model with imputation of most important baseline variables. Influential variables were used to correct the outcome of the analysis of variance. Statistical significance was set at a p-value $<0.05$.

\section{Results}

All of the 159 included patients received the first allocated injection. The second and third allocated injections were not received by all patients. Nine patients $(6 \%)$ did not receive the complete treatment for different reasons. One patient in the corticosteroid group did not receive the third injection because of complete resolution of pain.

A total of 22 of the 159 patients (13.8\%) withdrew from the study, with no further or incomplete follow-up. Reasons for withdrawal consisted of malignancy (2), too much pain (5), not wishing to continue (1) and loss to follow-up (14). Of the 14 patients lost to follow-up, ten could not be contacted; the other four did not wish to continue the study. All patients who withdrew from the study were included in the statistical analysis according to the intention-to-treat principle, in which the last observation carried forward principle was used.

\section{Interventions}

In group $\mathrm{A}$, the complete course of three injections with hyaluronic acid was received by 48 patients ( 48 of $51,94 \%$ ). Of these, four were lost to the study: one withdrew because 
of a malignancy, one withdrew with too much pain, one was lost to follow-up and one did not wish to continue.

In group B the complete course of injections with corticosteroids was received by 50 patients ( 50 of $53,94 \%$ ).

Three were lost to the study: one withdrew with too much pain, one was lost to followup and one did not receive the third injection because the pain had resolved.

In group $C$ the complete course of three injections with placebo was received by 52 patients ( 52 of 55, 95\%). Three were lost to the study; one was lost to follow-up, and two had too much pain and they received corticosteroid injections instead. Both the patients and the physician who gave the injections remained blinded to the initial allocated treatment. Outcome. The mean outcomes of the primary and secondary endpoints are shown in Table II. There was a normal distribution between the groups. Using the intention-totreat analysis and treating missing values using the last observation carried forward principle and mean trend substitution, no significant differences for the VAS score were found at baseline or at 26 weeks. At weeks three $(\mathrm{p}=0.004)$, six $(\mathrm{p}<0.001)$ and $12(\mathrm{p}$ $<0.001$ ) the difference between group A and B was significantly (ANOVA) in favour of corticosteroids. Placebo injections were superior to hyaluronic acid injections at week 12 $(\mathrm{p}=0.001)$. Compared with placebo injections, corticosteroids were significantly better only at six weeks $(\mathrm{p}=0.006)$. In a multivariate linear regression analysis the prognostic variables at baseline were of limited influence on the outcome of the study (Fig. 2). These variables where significant in the multivariate regression analysis: right-sided internal rotation $(\mathrm{p}=0.014)$, pain during abduction movement $(\mathrm{p}=0.014)$, labour above shoulder level $(\mathrm{p}=0.022)$ and chronic complaints $(\mathrm{p}=0.003)$.

The differences between the three groups went in the same direction as all of the other outcome measures; these differences were significant (ANOVA) at weeks three ( $p$ $=0.004)$, six $(\mathrm{p}<0.001)$ and $12(\mathrm{p}<0.001)$. The mean reduction in pain at 12 weeks was 7\% (SD 2.7; 97.5\% CI -0.207 to 1.55; ANOVA, $\mathrm{p}=0.084$ ) in group A, 28\% (SD 2.8; 97.5\% CI 1.86 to 3.65; ANOVA, $\mathrm{p}<0.001$ ) in group B and 23\% (SD 3.23; 97.5\% CI 1.25 to 3.26; ANOVA, $\mathrm{p}<0.001$ ) in group C. The mean reduction in pain at 26 weeks was $15 \%$ (SD 3.25 ; $97.5 \%$ CI 0.46 to 2.57 ; ANOVA, $\mathrm{p}=0.002$ ) in group A, 20\% (SD 2.95; $97.5 \% \mathrm{CI}$ 1.07 to 2.95 ; ANOVA, $\mathrm{p}=0.001$ ) in group $\mathrm{B}$, and $21 \%$ (SD 3.75; $97.5 \% \mathrm{CI} 0.92$ to 3.25 ; ANOVA, $\mathrm{p}<0.001)$ in group C. At 26 weeks a reduction in pain was shown in $63 \%$ (32 
of 51) of patients in group A, 72\% (38 of 53) of those in group B and 69\% (38 of 55) of those in group C.

Figure 2 - Graph showing the mean visual analogue scale (VAS) for pain (95\% confidence intervals) over the follow-up adjusted for significant prognostic baseline variables

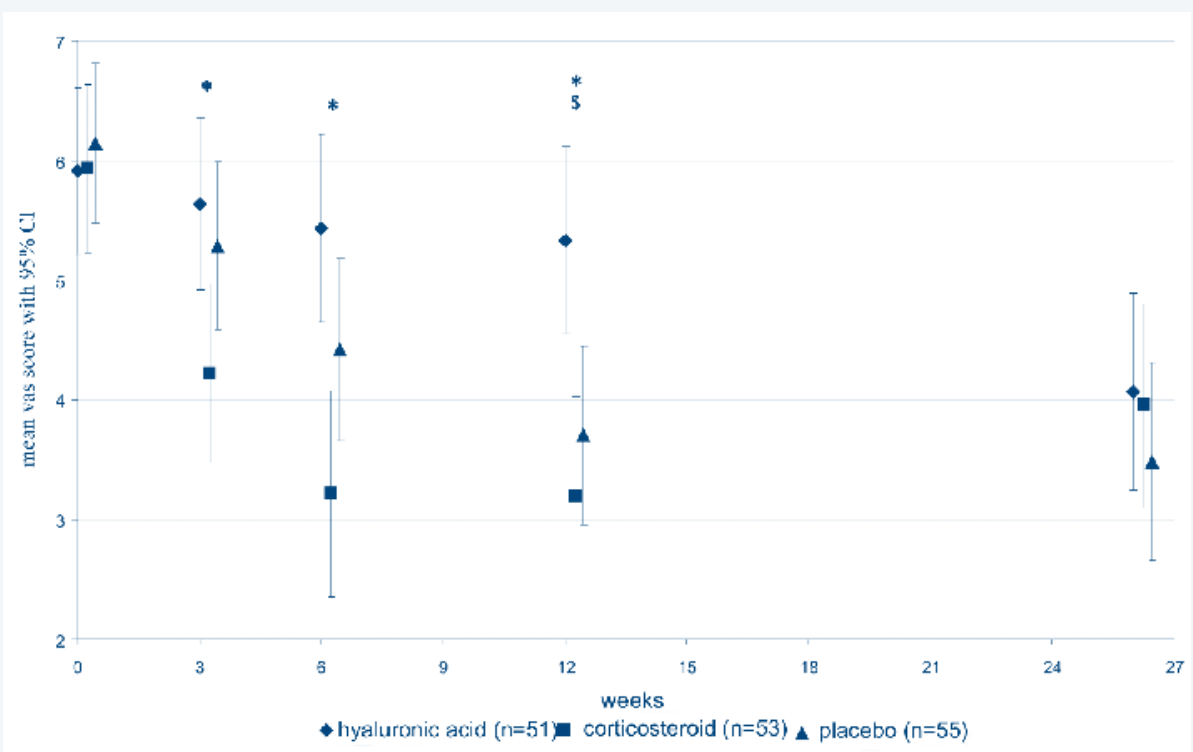

* The difference between corticosteroid and hyaluronic acid group is significant at weeks three $(p=0.004)$, six $(p<0.001)$ and $12(p<0.001)$. \$ The difference between hyaluronic acid and placebo group is significant $(p=$ $0.001)$. 
Table 2 - Mean outcome measures (with 95\% confidence intervals) in patients with subacromial impingement and differences in groups by treatment at different times of follow-up

\begin{tabular}{|c|c|c|c|}
\hline & Hyaluronic acid $(A)$ & Corticosteroid (B) & Placebo (C) \\
\hline \multicolumn{4}{|c|}{ Mean visual analogue scale ( 0 to 10 ) } \\
\hline Baseline & 6.1 (5.4 to 6.8$)$ & 5.8 (5.1 to 6.5$)$ & 6 (5.4 to 6.8$)$ \\
\hline Week 3 & 5.8 (5.0 to 6.6$)$ & 4.2 (3.4 to 4.9 ) & $5.2(4.5$ to 5.9$)$ \\
\hline Week 6 & 5.4 (4.6 to 6.1$)$ & $3.2(2.4$ to 4.1$)$ & 4.4 (3.7 to 5.2$)$ \\
\hline Week 12 & 5.4 (4.5 to 6.2$)$ & $3.1(2.2$ to 4.0$)$ & 3.7 (3.0 to 4.5$)$ \\
\hline Week 26 & 4.3 (3.4 to 5.2 ) & 3.7 (2.8 to 4.7$)$ & 3.6 (2.7 to 4.5$)$ \\
\hline \multicolumn{4}{|c|}{ Constant score (100 to 0$)$} \\
\hline Baseline & 71.1 ( 67.5 to 74.8$)$ & 75.8 (72.2 to 79.5$)$ & 73.1 (69.6 to 76.6$)$ \\
\hline Week 3 & 71 (66.7 to 75.2$)$ & 79.4 (74.9 to 83.9$)$ & 75. 6 (71.4 to 79.8$)$ \\
\hline Week 6 & 73.7 (69.3 to 78.1$)$ & 82.8 (78.0 to 87.7$)$ & 77.8 (73.4 to 82.1$)$ \\
\hline Week 12 & 74.5 (70.0 to 79.1$)$ & 82.2 (77.4 to 87.0 ) & 78.2 (73.9 to 82.5$)$ \\
\hline Week 26 & 76 (71.7 to 80.2$)$ & 80.4 (76.1 to 84.8$)$ & 82.3 (78.1 to 86.5$)$ \\
\hline \multicolumn{4}{|c|}{ Functional mobility test (4 to 28 ) } \\
\hline Baseline & $12.9(11.9$ to 14$)$ & 11.7 (10.7 to 12.8$)$ & 11.7 (10.7 to 12.7$)$ \\
\hline Week 3 & $12.6(11.4$ to 13.86$)$ & 10.5 (9.2 to 11.8$)$ & 11.1 (9.9 to 12.3$)$ \\
\hline Week 6 & 11.9 (10.7 to 13.2$)$ & 9.8 (8.5 to 11.2$)$ & $10.6(9.4$ to 11.8$)$ \\
\hline Week 12 & 11.7 (10.4 to 13.0$)$ & 9.3 (79 to 10.7$)$ & 9.9 (8.6 to 11.1$)$ \\
\hline Week 26 & 11.6 (10.4 to 12.8$)$ & 10.1 (8.8 to 11.3$)$ & 9.3 (8.1 to 10.5$)$ \\
\hline \multicolumn{4}{|c|}{ Patient to specific disability score mam Item (0 to 10$)$} \\
\hline Baseline & $6.3(5.6$ to 70$)$ & 5.7 (5.0 to 6.4$)$ & 6.3 (5.7 to 7.0$)$ \\
\hline Week 3 & 5.6 (4.8 to 6.5$)$ & 4.3 (3.4 to 5.1$)$ & 4.7 (3.9 to 5.5$)$ \\
\hline Week 6 & 4.9 (4.1 to 5.7$)$ & $3.3(2.4$ to 4.1$)$ & 4.1 (3.3 to 4.8$)$ \\
\hline Week 12 & $5.0(4.1$ to 5.8$)$ & $3.4(2.4$ to 4.3$)$ & $4.2(3.3$ to 5.0$)$ \\
\hline Week 26 & 4.6 (3.7 to 5.5$)$ & 3.8 (2.9 to 4.7$)$ & 4.3 (3.4 to 5.2$)$ \\
\hline \multicolumn{4}{|c|}{ Shoulder disability questionnaire (100 to 0 ) } \\
\hline Baseline & $75.1(70.2$ to 80.1$)$ & 74.1 (69.1 to 79.1$)$ & 75.7 (70.9 to 80.5$)$ \\
\hline Week 3 & 75.0 (68.3 to 81.7$)$ & 58.0 (51.1 to 65.0$)$ & 69.4 (62.9 to 75.9$)$ \\
\hline Week 6 & 65.3 (57.3 to 73.2 ) & 51.5 (42.8 to 60.2 ) & 62.5 (54.7 to 70.3 ) \\
\hline Week 12 & 64.1 (55.1 to 73.1$)$ & 45.6 (36.1 to 55.1$)$ & 60.7 (52.1 to 69.2 ) \\
\hline Week 26 & 62.7 (53.8 to 71.5$)$ & 50.9 (41.9 to 60.0 ) & 58.7 (49.9 to 67.4$)$ \\
\hline \multicolumn{4}{|c|}{ Shoulder pain score (7 to 28 ) } \\
\hline Baseline & 21.8 (20.6 to 23.0 ) & 20.3 (19.1 to 21.5 ) & 21.0 (19.8 to 22.1 ) \\
\hline Week 3 & 20.6 (19.0 to 22.1 ) & 16.5 (14.8 to 18.1$)$ & 18.7 (17.2 to 20.2$)$ \\
\hline Week 6 & 18.7 (17.1 to 20.2 ) & 14.5 (12.8 to 16.2$)$ & 17.1 (15.6 to 18.6 ) \\
\hline Week 12 & 18.9 (17.2 to 20.6$)$ & 14.9 (13.1 to 16.7$)$ & 16.6 (15.0 to 18.2$)$ \\
\hline Week 26 & 18.1 (16.4 to 19.8$)$ & 15.2 (13.4 to 16.9$)$ & 16.4 (14.7 to 18.1$)$ \\
\hline
\end{tabular}




\section{Adverse reactions}

Mild adverse reactions after injection were reported by 67 patients (40\%); an increase in pain after the injection was reported by 29 patients (18\%). Two female patients, one in group B and one in group C, reported flushes. One patient in group B had increased menstrual bleeding. In ten patients $(6.3 \%)$ headaches occurred after injection. No patient developed an infection. A haematoma was reported at the site of injection by six patients (3.8\%), one of whom was on anticoagulants and two of whom used NSAIDs before joining the trial.

\section{Discussion}

The corticosteroid injections gave a better result from the start of the trial and were significantly better at six weeks than placebo. They produced a faster reduction in pain than hyaluronic acid and placebo in the first three to 12 weeks (Fig. 2, Table II). No significant differences were shown at 26 weeks, at which point the placebo group showed the best mean improvement in pain and functional mobility. However, the mean reduction in pain achieved at 26 weeks was $20 \%$ in the corticosteroid group, $15 \%$ in the hyaluronic acid group and $21 \%$ in the placebo group. We were therefore unable to prove our hypothesis that corticosteroid or hyaluronic acid injections lead to a reduction in pain of $70 \%$, compared with a reduction in pain of $50 \%$ in the placebo group.

In our trial blinding took place at many levels: the administering physician, the patients, the outcome assessor and the statistical analysis. This has not been the case in previously published trials. . $^{(7,13,15-17,32-34)}$

At baseline groups were compared for influential prognostic variables. The placebo group consisted of significantly more patients who used NSAIDs before the trial. This variable was tested in a multivariate linear regression analysis and shown to have no influence on the outcome measures.

The effectiveness of hyaluronic acid in treating shoulder pain has been evaluated in ten other trials. ${ }^{(15-19,33-37)}$ In only three was the hyaluronic acid injected into the subacromial bursa, ${ }^{(16-18)}$ and of these two did not adequately describe the placement of the needle into the joint or subacromial space, ${ }^{(16,17)}$ although one showed equal improvement in pain 
compared with corticosteroids at 12 weeks. It has been suggested that hyaluronic acid, when injected intra-articularly is beneficial in various disorders of the shoulder. ${ }^{(15,16,18,19,34)}$

In our trial it showed no beneficial effect.

In most trials on the effectiveness of corticosteroids the placebo consisted of local anaesthetic. ${ }^{(8,9,12,13,38)}$ We used the addition of sodium chloride as a placebo. In this way the amount of local anaesthetic could be kept the same between groups. Although recent systematic review on corticosteroid injections showed a reduction in pain in the short term compared to other interventions, this effect was reversed at mid- and long term. We found a beneficial effect of corticosteroid injection in the short term, but did not find it to be significantly different to hyaluronic acid or placebo at mid-term. ${ }^{(39)}$

Although there is some evidence that a better result follows more accurate ultrasoundguided injection, ${ }^{(10,40,41)}$ we believe that most injections are still placed in an unguided manner by clinicians from various disciplines. The physician (LIFP) who administered the injections was thoroughly trained in the subacromial injection technique before the trial and all were administered by the same physician in a blinded way. Most adverse reactions encountered were local and mild and concerned prolonged pain after injection; there were no allergic reactions or infections.

In our study we were able to prove some effectiveness of hyaluronic acid injections in subacromial impingement at 26 weeks. Although the reduction in pain was $15 \%$ compared to corticosteroid (20\%) and placebo (21\%), this reduction might be explained by the natural history of the condition. Only at short term (12 weeks) did both corticosteroid and placebo show a better reduction in pain. At all follow-up evaluations hyaluronic acid injections gave worse results than corticosteroid. The limited result of hyaluronic acid might be explained by breakdown of the high molecular hyaluronic acid into smaller fragments in an inflammatory environment, as has been shown in pulmonary and renal disease. 42 These smaller fragments might sustain the inflammatory reaction. ${ }^{(42)}$

Clinically, this study does not support the use of hyaluronic acid injections in the treatment of subacromial impingement. Corticosteroid injections seem to be effective in the short term. Accordingly we recommend using them for fast initial relief of pain in this condition, although in the long term the best improvement was in the placebo group. 


\section{Supplementary material}

Table 3 - Frequency of adverse reactions in patients treated for subacromial impingement

\begin{tabular}{|c|c|c|c|c|}
\hline & Total & $\begin{array}{l}\text { Hyaluronic acid ( } \mathrm{n} \\
\qquad=51)\end{array}$ & $\begin{array}{l}\text { Corticosteroid }(\mathrm{n} \\
\quad=53)\end{array}$ & Placebo $(n=55)$ \\
\hline $\begin{array}{l}\text { Number of patients having any } \\
\text { adverse reaction }\end{array}$ & 67 & $26(51 \%)$ & $20(38 \%)$ & $21(38 \%)$ \\
\hline Dizziness & 1 & 0 & 0 & 1 \\
\hline Flushes & 2 & 0 & 1 & 1 \\
\hline Headache & 10 & 3 & 5 & 2 \\
\hline Haematoma at injection site & 6 & 3 & 2 & 1 \\
\hline Increased pain after injection & 29 & 12 & 5 & 12 \\
\hline Infection & 0 & 0 & 0 & 0 \\
\hline Itching & 4 & 3 & 0 & 1 \\
\hline Loss of hair & 1 & 0 & 1 & 0 \\
\hline Menstrual bleeding & 1 & 0 & 1 & 0 \\
\hline Mild skin reaction & 2 & 0 & 1 & 1 \\
\hline Nausea & 6 & 2 & 3 & 1 \\
\hline Heartburn & 2 & 1 & 0 & 1 \\
\hline Urinary tract infections & 1 & 0 & 1 & 0 \\
\hline Warm sensation in shoulder & 2 & 2 & 0 & 0 \\
\hline
\end{tabular}

\section{Acknowledgements}

The authors would like to thank Dr F Kessels for generating a random numbers list and the research nurses at the outpatient clinic of our hospital for opening the consecutive numbered opaque envelopes and preparing of the according study medication.

No benefits in any form have been received or will be received from a commercial party related directly or indirectly to the subject of this article. 


\section{References}

1. van der Windt DA, Koes BW, de Jong BA, Bouter LM. Shoulder disorders in gen- eral practice: incidence, patiënt characteristics, and management. Ann Rheum Dis 1995;54:959964.

2. Greving K, Dorrestijn O, Winters J, et al. Incidence, prevalence, and consultation rates of shoulder complaints in general practice. Scand J Rheumatol 2012;41:150- 155.

3. Picavet HS, Schouten JS. Musculoskeletal pain in the Netherlands: prevalences, consequences and risk groups, the DMC3-study. Pain 2003;102:167-178.

4. van der Heijden GJ. Shoulder disorders: a state-of-the-art review. Baillieres Clin Rheumatol 1999;13:287-309.

5. Winters JC, de Jongh AC, van der Windt DA, et al. NHG-Standaard Schouderk- lachten. Huisarts Wet 1999;42:221-231.

6. Winters JC, Van der Windt DAWM, Spinnewijn WEM, et al. NHG-Standaard Schouderklachten (Tweede herziening). Huisarts Wet 2008;51:555-565.

7. Crawshaw DP, Helliwell PS, Hensor EM, et al. Exercise therapy after corticos- teroid injection for moderate to severe shoulder pain: large pragmatic randomised trial. BMJ 2010;340:3037.

8. Blair B, Rokito AS, Cuomo F, Jarolem K, Zuckerman JD. Efficacy of injections of corticosteroids for subacromial impingement syndrome. J Bone Joint Surg [Am] 1996;78A:1685-1689.

9. Kirkley A, Litchfield R, Alvarez C, Herbert S, Griffin S. Prospective double blind randomized clinical trial of subacromial injection of betamethasone and xylocaine versus xylocaine alone in rotator cuff tendinosis. J Bone Joint Surg [Br] 1999;81- B(Supp 1 ):107.

10. Gruson KI, Ruchelsman DE, Zuckerman JD. Subacromial corticosteroid injections. J Shoulder Elbow Surg 2008;17(Suppl):118-130.

11. Alvarez CM, Litchfield R, Jackowski D, Griffin S, Kirkley A. A prospective, dou- bleblind, randomized clinical trial comparing subacromial injection of betamethasone and xylocaine to xylocaine alone in chronic rotator cuff tendinosis. Am J Sports Med 2005;33:255-262.

12. Vecchio PC, Hazleman BL, King RH. A double-blind trial comparing subacromial methylprednisolone and lignocaine in acute rotator cuff tendinitis. $\mathrm{Br} J$ Rheumatol 1993;32:743-745. 
13. Plafki C, Steffen R, Willburger RE, Wittenberg RH. Local anaesthetic injection with and without corticosteroids for subacromial impingement syndrome. Int Orthop 2000;24:4042.

14. Buchbinder R, Green S, Youd JM. Corticosteroid injections for shoulder pain. Cochrane Database Syst Rev 2003;1:CD004016.

15. Shibata Y, Midorikawa K, Emoto G, Naito M. Clinical evaluation of sodium hya- luronate for the treatment of patients with rotator cuff tear. J Shoulder Elbow Surg 2001;10:209-216.

16. Itokazu M, Matsunaga T. Clinical evaluation of high-molecular-weight sodium hyaluronate for the treatment of patients with periarthritis of the shoulder. Clin Ther 1995; 17:946-955.

17. Funk L. Hyaluronan vs. steroid injections for subacromial impingement of the shoulder. Osteoarthritis Cartilage 2005;13(Suppl A):S80.

18. Chou WY, Ko JY, Wang FS, et al. in rotator cuff lesions without complete tears: a randomized, double-blind, placebo-controlled study. J Shoulder Elbow Surg 2010;19:557563.

19. Iwata H. Pharmacologic and clinical aspects of intraarticular injection of hyaluro- nate. Clin Orthop Relat Res 1993;289:285-291.

20. Kuiper-Geertsma DG, Bijlsma JW. Intra-articular injection of hyaluronic acid as an alternative option to corticosteroid injections for arthrosis. Ned Tijdschr Geneeskd 2000;144:2188-2192 (in Dutch).

21. MacGregor AJ. Classification criteria for rheumatoid arthritis. Baillieres Clin Rheumatol 1995;9:287-304.

22. van der Linden S, Valkenburg HA, Cats A. Evaluation of diagnostic criteria for ankylosing spondylitis: aproposal for modification of the New York criteria. Arthritis Rheum 1984;27:361-368.

23. Rowe CR. Injection technique for the shoulder and elbow. Orthop Clin North Am 1988;19:773-777.

24. Huskisson EC. Visual analogue scales. In: Melzack R, ed. Pain measurement and assessment. New York: Raven Press, 1983:33-37.

25. Constant CR, Murley AH. A clinical method of functional assessment of the shoulder. Clin Orthop 1987;214:160-164. 
26. Beurskens AJ, de Vet HC, Köke AJ. Responsiveness of functional status in low back pain: a comparison of different instruments. Pain 1996;65:71-76.

27. van der Heijden GJ, Leffers P, Bouter LM. Shoulder disability questionnaire design and responsiveness of a functional status measure. J Clin Epidemiol 2000;53:29-38.

28. Westerberg CE, Solem-Bertoft E, Lundh I. The reliability of three active motor tests used in painful shoulder disorders: presentation of a method of general applica- bility for the analysis of reliability in the presence of pain. Scand J Rehabil Med 1996;28-2:63-70.

29. Constant CR. Assessment of shoulder function. Orthopade 1991;20:289-294 (in German).

30. MacDonald PB, Clark P, Sutherland K. An analysis of the diagnostic accuracy of the Hawkins and Neer subacromial impingement signs. J Shoulder Elbow Surg 2000;9:299-301.

31. Winters JC, Sobel JS, Groenier KH, Arendzen JH, Meyboom-De Jong B. A shoulder pain score: a comprehensive questionnaire for assessing pain in patients with shoulder complaints. Scand J Rehabil Med 1996;28:163-167.

32. Berry H, Fernandes L, Bloom B, Clark RJ, Hamilton EB. Clinical study comparing acupuncture, physiotherapy, injection and oral anti-inflammatory therapy in shouldercuff lesions. Curr Med Res Opin 1980;7:121-126.

33. Rovetta G, Monteforte P. Intraarticular injection of sodium hyaluronate plus steroid versus steroid in adhesive capsulitis of the shoulder. Int J Tissue React 1998;20:125- 130.

34. Leardini G, Perbellini A, Franceschini M, Mattara L. Intra-articular injections of hyaluronic acid in the treatment of painful shoulder. Clin Ther 1988;10:521-526.

35. Silverstein E, Leger R, Shea KP. The use of intra-articular hylan G-F 20 in the treatment of symptomatic osteoarthritis of the shoulder: a preliminary study. Am J Sports Med 2007;35:979-985.

36. Meloni F, Milia F, Cavazzuti M, et al. Clinical evaluation of sodium hyaluronate in the treatment of patients with sopraspinatus tendinosis under echographic guide: experimental study of periarticular injections. Eur J Radiol 2008;68:170-173.

37. Blaine T, Moskowitz R, Udell J, et al. Treatment of persistent shoulder pain with sodium hyaluronate: a randomized, controlled trial: a multicenter study. J Bone Joint Surg [Am]2008;90-A:970-979.

38. Akgün K, Birtane M, Akarirmak U. Is local subacromial corticosteroid injection beneficial in subacromial impingement syndrome? Clin Rheumatol 2004;23:496-500. 
39. Coombes BK, Bisset L, Vicenzino B. Efficacy and safety of corticosteroid injections and other injections for management of tendinopathy: a systematic review of randomised controlled trials. Lancet 2010;376:1751-1767.

40. Kang MN, Rizio L, Prybicien M, Middlemas DA, Blacksin MF. The accuracy of subacromial corticosteroid injections: a comparison of multiple methods. J Shoulder Elbow Surg 2008;17(Suppl):61-66.

41. Henkus HE, Cobben LP, Coerkamp EG, Nelissen RG, van Arkel ER. The accuracy of subacromial injections: a prospective randomized magnetic resonance imaging study. Arthroscopy 2006;22:277-282.

42. Noble PW. Hyaluronan and its catabolic products in tissue injury and repair. Matrix Biol 2002;21:25-29. 


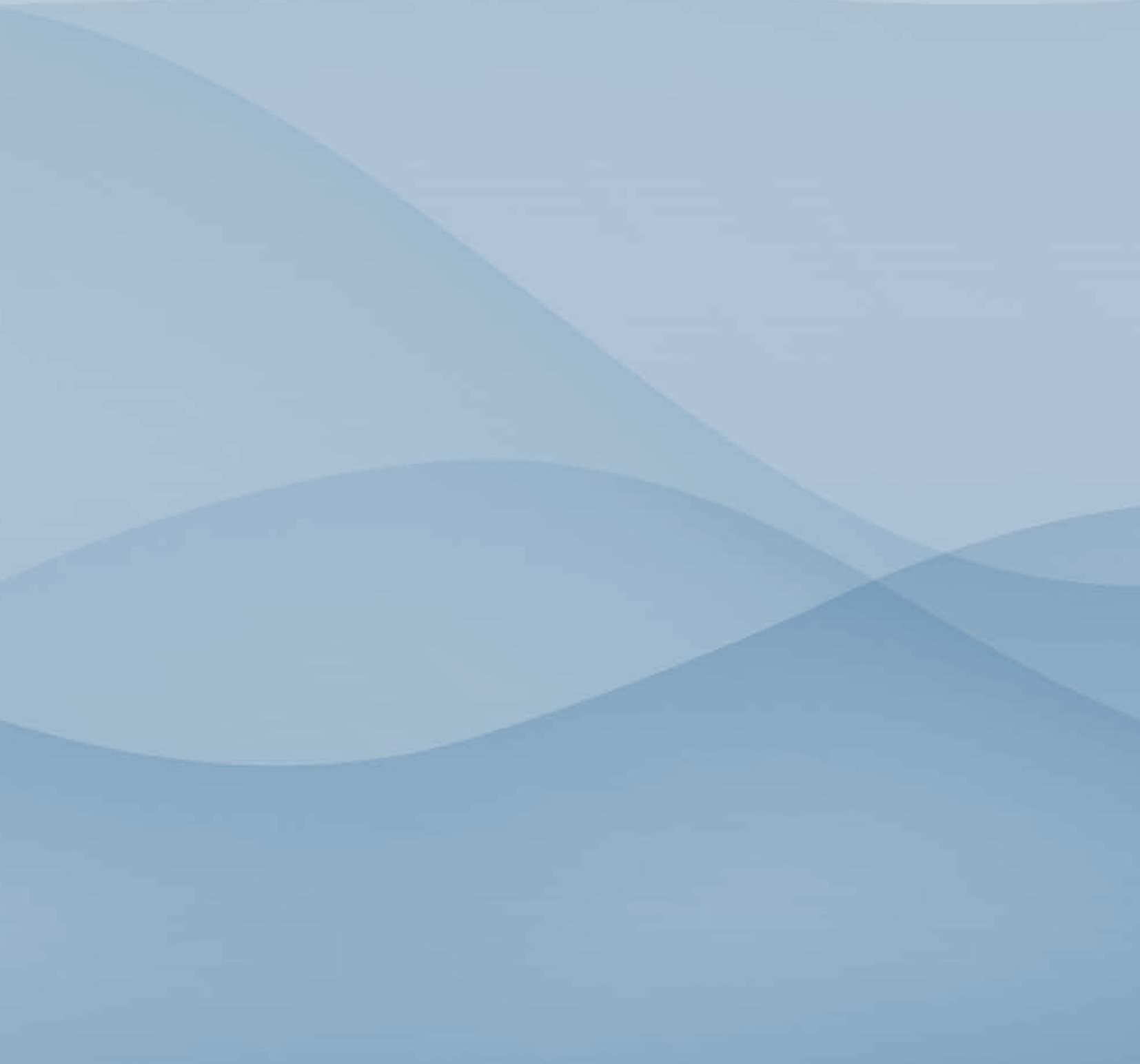




\section{Chapter 3}

Subacromial triamcinolone acetonide, hyaluronic acid and saline injections for shoulder pain an RCT investigating the effectiveness in the first days

Penning L.I.F.

de Bie R.A.

Walenkamp G.H.I.M.

BMC Musculoskelet Disord. 2014 Oct 23;15(1):352. 


\section{Abstract}

Background: Subacromial impingement is a common cause of shoulder complaints in general practice. When the initial treatment with acetaminophen and low dose Non Steroidal Anti Inflammatory Drugs fails, triamcinolone acetonide injections are commonly used. Triamcinolone acetonide injections are effective at four to six weeks. Little is known about the pain relief effect of triamcinolone acetonide injections in the first days after injection and the effect of repeated injection. In this study we investigate the effect of triamcinolone acetonide injections compared to hyaluronic acid and $\mathrm{NaCl}$ injections using a pain diary.

Methods: 159 Patients recruited for an RCT comparing the effect of subacromial injections of triamcinolone acetonide, hyaluronic acid and sodium chloride $(\mathrm{NaCl})$ were used in this study. They were blinded for their treatment and could receive up to three injections. Primary outcome consisted of the patient perceived pain on a VAS score recorded on a daily basis during 21 days following injection. Secondary outcome consisted of the amount of taken escape medication following injection and adverse effects.

Results: All patients received the first injection. 150 patients also received the second and third injections. 97\% Of the paper and pencil pain diaries were returned for data analysis.

The triamcinolone acetonide group showed the largest decrease in pain on the VAS scores after injection compared to the hyaluronic acid and $\mathrm{NaCl}$ group in the first week after injection. The reduction in pain was best achieved after the first injection, the second triamcinolone acetonide injection showed a further reduction in pain. The third triamcinolone acetonide injection only showed a slight improvement in pain reduction. 
Conclusions: In this study we could show a booster effect in pain reduction after repeated triamcinolone acetonide injection. The triamcinolone acetonide group showed a faster reduction in pain after injection compared to the hyaluronic acid and $\mathrm{NaCl}$ group. The effect was best seen after the first and second triamcinolone acetonide injection, it is therefore questionable whether it is necessary to repeat triamcinolone acetonide injections more than two times.

Trial registration: ISRCTN51511455. Registered 20 December 2005

Keywords: Subacromial impingement, Pain diary, Subacromial injection, Corticosteroid, Hyaluronic acid, Placebo 


\section{Background}

Shoulder complaints are frequently encountered in General Practice ${ }^{(1,2)}$, of which subacromial impingement is a common cause ${ }^{(3)}$. Early symptoms of subacromial impingement are treated with acetaminophen (paracetamol) or low-doses of nonsteroidal antiinflammatory drugs. When this therapy fails, impingement can be treated with subacromial injections. These injections merely consist of a combination of a corticosteroid and a local anesthetic ${ }^{(4,5)}$. Although it is known that corticosteroids are effective at short term, four to six weeks, only a few studies have investigated the effect of corticosteroids in the first days after injection. In the study of Lewis this was investigated for the treatment in lateral epicondylitis of the elbow in the review of Coombs this consisted of the study of the effectiveness of injections in a number of different tendinopathy pathologies like lateral epicondylalgia, medial epicondylalgia, rotator-cuff tendinopathy, Achilles tendinopathy and patellar tendinopathy ${ }^{(6,7)}$. These drug treatments are commonly combined with exercises and physiotherapy, the combination of subacromial injections and physiotherapy are stated to give a better result ${ }^{(8)}$.

A few studies have shown improvement in pain and function following the subacromial injection of hyaluronic acid alone ${ }^{(9-12)}$.

Hyaluronic acid is thought to serve as a lubricant ${ }^{(13)}$ and is reported to have an antiinflammatory effect ${ }^{(14)}$.

Several studies have investigated the side effect of corticosteroid injections, in these studies only few side effects are described provided injections are not repeated too often at the same site ${ }^{(15)}$. Some animal studies reported negative side effects concerning weakening of the rat rotator cuff in the first weeks after administration ${ }^{(16-18)}$. The corticosteroid injection reduces the inflammation and pain associated with the subacromial impingement ${ }^{(19)}$.

Little is known about the effect on pain reduction after repeated corticosteroid injection ${ }^{(20,21)}$. This study was part of a randomized clinical trial RCT, with a three arm design in which hyaluronic acid + lidocaine $1 \%$ (A) were compared to triamcinolone acetonide + lidocaine $1 \%(B)$ and placebo sodium chloride $(\mathrm{NaCl})+$ lidocaine $1 \%(\mathrm{C})$. In this trial we could prove a significant improvement in pain for triamcinolone acetonide after three, six and twelve weeks. Compared to placebo, injections containing hyaluronic acid did not show a significant improvement in pain ${ }^{(22)}$. 
In this study we investigated the effect of subacromial injections in the first days after administration. We also investigated the effect of repetition of subacromial injections on the perceived amount of pain in order to study an accumulative effect of repeated injection.

\section{Methods}

\section{Setting and participants}

This study was approved by the Medical Ethics Review Committee (MERC) of the Maastricht University Medical Center (MUMC) and was performed at the outpatient clinic of our orthopedic surgery department. Written informed consent was obtained from participants. A total of 159 patients were included in the study, including 75 men and 84 women with a mean age of 53 years (range 20 to 87). A large majority of patients could be included after direct referral by general practitioners. These patients did not receive prior injection treatment by their general practitioners for their current episode of shoulder pain.

Patients were randomized into three treatment groups and were blinded for their respective treatment. Eligible patients were over 18 years of age and had pain in the shoulder, either at rest or on movement. The diagnosis of impingement was made clinically without the routine use of ultrasound or MRI. All presented with a painful arc, with or without abnormal scapulohumeral movement.

Exclusion criteria included: pain for less than six weeks; injection with corticosteroids in the preceding three months; flexion of $<100^{\circ}$ in the frontal plane; external rotation limited by $>50 \%$ compared with the opposite side; allergy to lidocaine $1 \%$, steroids or hyaluronic acid; pregnancy or suspected pregnancy; dementia; prior infection of the shoulder joints; tumour; osteoporosis; rheumatoid arthritis according to the American College of Rheumatology (ACR) criteria ${ }^{(23)}$; referred pain, such as from the neck; an associated neurological disorder; polymyalgia; ankylosing spondylitis as diagnosed using the modified New York (NY) criteria ${ }^{(24)}$; whiplash injury; previous fractures or surgery on the shoulder, upper limb, neck or thorax; and behavioural, cognitive or psychiatric disorders. Patients unable to complete Dutch questionnaires independently or reluctant to adhere to the allocated treatment or to complete follow-up were also excluded ${ }^{(22)}$. 


\section{Intervention}

Treatment consisted of subacromial injection with either: a mixture of $8 \mathrm{ml}$ lidocaine $1 \%$ and $2 \mathrm{ml}$ hyaluronic acid (Ostenil) (TRB CHEMEDICA, Haar/München, Germany) (group A); a mixture of $8 \mathrm{ml}$ lidocaine $1 \%$ with $2 \mathrm{ml}$ triamcinolone acetonide $10 \mathrm{mg} /$ $\mathrm{ml}$ (group B); or a mixture of $8 \mathrm{ml}$ lidocaine $1 \%$ with $2 \mathrm{ml} \mathrm{NaCl} \mathrm{0.9 \%} \mathrm{(placebo;} \mathrm{group}$ C). Injections were repeated, if necessary, after three and six weeks. In case of complete resolution of pain, no further injections were given ${ }^{(22)}$.

\section{Randomization}

Patients were randomized blindly into three treatment groups. An independent statistician (FK) generated a random numbers list which, by permutation of random blocks, block size 9, was balanced for treatments within strata. Strata were based on age ( $\leq 40$ years versus $>40$ years). After selection and baseline assessment, consecutive numbered opaque envelopes of the appropriate stratum were opened by one of several independent trial nurses.

A total of 51 patients were randomized into group A, 53 into group B and 55 into group $\mathrm{C}^{(22)}$.

\section{Blinding}

All injections were administered by the same physician (LIFP). Both physician and patients were blinded to the contents of the syringe. In order to achieve an effective blinded injection a 19 gauge 1.5 inch needle and a $10 \mathrm{ml}$ syringe were used to prevent the physician identifying the difference in viscosity of the administered solutions. The syringes were filled by an independent trial nurse and masked with black adhesive tape. The nurse was thus responsible for the blinding procedure. Inclusion, follow-up assessments and data analysis were blinded for allocated treatment ${ }^{(22)}$.

\section{Administration of injection}

Injections were administered via a dorsolateral approach through the interval just beneath the dorsal acromial edge, with the patient sitting up ${ }^{(25)}$. The injection site was marked and disinfected with iodine, or with chlorhexidine solution in case of known allergy. 


\section{Outcome assessment}

The primary outcome measure was pain as measured on a horizontal $10 \mathrm{~cm}$ visual analogue scale (VAS) (0, no pain to 10 , severe pain) ${ }^{(26)}$. Measurements were taken at consultation before injection. The first 21 days after each injection patients were asked to record a VAS score each day in their pain diary.

We investigated the effect of injections of $\mathrm{A}, \mathrm{B}$ and $\mathrm{C}$ on a daily basis using a pain diary during the 21 th days after injection. In this study we focus on the effects of repeated triamcinolone acetonide injections versus placebo and hyaluronic acid, illustrating the potential benefit of a series of injections.

The pain diary was used to record the perceived amount of pain. With the pain diary we are able to show the immediate daily response the first days after injection. Pain diaries have been shown to be valid and reliable in the measurement of pain in patients with chronic pain and cancer. It is reported that patients tend to overestimate their remembered pain and psychosocial and pain related factors tend to bias the remembered pain. The daily self-recording of pain by a pain diary showed to reduce the amount of bias ${ }^{(27)}$.

Secondary outcome measures consisted of the type and amount of escape medication taken and the occurrence of adverse effects.

During the first visit patients were thoroughly instructed how to fill out the paper and pencil pain diary. Patients were told to record the maximum experienced pain for each day.

In the pain dairies the days were separated. For each day a VAS score could be recorded on a $10 \mathrm{~cm}$ line.

Although patients were instructed that only escape medication consisting of acetaminophen (paracetamol) was allowed, they were asked to record the type and amount of escape medication taken for each day.

A final question for each day consisted of the occurrence of adverse effects. The perceived adverse events were recorded on a text free basis.

Patients were instructed to complete the diary on a daily basis, they were suggested to fill out the diary at the same moment each day to improve compliance. 


\section{Statistical analysis}

For this study we obtained data of patients enrolled in the RCT. The number of participants was based on the power calculation used for the RCT in which we had calculated a total number of 159 participants, 53, per group, allowing for a dropout rate of $10 \%$. The power calculation of the RCT was based on the decrease in pain on a VAS score $^{(22)}$.

First, data were tested for normality. Second, a missing value analysis was performed. In case of loss to followup or withdrawal resulting in missing data, these values were handled by the method of linear trend at point imputation. Analysis of variance was used to establish effects of both interventions. The influence of prognostic variables and baseline differences for outcome measures was assessed in a multivariate linear regression model with imputation of most important baseline variables. Influential variables were used to correct the outcome of the analysis of variance. Statistical significance was set at a p-value $<0.05^{(22)}$.

\section{Results}

All of the 159 included patients received the first allocated injection. The second and third allocated injections were received by 150 patients. Nine patients (6\%) did not receive the second and third injection, 3 in each of the groups. In the hyaluronic acid group reasons for not receiving the allocated injections were: withdrawn because of malignancy $(n=1)$, lost to follow up $(n=1)$ and not wishing to continue $(n=1)$. In the triamcinolone acetonide group reasons for not receiving the allocated treatment were: withdrawn because of too much pain $(n=1)$, lost to follow up $(n=1)$ and complete relieve of pain after 2 injections $(\mathrm{n}=1)$. In the $\mathrm{NaCl}$ injection group reasons for not receiving the allocated treatment consisted of too much pain $(\mathrm{n}=2)$ and lost to follow up $(\mathrm{n}=1) .{ }^{(22)}$ Figure 1. 


\section{Figure 1 - Allocated treatment}

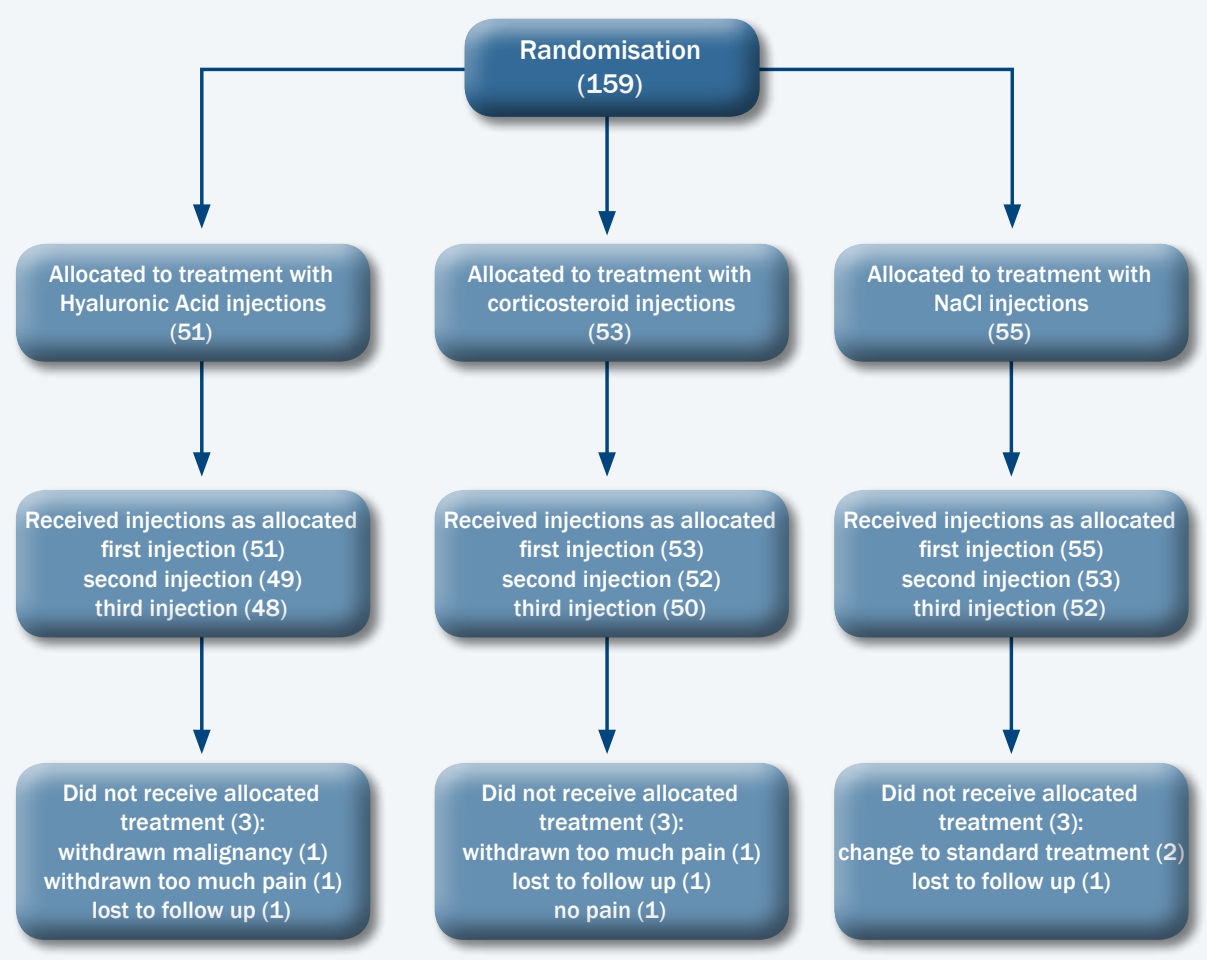

After each injection the result of the Neer test was recorded ${ }^{(28)}$. In the hyaluronic acid group we report a positive Neer test in $61 \%$, in the triamcinolone group in $70,5 \%$ and in the $\mathrm{NaCl}$ group in $73 \%$.

The analysis at baseline did not show any significant differences among the groups. At baseline the VAS score of the triamcinolone acetonide group was 5.8 (95\% CI 5.1-6.5), of the hyaluronic acid group 6.1(95\% CI 5.4-6.8) and of the $\mathrm{NaCl}$ group was 5.9 (95\% CI 5.1-6.5).

$3 \%(n=14)$ of the diaries was not returned, due to withdrawal from the study or lost diaries. In the hyaluronic acid group four diaries from the, first period, and two diaries of the second and third period were not returned. In the triamcinolone acetonide group two diaries in the first period, and one diary in the second and third period were not returned. For the $\mathrm{NaCl}$ group in both the first and second period one diary was not returned. In 
the third period al diaries were returned. (Table 1) Mean VAS scores and according trend lines are depicted in Figures 2, 3 and 4 and in Tables 2, 3 and 4. After the first injection a remarkable drop in VAS score is shown for the first week in the triamcinolone acetonide group, after ten days there is a slight increase in pain although the VAS score stays below the level of pain before injection at three weeks. The hyaluronic acid and $\mathrm{NaCl}$ group show only slight improvement in pain reduction with a less steep curve. After the second injection a slight improvement in pain is seen for the hyaluronic acid group and the $\mathrm{NaCl}$ group although the effect is limited compared to the effect after the first injection. After the third injection little change is shown in the VAS scores for all groups.

\section{Table 1 - Lost pain diaries per group}

\begin{tabular}{|cccc|}
\hline & $\begin{array}{c}\text { Hyaluronic acid } \\
(\mathrm{n}=\mathbf{5 1})\end{array}$ & $\begin{array}{c}\text { Triamcinolone } \\
\text { acetonide }(\mathrm{n}=53)\end{array}$ & $\begin{array}{c}\mathrm{NaCl} \\
(\mathrm{n}=55)\end{array}$ \\
\hline Week 0 - 3 & 4 & 2 & 1 \\
\hline Week 3 - 6 & 2 & 1 & 1 \\
\hline Week 6 - 9 & 2 & 1 & 0
\end{tabular}

Concerning the secondary outcome measures we report significant differences in the number of persons in need of escape medication. The hyaluronic acid group and the $\mathrm{NaCl}$ group needed significantly more escape medication because of pain throughout the study Tables 5, 6 and 7 .

Adverse effects described in the free text of the pain diaries consisted of: flushes, headache, nausea, redness at injection site and tingling sensations. 24 patients reported adverse effect, The most reported adverse effect was occurrence of headache. This occurred in 8 patients in the hyaluronic acid group, in 5 patients in the triamcinolone acetonide group and in 4 patients in the $\mathrm{NaCl}$ group Table 8. 
Figure 2 - Daily VAS scores after first injection and according linear trend lines

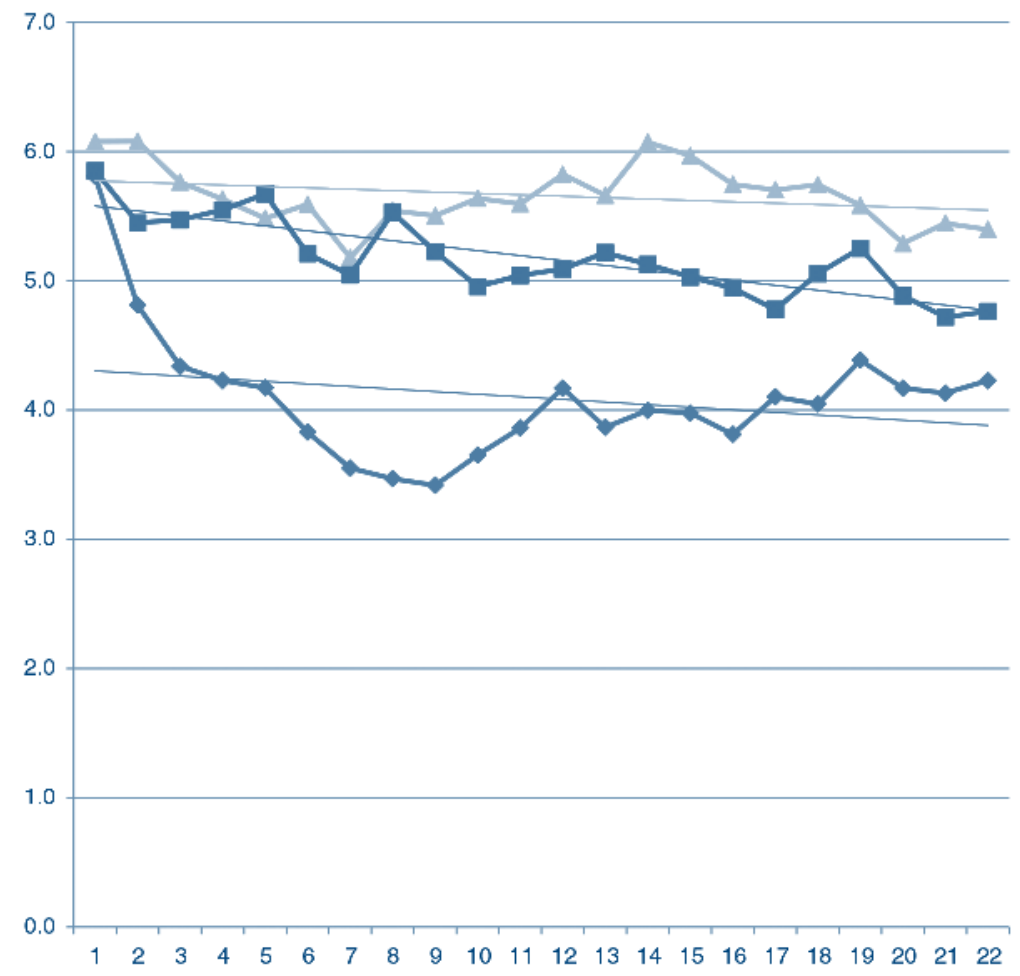

Legend: (triangle) hyaluronic acid. (square) $\mathrm{NaCl}$. (diamond) triamcinolone acetonide. 
Figure 3 - Daily VAS scores after second injection and according linear trend lines

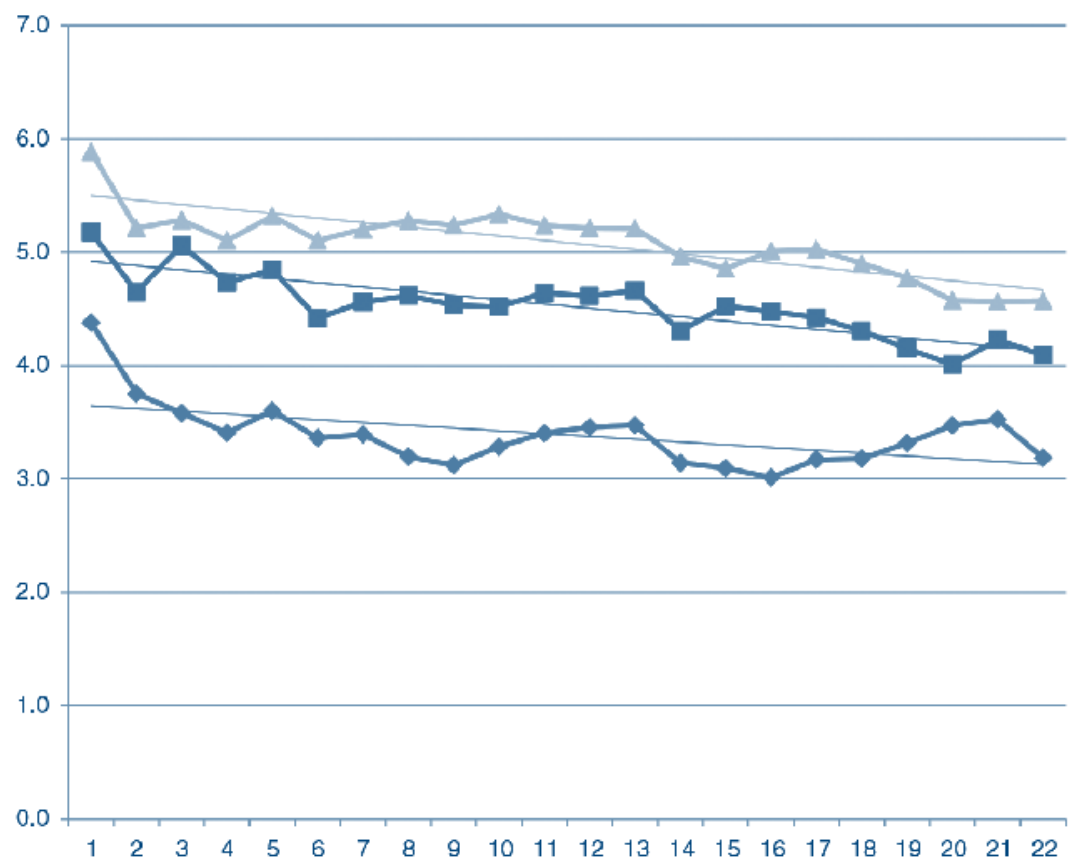

Legend: (triangle) hyaluronic acid. (square) $\mathrm{NaCl}$. (diamond) triamcinolone acetonide. 
Figure 4 - Daily VAS scores after third injection and according linear trend lines

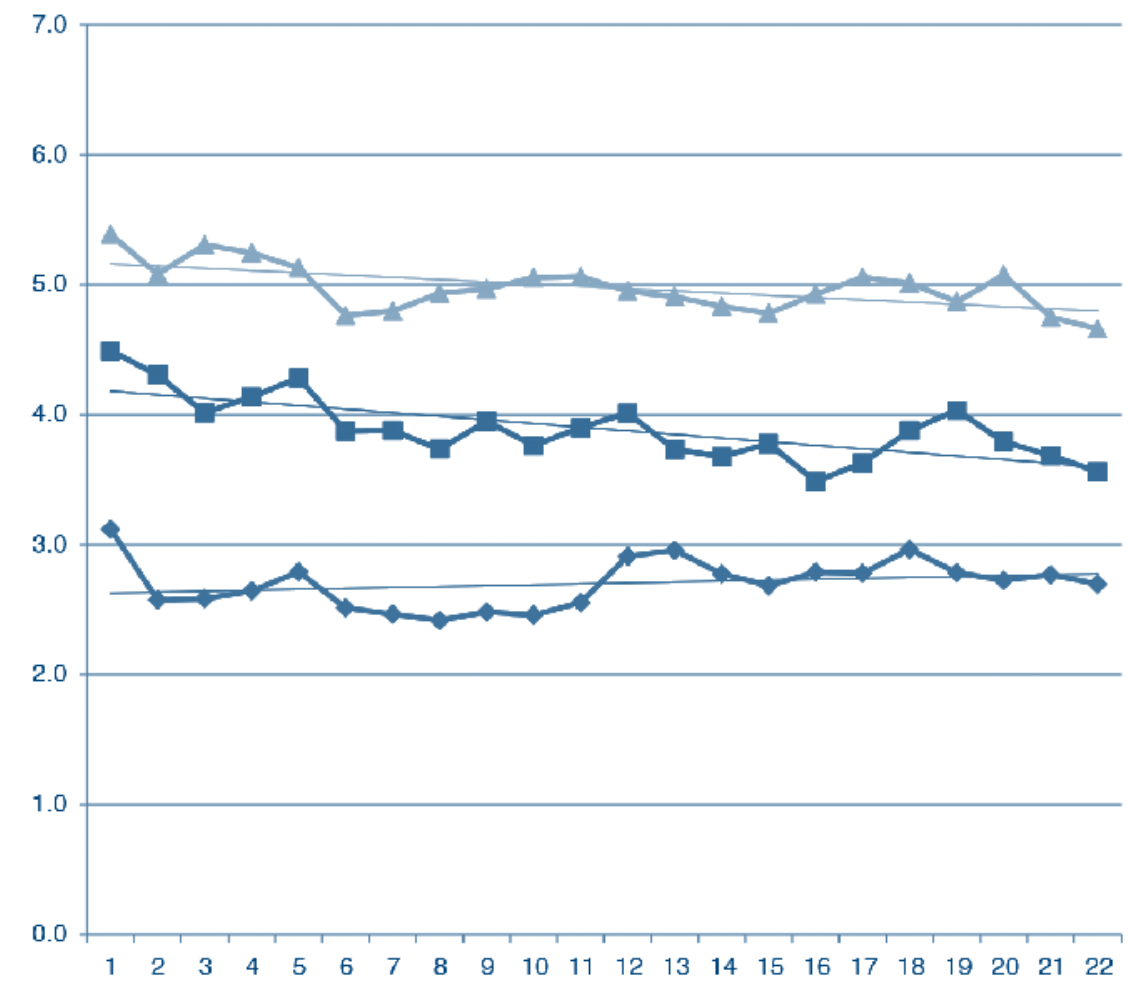

Legend: (triangle) hyaluronic acid. (square) $\mathrm{NaCl}$. (diamond) triamcinolone acetonide. 
Table 2 - Mean visual analogue scale

(0-10) after the first injection

\begin{tabular}{|c|c|c|c|c|}
\hline Day & $\begin{array}{c}\text { Hyaluronic } \\
\text { acid }\end{array}$ & $\begin{array}{c}\text { Triam- } \\
\text { cinolone } \\
\text { acetonide }\end{array}$ & $\mathrm{NaCl}$ & Sig. \\
\hline 0 & 6,1 & 5,8 & 5,9 & ,845 \\
\hline 1 & 6,1 & 4,8 & 5,4 & ,052 \\
\hline 2 & 5,8 & 4,3 & 5,5 & ,021 \\
\hline 3 & 5,6 & 4,2 & 5,5 & ,014 \\
\hline 4 & 5,5 & 4,2 & 5,7 & ,008 \\
\hline 5 & 5,6 & 3,8 & 5,2 & ,002 \\
\hline 6 & 5,2 & 3,6 & 5,0 & ,002 \\
\hline 7 & 5,5 & 3,5 & 5,5 & ,000 \\
\hline 8 & 5,5 & 3,4 & 5,2 & ,000 \\
\hline 9 & 5,6 & 3,7 & 5,0 & ,001 \\
\hline 10 & 5,6 & 3,9 & 5,0 & ,005 \\
\hline 11 & 5,8 & 4,2 & 5,1 & ,009 \\
\hline 12 & 5,7 & 3,9 & 5,2 & ,002 \\
\hline 13 & 6,1 & 4,0 & 5,1 & ,000 \\
\hline 14 & 6,0 & 4,0 & 5,0 & ,000 \\
\hline 15 & 5,7 & 3,8 & 4,9 & ,001 \\
\hline 16 & 5,7 & 4,1 & 4,8 & ,008 \\
\hline 17 & 5,7 & 4,0 & 5,1 & ,004 \\
\hline 18 & 5,6 & 4,4 & 5,3 & ,046 \\
\hline 19 & 5,3 & 4,2 & 4,9 & ,059 \\
\hline 20 & 5,4 & 4,1 & 4,7 & ,018 \\
\hline 21 & 5,4 & 4,2 & 4,8 & ,013 \\
\hline
\end{tabular}

Table 3 - Mean visual analogue scale $(0-10)$ after the second injection

\begin{tabular}{|c|c|c|c|c|}
\hline Day & $\begin{array}{l}\text { Hyaluronic } \\
\text { acid }\end{array}$ & $\begin{array}{c}\text { Triam- } \\
\text { cinolone } \\
\text { acetonide }\end{array}$ & $\mathrm{NaCl}$ & Sig. \\
\hline 0 & 5,9 & 4,4 & 5,2 & ,017 \\
\hline 1 & 5,2 & 3,8 & 4,7 & ,022 \\
\hline 2 & 5,3 & 3,6 & 5,1 & ,004 \\
\hline 3 & 5,1 & 3,4 & 4,7 & ,005 \\
\hline 4 & 5,3 & 3,6 & 4,8 & ,005 \\
\hline 5 & 5,1 & 3,4 & 4,4 & ,004 \\
\hline 6 & 5,2 & 3,4 & 4,6 & ,003 \\
\hline 7 & 5,3 & 3,2 & 4,6 & ,000 \\
\hline 8 & 5,2 & 3,1 & 4,5 & ,000 \\
\hline 9 & 5,3 & 3,3 & 4,5 & ,001 \\
\hline 10 & 5,2 & 3,4 & 4,6 & ,003 \\
\hline 11 & 5,2 & 3,5 & 4,6 & ,006 \\
\hline 12 & 5,2 & 3,5 & 4,7 & 008, \\
\hline 13 & 5,0 & 3,1 & 4,3 & ,003 \\
\hline 14 & 4,9 & 3,1 & 4,5 & ,003 \\
\hline 15 & 5,0 & 3,0 & 4,5 & ,001 \\
\hline 16 & 5,0 & 3,2 & 4,4 & ,003 \\
\hline 17 & 4,9 & 3,2 & 4,3 & ,005, \\
\hline 18 & 4,8 & 3,3 & 4,2 & ,023 \\
\hline 19 & 4,6 & 3,5 & 4,0 & ,088, \\
\hline 20 & 4,6 & 3,5 & 4,2 & 093, \\
\hline 21 & 4,6 & 3,2 & 4,1 & ,006 \\
\hline
\end{tabular}

\section{Discussion}

We could show a significant reduction in pain after a triamcinolone acetonide injection as we described in the results of the RCT ${ }^{(22)}$. In the data of the pain diaries we found a faster reduction and steeper downward curve in the triamcinolone acetonide group compared to the hyaluronic acid group and the $\mathrm{NaCl}$ group. The second injection showed a booster effect in the stepwise reduction of pain in the triamcinolone acetonide group, this effect was not seen in the hyaluronic acid and $\mathrm{NaCl}$ group. Little is known about the pattern of perceived pain after corticosteroid injection, by means of the recorded VAS scores we were able to give a graphic better description of this pattern. In the study of 
Table 4 - Mean visual analogue scale

$(0-10)$ after the third injection

\begin{tabular}{|c|c|c|c|c|}
\hline Day & $\begin{array}{l}\text { Hyaluronic } \\
\text { acid }\end{array}$ & $\begin{array}{c}\text { Triam- } \\
\text { cinolone } \\
\text { acetonide }\end{array}$ & $\mathrm{NaCl}$ & Sig. \\
\hline 0 & 5,4 & 3,1 & 4,5 & ,000 \\
\hline 1 & 5,1 & 2,6 & 4,3 & ,000 \\
\hline 2 & 5,3 & 2,6 & 4,0 & ,000 \\
\hline 3 & 5,2 & 2,6 & 4,1 & ,000 \\
\hline 4 & 5,1 & 2,8 & 4,3 & ,000, \\
\hline 5 & 4,8 & 2,5 & 3,9 & ,000, \\
\hline 6 & 4,8 & 2,5 & 3,9 & ,000 \\
\hline 7 & 4,9 & 2,4 & 3,7 & ,000 \\
\hline 8 & 5,0 & 2,5 & 4,0 & ,000 \\
\hline 9 & 5,1 & 2,5 & 3,8 & ,000, \\
\hline 10 & 5,1 & 2,6 & 3,9 & ,000 \\
\hline 11 & 5,0 & 2,9 & 4,0 & ,001 \\
\hline 12 & 4,9 & 3,0 & 3,7 & ,001 \\
\hline 13 & 4,8 & 2,8 & 3,7 & ,001 \\
\hline 14 & 4,8 & 2,7 & 3,8 & ,001 \\
\hline 15 & 4,9 & 2,8 & 3,5 & ,000 \\
\hline 16 & 5,1 & 2,8 & 3,6 & ,000 \\
\hline 17 & 5,0 & 3,0 & 3,9 & ,001 \\
\hline 18 & 4,9 & 2,8 & 4,0 & ,001 \\
\hline 19 & 5,1 & 2,7 & 3,8 & ,000 \\
\hline 20 & 4,8 & 2,8 & 3,7 & ,000 \\
\hline 21 & 4,7 & 2,7 & 3,6 & ,000 \\
\hline
\end{tabular}

Table 5 - Number of persons ( $n$ ) in need of escape medication after the first injection

\begin{tabular}{|c|c|c|c|c|}
\hline Day & $\begin{array}{l}\text { Hyaluronic } \\
\text { acid }\end{array}$ & $\begin{array}{c}\text { Triam- } \\
\text { cinolone } \\
\text { acetonide }\end{array}$ & $\mathrm{NaCl}$ & Sig. \\
\hline 1 & 20 & 10 & 20 & ,051 \\
\hline 2 & 21 & 11 & 19 & ,051 \\
\hline 3 & 17 & 13 & 15 & ,514 \\
\hline 4 & 15 & 13 & 17 & 665 \\
\hline 5 & 22 & 14 & 18 & 142 \\
\hline 6 & 19 & 14 & 19 & ,379 \\
\hline 7 & 18 & 10 & 20 & ,061 \\
\hline 8 & 21 & 10 & 20 & ,022 \\
\hline 9 & 23 & 7 & 20 & ,001 \\
\hline 10 & 20 & 8 & 21 & ,005, \\
\hline 11 & 21 & 9 & 25 & ,002 \\
\hline 12 & 20 & 7 & 19 & ,003 \\
\hline 13 & 23 & 8 & 20 & ,001 \\
\hline 14 & 18 & 7 & 20 & ,006 \\
\hline 15 & 24 & 6 & 19 & ,000, \\
\hline 16 & 21 & 11 & 15 & ,029 \\
\hline 17 & 21 & 9 & 17 & ,007, \\
\hline 18 & 18 & 10 & 17 & ,063 \\
\hline 19 & 15 & 6 & 13 & ,011 \\
\hline 20 & 15 & 8 & 14 & ,049, \\
\hline 21 & 8 & 6 & 8 & ,510 \\
\hline
\end{tabular}

Lewis et al. the pain after corticosteroid injection in Tennis Elbow complaints was described as an increase in pain for the first day after injection and a reduction after three to four days. In our study we have not found an increase in pain as reported on the VAS score after the subacromial injections ${ }^{(7)}$.

In literature most studies describe a repetition of corticosteroid injections in the treatment of shoulder disorders ${ }^{(19,21)}$.

A number of studies focus on the negative side effects of corticosteroid injections. In these studies merely the effect on the cuff tissue is described with increased damage of this tissue as summarized in the systematic review of Dean ${ }^{(18)}$. The group of Bathia however could not show a significant higher number of cuff ruptures after higher numbers of repeated corticosteroid 
Table 6 - Number of persons ( $n$ ) in need of escape

medication after the second injection

\begin{tabular}{|c|c|c|c|c|}
\hline Day & $\begin{array}{l}\text { Hyaluronic } \\
\text { acid }\end{array}$ & $\begin{array}{c}\text { Triam- } \\
\text { cinolone } \\
\text { acetonide }\end{array}$ & $\mathrm{NaCl}$ & Sig. \\
\hline 1 & 13 & 18 & 14 & 292, \\
\hline 2 & 19 & 6 & 17 & ,003 \\
\hline 3 & 14 & 5 & 14 & ,031 \\
\hline 4 & 18 & 7 & 17 & ,014 \\
\hline 5 & 20 & 6 & 17 & ,002 \\
\hline 6 & 21 & 6 & 16 & ,001 \\
\hline 7 & 20 & 7 & 17 & ,005 \\
\hline 8 & 22 & 8 & 13 & ,001 \\
\hline 9 & 21 & 8 & 14 & ,005 \\
\hline 10 & 23 & 6 & 16 & ,000, \\
\hline 11 & 19 & 9 & 14 & ,037 \\
\hline 12 & 18 & 8 & 17 & ,036 \\
\hline 13 & 19 & 8 & 15 & ,022 \\
\hline 14 & 22 & 8 & 15 & ,003 \\
\hline 15 & 21 & 11 & 17 & ,047 \\
\hline 16 & 18 & 8 & 16 & ,038 \\
\hline 17 & 18 & 6 & 18 & ,003 \\
\hline 18 & 17 & 6 & 15 & 010, \\
\hline 19 & 16 & 6 & 14 & ,011 \\
\hline 20 & 12 & 5 & 14 & ,061 \\
\hline 21 & 12 & 5 & 13 & ,068 \\
\hline
\end{tabular}

Table 7 - Number of persons (n) in need of escape medication after the third injection

\begin{tabular}{|c|c|c|c|c|}
\hline Day & $\begin{array}{l}\text { Hyaluronic } \\
\text { acid }\end{array}$ & $\begin{array}{c}\text { Triamci- } \\
\text { nolone } \\
\text { acetonide }\end{array}$ & $\mathrm{NaCl}$ & Sig. \\
\hline 1 & 20 & 5 & 12 & ,001 \\
\hline 2 & 22 & 6 & 9 & ,000 \\
\hline 3 & 22 & 5 & 11 & ,000 \\
\hline 4 & 18 & 5 & 10 & ,003 \\
\hline 5 & 19 & 3 & 10 & ,000 \\
\hline 6 & 20 & 3 & 10 & 000, \\
\hline 7 & 20 & 4 & 11 & ,000 \\
\hline 8 & 16 & 5 & 11 & ,014 \\
\hline 9 & 20 & 4 & 11 & ,000 \\
\hline 10 & 19 & 4 & 11 & ,001 \\
\hline 11 & 20 & 5 & 12 & ,001 \\
\hline 12 & 19 & 5 & 11 & ,002 \\
\hline 13 & 21 & 4 & 10 & 000, \\
\hline 14 & 20 & 7 & 11 & ,004 \\
\hline 15 & 23 & 4 & 10 & ,000 \\
\hline 16 & 24 & 3 & 10 & 000, \\
\hline 17 & 22 & 4 & 12 & 000, \\
\hline 18 & 19 & 3 & 12 & ,000, \\
\hline 19 & 21 & 4 & 10 & ,000 \\
\hline 20 & 18 & 5 & 10 & ,002 \\
\hline 21 & 21 & 3 & 9 & ,000 \\
\hline
\end{tabular}

injections ${ }^{(20)}$. The group of Mykolyzk showed a reversible effect of these tissues after 3 weeks ${ }^{(17)}$. Based on these findings there seems to be some evidence to belief that cuff tissue has the ability to recover after corticosteroid injection and that repetition of corticosteroid injections does not necessary lead to increased numbers of cuff ruptures.

There are some limitations concerning our study, the selection of patients before entering the study was performed without use of MRI or Ultrasound, this might give some bias in the selection. In general practice however most patients will be treated based on a clinical diagnosis. The results of this study therefore can be used for extrapolation to general practice. 
The injections where placed without use of ultrasound guidance. A recent study however showed that there is little evidence for the need of ultrasound guided needle placement ${ }^{(29)}$.

As far as we know there are no studies which show the short term accumulative effect of corticosteroids in pain reduction. One of the strengths of our study is that we were able to show a booster effect of a repeated triamcinolone acetonide injection after the second injection.

In the previously published results of the RCT we could show a significant reduction in pain on a VAS score after triamcinolone acetonide injection at three, six and twelve weeks. In the current study we were able to show the results at nine weeks after the start of the trial. Given the limited effect of reduction in pain after the third injection it is questionable whether it is necessary to administer more than two injections in case of subacromial impingement ${ }^{(22)}$.

An increase in pain after corticosteroid injection is a common adverse effect ${ }^{(19)}$. Although compared to other studies in which the effect of corticosteroids was studied in the treatment of lateral epicondylitis, in our study the amount of perceived pain after triamcinolone acetonide injection was limited ${ }^{(7)}$. Patients in the hyaluronic acid group needed significantly more co-medication compared to patients in the triamcinolone acetonide group.

\section{Conclusions}

In the first week after injection of triamcinolone acetonide we could show a fast reduction in pain. After the second injection we could show a limited booster effect

of repeated triamcinolone acetonide injection. We were able to graphically show this booster effect of fast reduction in pain after the triamcinolone acetonide injection by displaying the patient perceived pain on a VAS score in the days after injection. Given the limited effect in pain reduction after the third triamcinolone acetonide injection there might be evidence to reduce the total number of repeated triamcinolone acetonide injections to two injections. 
Compared to hyaluronic acid and $\mathrm{NaCl}$ injections, triamcinolone acetonide injections showed a fast and effective reduction in pain on a VAS score already after a limited number of injections.

\section{Table 8 - Adverse events}

\begin{tabular}{|c|c|c|c|}
\hline & $\begin{array}{l}\text { Hyaluronic acid } \\
\text { group } n=51\end{array}$ & $\begin{array}{c}\text { Triamcinolon acetonide } \\
\text { group } n=53\end{array}$ & $\begin{array}{c}\mathrm{NaCl} \text { group } \\
n=55\end{array}$ \\
\hline Flushes & & & 1 \\
\hline Redness at injection site & 1 & & \\
\hline Headache & 8 & 5 & 4 \\
\hline Tingling & & & 1 \\
\hline Nausea & 2 & 2 & \\
\hline
\end{tabular}

\section{Competing interests}

The authors declare that they have no competing interests.

\section{Authors' contributions}

LIFP, GHIMW and RAdB participated in the design of the study. LIFP performed data collection. RAdB and LIFP performed the data analysis. All authors participated in the writing of the manuscript and read and approved the final version.

\section{Acknowledgements}

We acknowledge the staff of the outpatient orthopedics department for their recruitment and handling of the patients who contributed to this study. We also acknowledge Dr. Fons Kessels (FK) who kindly generated the random numbers list used for randomization of the study. There was no funding of any kind for the authors of this study. 


\section{References}

1. Greving K, Dorresteijn O, Winters JC, Groenhof F, van der Meer K, Stevens M, Diercks RL: Incidence, prevalence, and consultation rates of shoulder complaints in general practice. Scand J Rheumatol 2012, 41(2):150-155.

2. Picavet HSJ, Schouten JSAG: Musculoskeletal pain in the Netherlands: prevalences, consequences and risk groups, the DMC3-study. Pain 2003, 102(1-2):167-178.

3. Michener LA, McClure PW, Karduna AR: Anatomical and biomechanical mechanisms of subacromial impingement syndrome. Clin Biomech 2003, 18(5):369-379.

4. Blair B, Rokito AS, Cuomo F, Jarolem K, Zuckerman J: Efficacy of injections of corticosteroids for subacromial impingement syndrome. J Bone Joint Surg Am 1996, 78(11):1685-1689.

5. Winters JC, van der Windt DAWM, Spinnewijn WEM, De Jogh AC, Van der Heijden GJMG, Buis PAJ, Boeke AJP, Feleus A, Geraedts JJXR: NHG-Standaard Schouderklachten. Huisarts en Wetenschap 2008, 51(11):555-565.

6. Coombes BK, Bisset L, Vicenzino B: Efficacy and safety of corticosteroid injections and other injections for management of tendinopathy: a systematic review of randomised controlled trials. Lancet 2010, 376(9754):1751-1767.

7. Lewis M, Hay E, Paterson SM, Croft P: Local steroid injections for tennis elbow: does the pain get worse before it gets better?: Results from a randomized controlled trial. Clin J Pain 2005, 21(4):330-334.

8. Crawshaw DP, Helliwell PS, Hensor EM, Hay EM, Aldous SJ, Conaghan PG: Exercise therapy after corticosteroid injection for moderate to severe shoulder pain: large pragmatic randomised trial. BMJ 2010, 340:c3037.

9. Shibata Y, Midorikawa K, Emoto G, Naito M: Clinical evaluation of sodium hyaluronate for the treatment of patients with rotator cuff tear. J Shoulder Elbow Surg 2001, 10(3):209216.

10. Itokazu M, Matsunaga $\mathrm{T}$ : Clinical evaluation of high-molecular-weight sodium hyaluronate for the treatment of patients with periarthritis of the shoulder. Clin Ther 1995, 17(5):946-955.

11. Funk L: P153 Hyaluronan vs. steroid injection for subacromial impingement of the shoulder. Osteoarthr Cartil 2005, 13:S80. 
12. Chou WY, Ko JY, Wang FS, Huang CC, Wong T, Wang CJ, Chang HE: Effect of sodium hyaluronate treatment on rotator cuff lesions without complete tears: a randomized, double-blind, placebo-controlled study. J Shoulder Elbow Surg 2010, 19(4):557-563.

13. Iwata $\mathrm{H}$ : Pharmacologic and clinical aspects of intraarticular injection of hyaluronate. Clin Orthop Relat Res 1993, 289:285-291.

14. Kuiper-Geertsma DG, Bijlsma JW: [Intra-articular injection of hyaluronic acid as an alternative option to corticosteroid injections for arthrosis]. Ned Tijdschr Geneeskd 2000, 144(46):2188-2192.

15. Eustace JA, Brophy DP, Gibney RP, Bresnihan B, FitzGerald O: Comparison of the accuracy of steroid placement with clinical outcome in patients with shoulder symptoms. Ann Rheum Dis 1997, 56(1):59-63.

16. Tillander B, Franzen LE, Karlsson MH, Norlin R: Effect of steroid injections on the rotator cuff: an experimental study in rats. J Shoulder Elbow Surg 1999, 8(3):271-274.

17. Mikolyzk DK, Wei AS, Tonino P, Marra G, Williams DA, Himes RD, Wezeman FH, Callaci JJ: Effect of corticosteroids on the biomechanical strength of rat rotator cuff tendon. J Bone Joint Surg 2009, 91(5):1172-1180.

18. Dean BJF, Lostis E, Oakley T, Rombach I, Morrey ME, Carr AJ: The Risks and Benefits of Glucocorticoid Treatment for Tendinopathy: A Systematic Review of the Effects of Local Glucocorticoid on Tendon. Semin Arthritis Rheum 2014, 43(4):570-576.

19. Buchbinder R, Green S, Youd JM: Corticosteroid injections for shoulder pain. Cochrane Database Syst Rev 2003, 1:CD004016.

20. Bhatia M, Singh B, Nicolaou N, Ravikumar KJ: Correlation between rotator cuff tears and repeated subacromial steroid injections: a case-controlled study. Ann R Coll Surg Engl 2009, 91(5):414-416.

21. Gaujoux-Viala C, Dougados M, Gossec L: Efficacy and safety of steroid injections for shoulder and elbow tendonitis: a meta-analysis of randomised controlled trials. Ann Rheum Dis 2009, 68(12):1843-1849.

22. Penning LIF, de Bie RA, Walenkamp GHIM: The effectiveness of injections of hyaluronic acid or corticosteroid in patients with subacromial impingement: a three-arm randomised controlled trial. J Bone Joint Surg 2012, 94-B(9):1246-1252. British Volume.

23. MacGregor AJ: Classification criteria for rheumatoid arthritis. Baillieres Clin Rheumatol 1995, 9(2):287-304. 
24. van der Linden S, Valkenburg HA, Cats A: Evaluation of diagnostic criteria for ankylosing spondylitis. A proposal for modification of the New York criteria. Arthritis Rheum 1984, 27(4):361-368.

25. Rowe CR: Injection technique for the shoulder and elbow. Orthop Clin North Am 1988, 19(4):773-777.

26. Huskisson EC: Visual Analogue Scales. In Pain Measurement and Assessment. Edited by Melzack R. New York: Raven; 1983:33-37.

27. de Wit R, van Dam F, Hanneman M, Zandbelt L, van Buuren A, van der Heijden K, Leenhouts G, Loonstra S, Huijer Abu-Saad H: Evaluation of the use of a pain diary in chronic cancer pain patients at home. Pain 1999, 79(1):89-99.

28. Neer CS 2nd: Impingement lesions. Clin Orthop Relat Res 1983, 173:70-77.

29. Ekeberg OM, Bautz-Holter E, Tveita EK, Juel NG, Kvalheim S, Brox JI: Subacromial ultrasound guided or systemic steroid injection for rotator cuff disease: randomised double blind study. BMJ 2009, 338:a3112. 


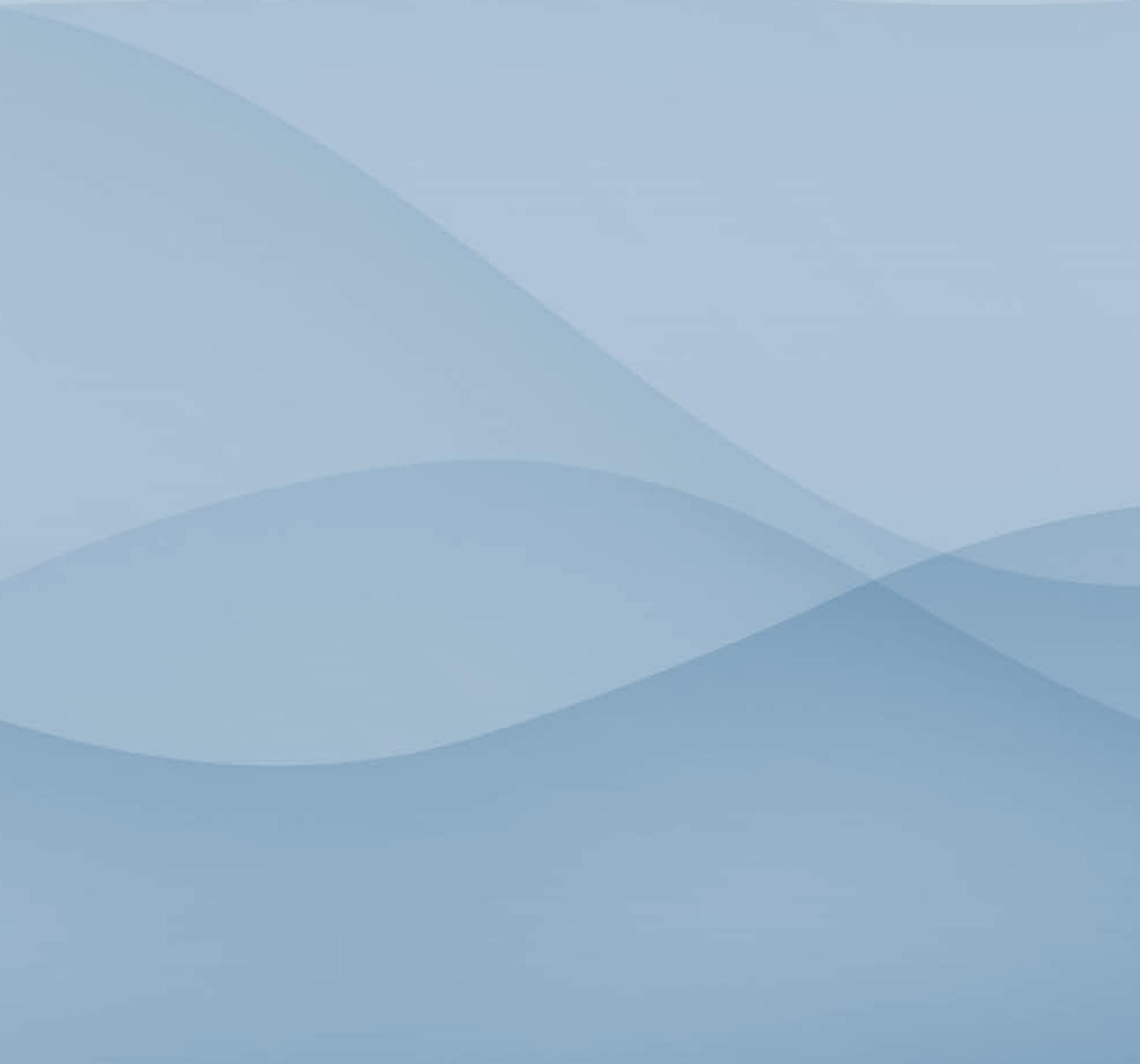




\section{Chapter 4}

\section{Empty can and drop arm tests}

for cuff rupture:

Improved specificity after

subacromial injection

Penning L.I.F.

de Bie R.A.

Leffers $P$.

Weijers R.E.

Walenkamp G.H.I.M.

Accepted: Acta Orthopaedica Belgica 2015. 


\section{Abstract}

Shoulder disorders are common in the general population: they occur in about 25 of every 1000 patients per year. A rather large majority are caused by cuff disorders. Differentiating between impingement and cuff rupture is essential to adequate treatment. Clinical tests have been developed, but their accuracy is limited. This study was performed to improve clinical accuracy by combining single tests and adding a subacromial injection. We postulated that the empty can and drop arm tests would result in higher sensitivity and specificity after subacromial injection.

Method: We prospectively assessed 49 patients with the empty can and drop arm tests and used ultrasound to compare the individual and combined results.

Results: The ultrasound found six cuff ruptures. Specificity improved and sensitivity decreased after subacromial injection.

Conclusions: Only specificity improved after subacromial injection. Combining the test results led to an increase in both sensitivity and specificity without injection.

Keywords: Subacromial impingement, diagnostic accuracy study design, rotator cuff, empty can test, drop arm test, sensitivity, specificity. 


\section{Introduction}

Shoulder disorders are frequently encountered in general practice: the reported incidence rates of new episodes of shoulder disorders in general practice range from 12 to 25 per 1000 patients per year ${ }^{(42)}$. The cumulative incidence of shoulder disorders in the general population in the Netherlands has been estimated at 11.2 per 1000 patients per year (95\% CI 10.1-12.3) ${ }^{(43)}$. Shoulder disorders involve pain in the upper arm and deltoid region accompanied by stiffness. Pain and stiffness limit a person's ability to perform normal daily activities ${ }^{(41)}$.

The majority of patients have a painful arc: pain within a specific range (usually between 90 and 140 degrees) of shoulder abduction. This painful arc originates from cuff impingement, which is supposedly caused by an inflammatory reaction. A sustained inflammatory reaction can lead to effusion and occasionally calcification in the subacromial space ${ }^{(35)}$. Long-lasting impingement causes cuff degeneration and cuff rupture, for which surgical treatment is needed ${ }^{(12)}$.

Subacromial impingement is a common cause of shoulder disorders, but differentiating between impingement and cuff rupture is essential to adequate treatment. Without differentiation, the number of missed or misdiagnosed cuff ruptures will increase. This may lead to more extensive cuff ruptures, making complex surgical interventions necessary ${ }^{(23)}$. With large and degenerative cuff ruptures, the chance of complete recovery after surgery is small ${ }^{(7,13,22)}$.

Traditional physical examination is insufficient for making a valid and reproducible differentiation of the causes and sources of shoulder disorders ${ }^{(11)}$. Recent reviews of physical tests for shoulder impingement advocate the use of multiple tests for diagnosing pathological shoulder disorders ${ }^{(2,14)}$.

A number of clinical tests have been developed to prove and exclude rotator cuff tears. However, the evidence for their diagnostic accuracy is very limited. Estimates of sensitivity and specificity are based on research in specialised care settings and have large 
confidence intervals. The tests are generally compared to arthrography, findings during surgery or subacromial infiltration ${ }^{(8,24,29)}$. Available clinical tests for assessing rotator cuff ruptures are based on an assessment of muscular strength and an assessment of pain. The accompanying pain might influence muscular strength and mask a cuff rupture.

The current interpretation of tests is not adjusted for the influence of pain. We conducted this study to examine the effect of pain on individual shoulder tests. In accordance with the STARD (STandards for Reporting of Diagnostic Accuracy) initiative, the clinical tests under study will be referred to as index tests and ultrasound will be referred to as the reference test $(4,6,5,31,36,37)$.

The majority of patients suffering from shoulder disorders are seen and treated by their general practitioners or orthopaedic surgeons. Given the limited value of the currently used individual shoulder tests, there is a need for tests that can differentiate between impingement and cuff rupture and that are suitable for use in both primary and secondary health care.

The available clinical tests designed to detect cuff ruptures have limited accuracy. This study will assess the accuracy of the empty can and drop arm tests before and after subacromial injection to differentiate between the presence and absence of cuff ruptures in patients with shoulder disorders. The effect of the subacromial injection and the results of the clinical tests will be compared, individually and together, with ultrasound (i.e. the reference test). We postulate that the empty can and drop arm tests for cuff rupture will be more sensitive and specific after the administration of an anaesthetic than before injection.

\section{Patients and methods}

This study was approved by the Medical Ethics Review Committee of our hospital and was performed at the outpatient clinic of our orthopaedic surgery department. Data were prospectively collected from consecutive patients diagnosed with subacromial impingement, referred by their general practitioners. Based on histories and regular 
physical examinations, the diagnosis was confirmed and patients were treated according to standard conservative treatment: administration of a subacromial corticosteroid injection.

Patients were eligible for this study if they were 18 years of age or older, had consulted an orthopaedic surgeon for pain in their shoulder and had a painful arc (painful movement between 90 and 140 degrees of abduction). Patients were excluded if they exhibited clinical signs of instability, or if a frozen shoulder or a cervical radicular syndrome were the suspected or definite cause of their shoulder disorders.

This was a cohort diagnostic accuracy study. All clinical tests, including the subacromial injection, were performed during intake at the outpatient clinic. The reference test (i.e. ultrasound) was performed within two weeks after intake.

\section{Reference Test}

Ultrasound was used as the reference test for detection of cuff ruptures because it can detect both full and partial thickness ruptures. Sensitivity and specificity for the assessment of partial thickness ruptures were 0.84 and 0.89 , respectively. For detection of full thickness rotator cuff tears, sensitivity was 0.96 and specificity was $0.93^{(3,9,15-17,20 \text {, }}$ $21,25-27,30,33,38-40,44)$.

All the ultrasound diagnostics for this study were performed by two radiologists who are specialised in musculoskeletal radiology. They are highly trained and experienced in using ultrasound to diagnose shoulder disorders.

The result of the ultrasound was noted as either positive or negative for cuff rupture. If it was positive, the type of rupture was described as either full or partial thickness with the size given in centimetres.

\section{Empty Can Test (Jobe Test)}

This test is used to determine the presence of weakness in the supraspinatus muscle due to cuff rupture or pain (in the case of tendonitis). During this test, the patient is either standing or sitting in an upright position. The shoulder is fully internally rotated to 90 degrees of abduction and 30 degrees of anteflexion. The patient is instructed to resist the downward pressure exerted by the examiner. 
The results of this test are positive if there is limited function (i.e. the patient is unable to withstand the applied resistance) or negative if there is good function ${ }^{(19)}$. For this test, a mean pooled sensitivity of $69 \%$ and a mean pooled specificity of $62 \%$ have been reported $^{(1)}$.

\section{Drop Arm Test (Codman's Sign)}

After maximal passive abduction, the patient is asked to actively lower the arm in the frontal plane. Based on muscle weakness, pain or cuff rupture, the arm will drop. The test results are positive if the arm drops while it is being lowered and negative if there is good function ${ }^{(10)}$. For this test, a mean pooled sensitivity of $21 \%$ and a mean pooled specificity of $92 \%$ have been reported ${ }^{(1)}$.

\section{Neer Test}

The Neer test is performed with the patient in an upright sitting position and both arms hanging down. The arm is passively elevated in anteflexion while the ipsilateral scapula is fixed to prevent movement. The occurrence of pain during this anteflexion movement is a painful arc. The test is performed again approximately a quarter of an hour after $10 \mathrm{ml}$ of lidocaine $1 \%$ has been injected in the subacromial bursa. When there is no more pain during the passive elevation, the Neer test results are positive ${ }^{(28)}$.

During the injection, the patient is seated in an upright position with zero degrees of abduction. Just medio caudal of the dorsal lateral acromial edge, a soft spot can be palpated (i.e. the posterior of the greater tubercle): this is the injection site. It is marked with the back of a cotton bud and disinfected with iodine in alcohol or, in case of a known iodine allergy, with a chlorhexidine $0.5 \%$ solution. The injection is then made at the marked spot (34). The injections used in this study consisted of $2 \mathrm{ml}$ Triamcinolone acetonidum $10 \mathrm{mg} /$ $\mathrm{ml}(2 \mathrm{ml})$ and lidocaine $1 \%(8 \mathrm{ml})$ and were used both diagnostically and therapeutically.

\section{Combination of Tests}

The empty can and drop arm tests are part of the regular physical examination to detect cuff ruptures in cases of subacromial impingement. Since the drop arm test generally causes more pain, the empty can test was performed first. They were performed individually before and after subacromial injection. The results were then analysed for 
the individual tests and the combined tests. The test results were documented as either positive or negative.

During the consultation for shoulder disorders, an orthopaedic surgeon (first author) took the regular history and performed the physical examination. The orthopaedic surgeon was well trained and experienced in taking histories and performing physical examinations related to shoulder disorders. All the patients were examined and injected by the same orthopaedic surgeon.

The results of the tests under study were compared with the reference test (ultrasound). Based on these comparisons, we constructed $2 \times 2$ tables and calculated the sensitivity and specificity of testing and the $95 \%$ confidence intervals. We also calculated the derived positive predictive value, the negative predictive value, overall accuracy, pre-test probability, pre-test odds, likelihood ratio, post-test odds and post-test probability.

For the analysis of the combined test results before and after injection, we used a rule for parallel testing. This means that in order to obtain a positive test result for the combination of tests, either the drop arm test or the empty can test had to have a positive result. In serial testing, the result would be positive when both tests had positive results. After applying this rule of parallel testing, we constructed new $2 \times 2$ tables to calculate sensitivity and specificity.

\section{Results}

We originally enrolled 50 patients in this study. One patient was not assessed by ultrasound and thus excluded. The final study group consisted of 49 patients, 20 male and 29 female, with a mean age of 56.6 years (range 26-80 years). Most patients were affected on the right-hand side $(n=29)$ Eleven patients had suffered a shoulder trauma that was considered to be the cause of their complaints (Table I). 


\section{Table 1 - Demographic Data}

\begin{tabular}{|lc|}
\hline Participants $(n=49)$ & \\
\hline Sex & $41 \%$ male $/ 59 \%$ female \\
\hline Age & mean $=56.5$ years; range $=26-80$ years \\
\hline Affected side & $41 \%$ left $/ 59 \%$ right \\
\hline Dominant side & $10 \%$ left $/ 90 \%$ right \\
\hline Trauma & $22 \%$ yes $/ 78 \%$ no \\
\hline
\end{tabular}

Ultrasound performed on the patients found six rotator cuff ruptures: five full thickness ruptures and one partial thickness rupture (Figures 1 and 2). All the ruptures were located in the supraspinatus tendon. The size of the full thickness ruptures ranged from $1.0-2.5 \mathrm{~cm}$. The partial thickness rupture was $0.8 \mathrm{~cm}$ in size.

\section{Empty Can Test}

The results were dramatically different before and after injection. Before injection, the test results were positive for $65 \%$ of the patients $(n=32)$ and negative for $35 \%(n=17)$. The test showed a sensitivity of $67 \%$ (95\% CI 0.3-0.90) and a specificity of 35\% (95\% CI 0.22-0.49; $L R+=1 ; \mathrm{LR}-=.95)$. After injection, the results of the empty can test switched: it was positive for $35 \%$ of the patients $(n=17)$ and negative for $65 \%(n=32)$. It showed a sensitivity of 33\% (95\% CI 0.09-0.70) and a specificity of 67\% (95\% CI 0.52-0.79; LR+=1; LR-=1) after injection.

\section{Drop Arm Test}

Patients also performed better on the drop arm test after injection. Before injection, the test results were positive for $12 \%$ of the patients $(n=6)$ and negative for $88 \%(n=43)$. The test showed a sensitivity of $17 \%$ (95\% CI $0.03-0.56)$ and a specificity of $88 \%(95 \%$ CI 0.75-0.94; $L R+=1.4 ; \mathrm{LR}-=.94)$. After injection, the test results were positive for $6 \%$ of the patients $(n=3)$ and negative for $94 \%(n=46)$. The sensitivity remained $17 \%(95 \%$ CI $0.03-0.56)$ with a specificity of $95 \%$ (95\% CI 0.84-0.98; LR+=3.58; LR-=0.87).

\section{Neer Test}

After injection, $69 \%(n=34)$ of patients tested positive. 
Figure 1 - STARD Flowchart for the Empty Can Test

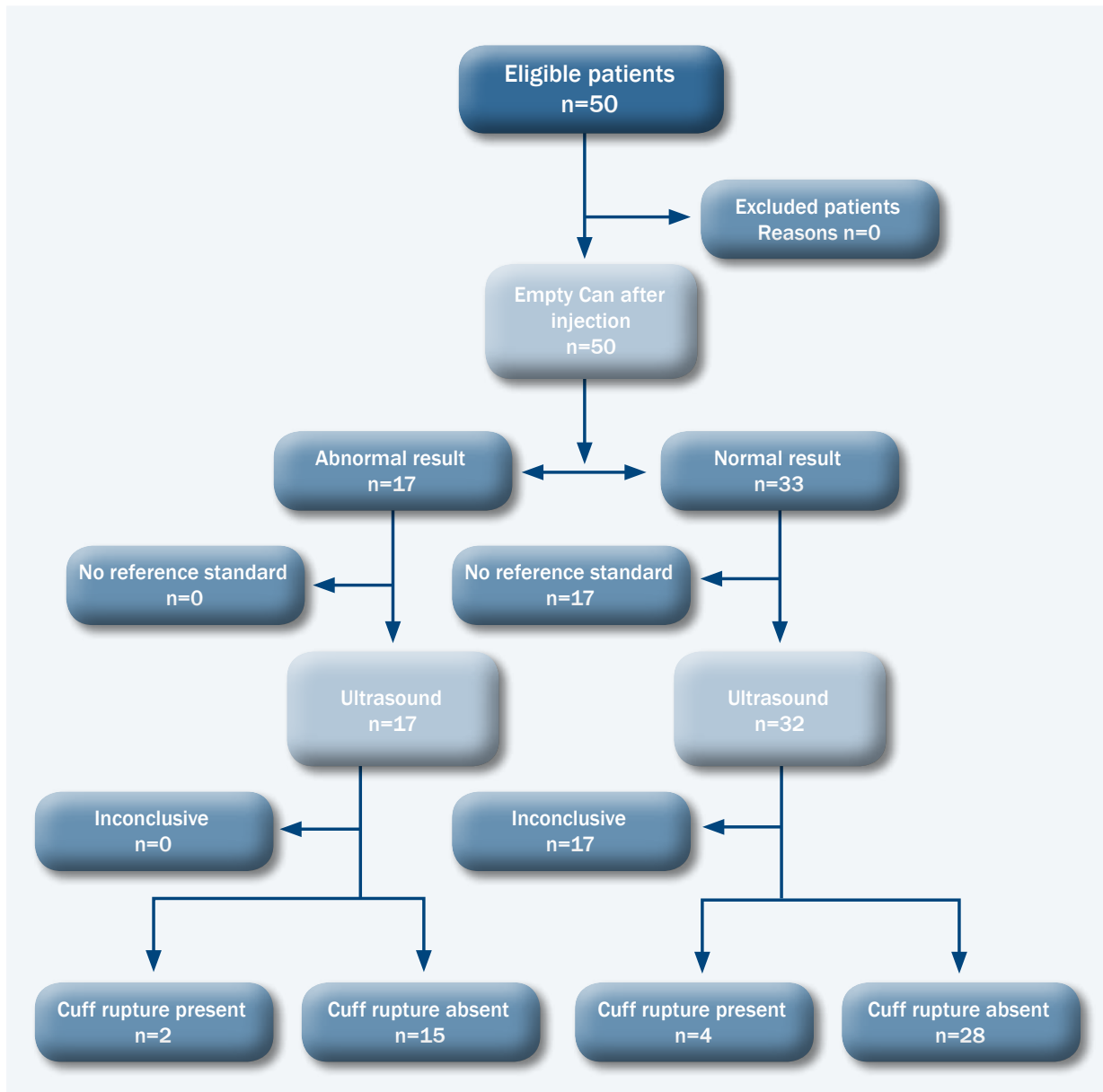

Table 2 - Results

\begin{tabular}{|lcc|}
\hline Test & Positive & Negative \\
\hline Neer test & 34 & 15 \\
\hline $\begin{array}{l}\text { Empty can test } \\
\text { before injection }\end{array}$ & \\
$\quad$ after injection & 32 & 17 \\
\hline $\begin{array}{l}\text { Drop arm test } \\
\text { before injection }\end{array}$ & 16 & 33 \\
\hline$\quad$ after injection & 6 & \\
\hline Cuff rupture on ultrasound & 3 & 43 \\
\hline
\end{tabular}


Figure 2 - STARD Flowchart for the Drop Arm Test

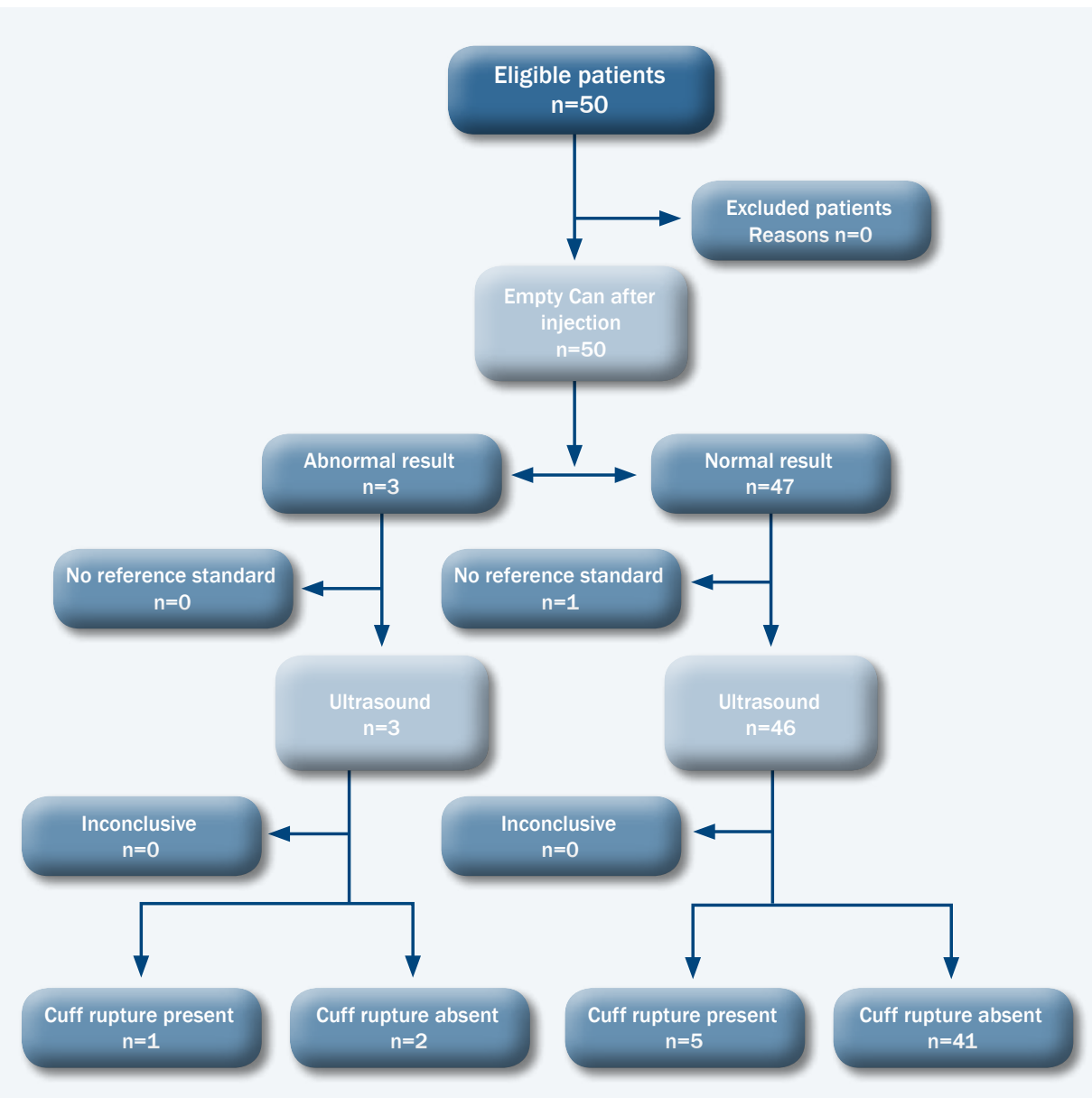

\section{Combined Results}

Combining the results of the empty can and drop arm tests, we found a sensitivity of $72 \%$ before injection and $44 \%$ after injection. We found a specificity of $92 \%$ before injection and $98 \%$ after injection (Table III). 
Table 3 - Overall Calculated Results

\begin{tabular}{|c|c|c|c|c|c|c|}
\hline & \multicolumn{2}{|c|}{ Empty Can Test } & \multicolumn{2}{|c|}{ Drop Arm Test } & \multicolumn{2}{|c|}{ Combined Tests } \\
\hline & $\begin{array}{c}\text { Before } \\
\text { injection }\end{array}$ & $\begin{array}{c}\text { After } \\
\text { injection }\end{array}$ & $\begin{array}{c}\text { Before } \\
\text { injection }\end{array}$ & $\begin{array}{c}\text { After } \\
\text { injection }\end{array}$ & $\begin{array}{c}\text { Before } \\
\text { injection }\end{array}$ & $\begin{array}{c}\text { After } \\
\text { injection }\end{array}$ \\
\hline $\begin{array}{l}\text { Sensitivity } \\
(95 \% \mathrm{Cl})\end{array}$ & $\begin{array}{c}67 \% \\
(.23-.94)\end{array}$ & $\begin{array}{c}33 \% \\
(.05-.80)\end{array}$ & $\begin{array}{c}17 \% \\
(.03-.63)\end{array}$ & $\begin{array}{c}17 \% \\
(.03-.63)\end{array}$ & $\begin{array}{c}67 \% \\
(.23-.95)\end{array}$ & $\begin{array}{c}33 \% \\
(.05-.77)\end{array}$ \\
\hline Specificity & $\begin{array}{c}34 \% \\
(.21-.50)\end{array}$ & $\begin{array}{c}67 \% \\
(.51-.81)\end{array}$ & $\begin{array}{c}88 \% \\
(.75-.97)\end{array}$ & $\begin{array}{c}95 \% \\
(.80-.99)\end{array}$ & $\begin{array}{c}33 \% \\
(.19-.49)\end{array}$ & $\begin{array}{c}65 \% \\
(.49-.79)\end{array}$ \\
\hline $\begin{array}{l}\text { Predictive value } \\
\text { Positive } \\
\text { Negative }\end{array}$ & $\begin{array}{l}13 \% \\
12 \%\end{array}$ & $\begin{array}{l}13 \% \\
12 \%\end{array}$ & $\begin{array}{l}17 \% \\
12 \%\end{array}$ & $\begin{array}{l}33 \% \\
11 \%\end{array}$ & $\begin{array}{l}12 \% \\
88 \%\end{array}$ & $\begin{array}{l}12 \% \\
88 \%\end{array}$ \\
\hline Overall accuracy & $8 \%$ & $63 \%$ & $80 \%$ & $86 \%$ & $8 \%$ & $4 \%$ \\
\hline $\begin{array}{l}\text { Probability } \\
\text { Pre-test } \\
\text { Post-test }\end{array}$ & $\begin{array}{l}12 \% \\
13 \%\end{array}$ & $\begin{array}{l}12 \% \\
13 \%\end{array}$ & $\begin{array}{l}12 \% \\
17 \%\end{array}$ & $\begin{array}{l}12 \% \\
33 \%\end{array}$ & $\begin{array}{l}12 \% \\
12 \%\end{array}$ & $\begin{array}{l}12 \% \\
12 \%\end{array}$ \\
\hline $\begin{array}{l}\text { Odds } \\
\text { Pre-test } \\
\text { Post-test }\end{array}$ & $\begin{array}{l}.14 \\
.14\end{array}$ & $\begin{array}{l}.14 \\
.14\end{array}$ & $\begin{array}{l}.14 \\
.20\end{array}$ & $\begin{array}{l}.14 \\
.50\end{array}$ & $\begin{array}{l}.14 \\
.14\end{array}$ & $\begin{array}{l}.14 \\
.13\end{array}$ \\
\hline Likelihood ratio & 1 & 1 & 1.4 & 3.5 & .98 & .95 \\
\hline
\end{tabular}

\section{Discussion}

The empty can test had an intermediate sensitivity of $67 \%$ and a low specificity of $35 \%$ compared to the reference test without anaesthesia. In contrast, for cuff ruptures, the drop arm test had a low sensitivity of $17 \%$ and a high specificity of $88 \%(L R+=1.4 ; \mathrm{LR}-=+0.94)$ compared to the reference test without anaesthesia. When the tests were performed after administering anaesthesia, the specificity of testing improved for both tests. In contrast to our hypothesis, only specificity improved after injection.

Some of our results and techniques were different than those of other studies. Several other studies have used different techniques for detecting rotator cuff tears: arthrography, findings during surgery or magnetic resonance imaging ${ }^{(25-27,32,33,40)}$. Compared to results in the literature, we found that the empty can test resulted in rather low sensitivity and specificity ${ }^{(1,18)}$. This might be due to the small number of cuff ruptures in our population. When we compared specificity, we found that the numbers were equal to those in the literature for the drop arm test ${ }^{(8)}$. The combination of the empty can and drop arm tests showed that, in contrast to the individual test results, sensitivity and specificity increased 
before injection. After injection, the specificity improved even more, although there was a decrease in sensitivity. These results stress the importance of combining different tests when making physical examinations of shoulder disorders, as other researchers also concluded $^{(2,14)}$.

\section{Conclusions}

We found relatively low to intermediate sensitivity and specificity levels for the empty can and drop arm tests. Administration of an anaesthetic and repeated performance of the tests improved the specificity of testing, but decreased the sensitivity. When the tests were combined, we found higher sensitivity and specificity levels before injection and higher specificity after injection.

\section{Competing Interests}

The authors declare that they have no competing interests.

\section{Authors' Contributions}

Authors 1,2, 3 and 5 participated in the design of the study. Authors 1 and 4 collected the data and Author 1 analysed it. All the authors participated in the writing of the manuscript and read and approved the final version.

\section{Acknowledgements}

We acknowledge the staff of the outpatient orthopaedics department for their recruitment and handling of the patients who contributed to this study.

The authors of this study received no funding of any kind for this study. 


\section{References}

1. Alqunaee M, Galvin R, Fahey T. Diagnostic accuracy of clinical tests for subacromial impingement syndrome: a systematic review and meta-analysis. Arch Phys Med Rehabil $2012 ; 93: 229-236$.

2. Biederwolf NE. A proposed evidence-based shoulder special testing examination algorithm: clinical utility based on a systematic review of the literature. International journal of sports physical therapy $2013 ; 8: 427-440$.

3. Birtane $\mathrm{M}$, Calis $\mathrm{M}$, Akgun $\mathrm{K}$. The diagnostic value of magnetic resonance imaging in subacromial impingement syndrome. Yonsei Med J 2001 ; 42 : 418-424.

4. Bossuyt PM, Reitsma JB, Bruns DE et al. [Reporting studies of diagnostic accuracy according to a standard method; the Standards for Reporting of Diagnostic Accuracy (STARD)]. Ned Tijdschr Geneeskd 2003; 147 : 336-340.

5. Bossuyt PM, Reitsma JB, Bruns DE et al. Towards complete and accurate reporting of studies of diagnostic accuracy: the STARD initiative. Fam Pract $2004 ; 21: 4-10$.

6. Bossuyt PM, Reitsma JB, Bruns DE et al. Towards complete and accurate reporting of studies of diagnostic accuracy: the STARD initiative. Clin Radiol 2003 ; 58 : 575-580.

7. Burkhart SS, Danaceau SM, Pearce CE, Jr. Arthroscopic rotator cuff repair: analysis of results by tear size and by repair technique-margin convergence versus direct tendon-tobone repair. Arthroscopy $2001 ; 17$ : 905-912.

8. Calis M, Akgun K, Birtane $M$ et al. Diagnostic values of clinical diagnostic tests in subacromial impingement syndrome. Ann Rheum Dis 2000 ; 59 : 44-47.

9. Chang CY, Wang SF, Chiou HJ et al. Comparison of shoulder ultrasound and MR imaging in diagnosing full-thickness rotator cuff tears. Clin Imaging $2002 ; 26: 50-54$.

10. Codman EA. The Shoulder: rupture of the supraspinatus tendon and other lesions in or about the subacromial bursa. Privately printed, 1934. Reprint, Malabar, Florida: Krieger, 1965.) ed. Boston 1934.

11. Dinnes J, Loveman E, McIntyre L et al. The effectiveness of diagnostic tests for the assessment of shoulder pain due to soft tissue disorders: a systematic review. Health Technol Assess 2003 ; 7 : iii, 1-166.

12. Fukuda H, Hamada K, Nakajima T et al. Pathology and pathogenesis of the intratendinous tearing of the rotator cuff viewed from en bloc histologic sections. Clin Orthop Relat Res $1994 ; 304: 60-67$. 
13. Galatz LM, Rothermich SY, Zaegel M et al. Delayed repair of tendon to bone injuries leads to decreased biomechanical properties and bone loss. J Orthop Res 2005 ; 23 : 1441-1447.

14. Hanchard NC, Lenza M, Handoll HH et al. Physical tests for shoulder impingements and local lesions of bursa, tendon or labrum that may accompany impingement. Cochrane Database Syst Rev 2013 ; 4 : CD007427.

15. Hedtmann A, Fett H. [Ultrasound diagnosis of the rotator cuff]. Orthopade 2002; 31 : 236-246.

16. Heininger-Biner K, Muller M, Hertel R. [Diagnosis of rotator cuff rupture: correlation of clinical findings and magnetic resonance tomography with intraoperative findings]. Z Orthop Ihre Grenzgeb 2000 ; 138: 478-480.

17. Iannotti JP, Ciccone J, Buss DD et al. Accuracy of office-based ultrasonography of the shoulder for the diagnosis of rotator cuff tears. J Bone Joint Surg Am 2005 ; 87 : 1305-1311.

18. Itoi E, Kido T, Sano A et al. Which is more useful, the "full can test" or the "empty can test," in detecting the torn supraspinatus tendon? Am J Sports Med 1999 ; 27 : 65-68.

19. Jobe FW, Moynes DR. Delineation of diagnostic criteria and a rehabilitation program for rotator cuff injuries. Am J Sports Med 1982 ; 10 : 336-339.

20. Kayser R, Hampf S, Pankow M et al. [Validity of ultrasound examinations of disorders of the shoulder joint]. Ultraschall Med $2005 ; 26: 291-298$.

21. Kenn W, Hufnagel P, Muller T et al. [Arthrography, ultrasound and MRI in rotator cuff lesions: a comparison of methods in partial lesions and small complete ruptures]. Rofo Fortschr Geb Rontgenstr Neuen Bildgeb Verfahr 2000 ; 172 : 260-266.

22. Koike Y, Trudel G, Curran D et al. Delay of supraspinatus repair by up to 12 weeks does not impair enthesis formation: a quantitative histologic study in rabbits. J Orthop Res 2006; 24 : 202-210.

23. Lahteenmaki HE, Virolainen P, Hiltunen A et al. Results of early operative treatment of rotator cuff tears with acute symptoms. J Shoulder Elbow Surg 2006 ; 15 : 148-153.

24. Luime J. Diagnostic evaluation of shoulder pain: a systematic review on the accuracy of signs and symptoms related to rotator cuff disorders. $\mathrm{PhD}$ thesis: Shoulder complaints; the occurrence, course and diagnosis. 2004.

25. Martin-Hervas C, Romero J, Navas-Acien A et al. Ultrasonographic and magnetic resonance images of rotator cuff lesions compared with arthroscopy or open surgery findings. J Shoulder Elbow Surg 2001 ; 10 : 410-415. 
26. Milosavljevic J, Elvin A, Rahme H. Ultrasonography of the rotator cuff: a comparison with arthroscopy in one-hundred-and-ninety consecutive cases. Acta Radiol 2005 ; 46 : 858-865.

27. Moosmayer S, Smith HJ. Diagnostic ultrasound of the shoulder--a method for experts only? Results from an orthopedic surgeon with relative inexpensive compared to operative findings. Acta Orthop $2005 ; 76: 503-508$.

28. Neer CS, 2nd. Impingement lesions. Clinical orthopaedics and related research. 1983; 173: 70-77.

29. Park HB, Yokota A, Gill HS et al. Diagnostic accuracy of clinical tests for the different degrees of subacromial impingement syndrome. J Bone Joint Surg Am 2005 ; 87 : 14461455.

30. Radke S, Kenn W, Gohlke F. [MRI of the shoulder. Degenerative changes and rotator cuff tears]. Orthopade $2001 ; 30: 484-491$.

31. Rama KR, Poovali S, Apsingi S. Quality of reporting of orthopaedic diagnostic accuracy studies is suboptimal. Clin Orthop Relat Res 2006 ; 447 : 237-246.

32. Read JW, Perko M. Shoulder ultrasound: diagnostic accuracy for impingement syndrome, rotator cuff tear, and biceps tendon pathology. J Shoulder Elbow Surg 1998 ; 7 : 264-271.

33. Roberts CS, Walker JA, 2nd, Seligson D. Diagnostic capabilities of shoulder ultrasonography in the detection of complete and partial rotator cuff tears. Am J Orthop 2001; 30 : 159-162.

34. Rowe CR. Injection technique for the shoulder and elbow. Orthop Clin North Am 1988 ; 19 : 773-777.

35. Rupp S, Seil R, Kohn D. [Tendinosis calcarea of the rotator cuff]. Orthopade $2000 ; 29$ : 852-867.

36. Smidt N, Rutjes AW, van der Windt DA et al. Quality of reporting of diagnostic accuracy studies. Radiology 2005 ; 235 : 347-353.

37. Smidt N, Rutjes AW, van der Windt DA et al. Reproducibility of the STARD checklist: an instrument to assess the quality of reporting of diagnostic accuracy studies. BMC Med Res Methodol $2006 ; 6: 12$.

38. Smith TO, Back T, Toms AP et al. Diagnostic accuracy of ultrasound for rotator cuff tears in adults: a systematic review and meta-analysis. Clin Radiol $2011 ; 66$ : 1036-1048.

39. Swen WA, Jacobs JW, Algra PR et al. Sonography and magnetic resonance imaging equivalent for the assessment of full-thickness rotator cuff tears. Arthritis Rheum 1999; 42 : 2231-2238. 
40. Teefey SA, Rubin DA, Middleton WD et al. Detection and quantification of rotator cuff tears. Comparison of ultrasonographic, magnetic resonance imaging, and arthroscopic findings in seventy-one consecutive cases. J Bone Joint Surg Am 2004 ; 86-A : 708-716.

41. van der Heijden GJ. Shoulder disorders: a state-of-the-art review. Baillieres Best Pract Res Clin Rheumatol $1999 ; 13: 287-309$.

42. van der Linden $M$, Westert G, De Bakker D et al. Complaints and disorders in the population and general practice. NIVEL / RIVM, Utrecht. 2005.

43. van der Windt DA, Koes BW, de Jong BA et al. Shoulder disorders in general practice: incidence, patient characteristics, and management. Ann Rheum Dis 1995 ; 54 : 959-964.

44. Winters JC, Sobel JS, Groenier KH et al. Comparison of physiotherapy, manipulation, and corticosteroid injection for treating shoulder complaints in general practice: randomised, single blind study. Bmj $1997 ; 314: 1320-1325$. 


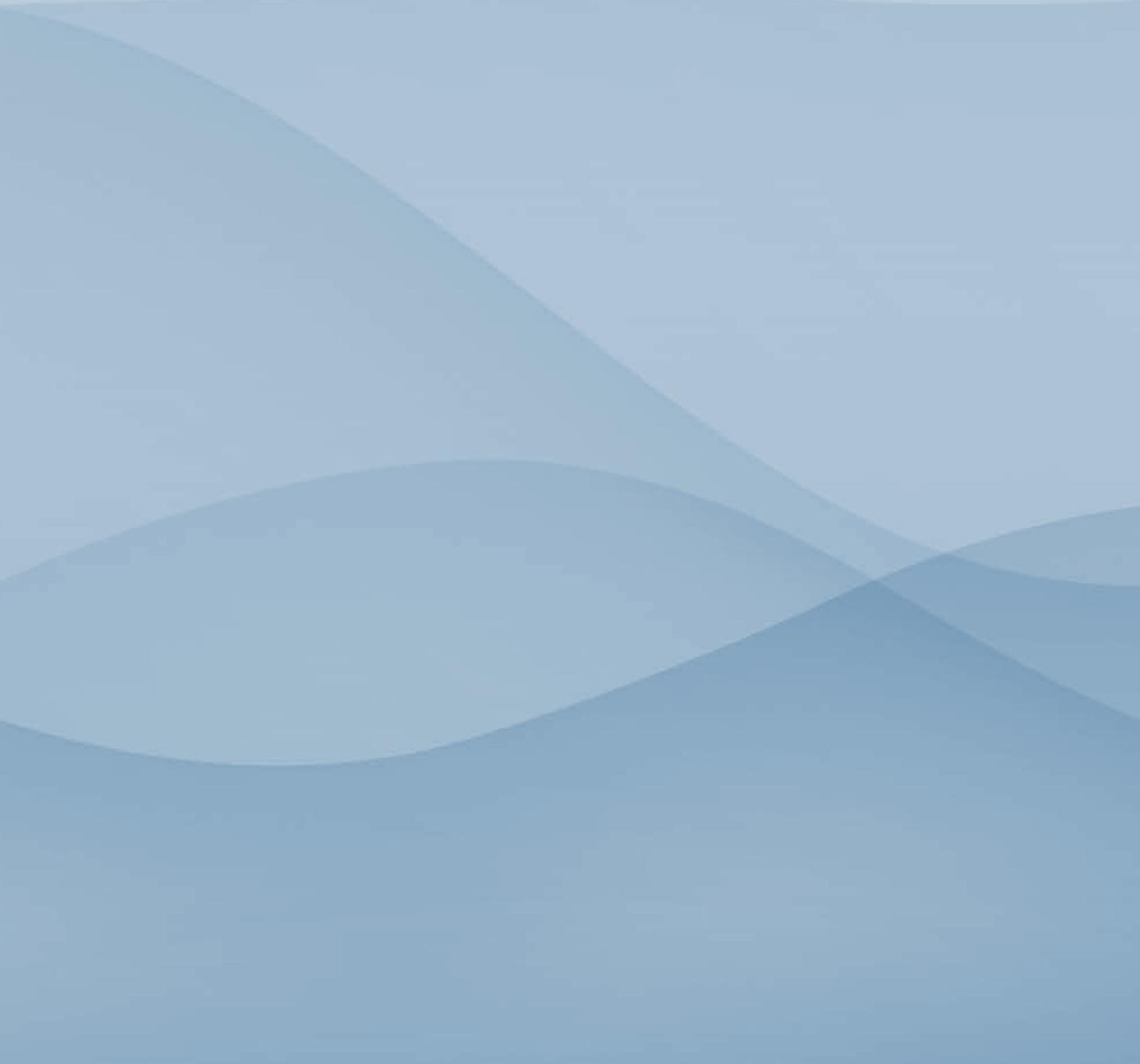




\section{Chapter 5}

Painful shoulder movement in

the frontal plane, a gradation

of the painful arc

Penning L.I.F.

de Bie R.A.

Walenkamp G.H.I.M. 


\section{Abstract}

Background: Shoulder disorders are common in the general population. In secondary healthcare $36 \%$ of complaints have a subacromial cause. A typical feature of subacromial complaints is the specific painful range of motion between 60 and 120 degrees of abduction, described as the painful arc. Based on clinical observation it is possible to differentiate the severity of a painful arc. For this study we propose a gradation of the painful arc into four categories based on observations of pain and movement in the frontal plane.

Patients and methods: This study was part of a RCT for which a total of 159 patients were included. Patients were randomized to treatment for subacromial disorders with repeated subacromial injections using lidocaine with hyaluronic acid, corticosteroid or saline (placebo). Patients had their painful arc scored as being either grade 0 , no pain and normal movement, grade 1 , slight painful normal movement, grade 2, painful disturbed scapulothoracic and glenohumeral movement and grade 3 painful, disturbed scapulothoracic and glenohumeral movement with a painful drop. The scores were compared to the VAS score and secondary outcome measures as Constant score, Functional mobility test, Shoulder disability questionnaire and shoulder pain score.

Results: At baseline no grade 0 was observed. Grade 1 was observed in 26\% $(n=41)$, grade 2 in $43 \%(n=69)$ and grade 3 in $31 \%(n=49)$. After three weeks, grade 0 was observed $3 \%(n=4)$, grade 1 in $31 \%(n=49)$, grade 2 in $40 \%(n=64$ and grade 3 in $26 \%(n=42)$. At final follow up at 26 weeks grade 0 was observed in $23 \%(n=36)$, grade 1 in $40 \%(n=63)$, grade 2 in $21 \%(n=33)$ and grade 3 in $17 \%(n=27)$.

In comparison to primary and secondary outcome measures we found a positive correlation with the observed gradation.

Discussion: The observations of a graded painful arc showed to be complementary in the observation of subacromial disorders. As far as known, this is the first 
study to describe a gradation for the painful arc. Single observations by a single observer slightly flaw the study and further research is needed for investigation of reproducibility and validity.

Based on the present observations gradation of the painful arc seems to be of use for clinical decision making.

Keywords: Shoulder, painful arc, classification, subacromial impingement 


\section{Introduction}

Shoulder disorders account for a rather large majority of musculoskeletal complaints in the general population. Incidence rates of shoulder disorders in Orthopedic practice are estimated at 9 / 1000 patients / year. ${ }^{(1)}$

Common encountered symptoms consist of pain in the upper arm and deltoid region, sometimes accompanied with stiffness. ${ }^{(2,3)}$ The causes and sources are variable, but a rather large group consists of subacromial complaints. In secondary health care approximately $36 \%$ of complaints have a subacromial cause. ${ }^{(4)}$ Most patients will present with limited or painful movement in the frontal plane. The frontal or coronal plane is defined as the plane perpendicular to the sagittal planes. Both abduction and adduction are performed in the frontal plane. (Fig 1)

During the first phase of shoulder elevation the movement is largely glenohumeral, after 30 degrees of elevation the glenohumeral and scapulothoracic joint move simultaneously in an overall ratio of 2:1 of glenohumeral to scapulothoracic movement. ${ }^{(5)}$

A rather typical feature of subacromial complaints is the specific range of motion in the frontal plane in which pain is expressed. This range of painful motion is most expressed between 60 and 120 degrees of abduction and has been described as the painful arc. ${ }^{(6)}$ There is some variety in the definition of the painful arc concerning the specific range of painful motion. Neer described the painful arc as a painful movement in the frontal plane during active elevation between 70 and 120 degrees. In this frontal plane impingement of the rotator cuff beneath the coraco-acromial arch occurs causing the painful arc. ${ }^{(7)}$

The observation of a painful arc consists of an assessment of disturbed motion and occurring pain.

Although the complaints causing this pain were traditionally explained based on an anatomical subacromial impingement ${ }^{(8)}$ there is a tendency to describe the complaints as subacromial pain. ${ }^{(9)}$ In general the impingement is the result of a decreased acromiohumeral distance. A number of causes have been described for the subacromial pain syndrome; calcified tendonitis, osteoarthritic osteophytes, micro instability and overuse. ${ }^{(10)}$ Further stages of the impingement as well as genetic predisposition and wear and tear lead to degeneration of the cuff causing pain. ${ }^{(9,11,12)}$ 


\section{Figure 1 - Frontal plane}

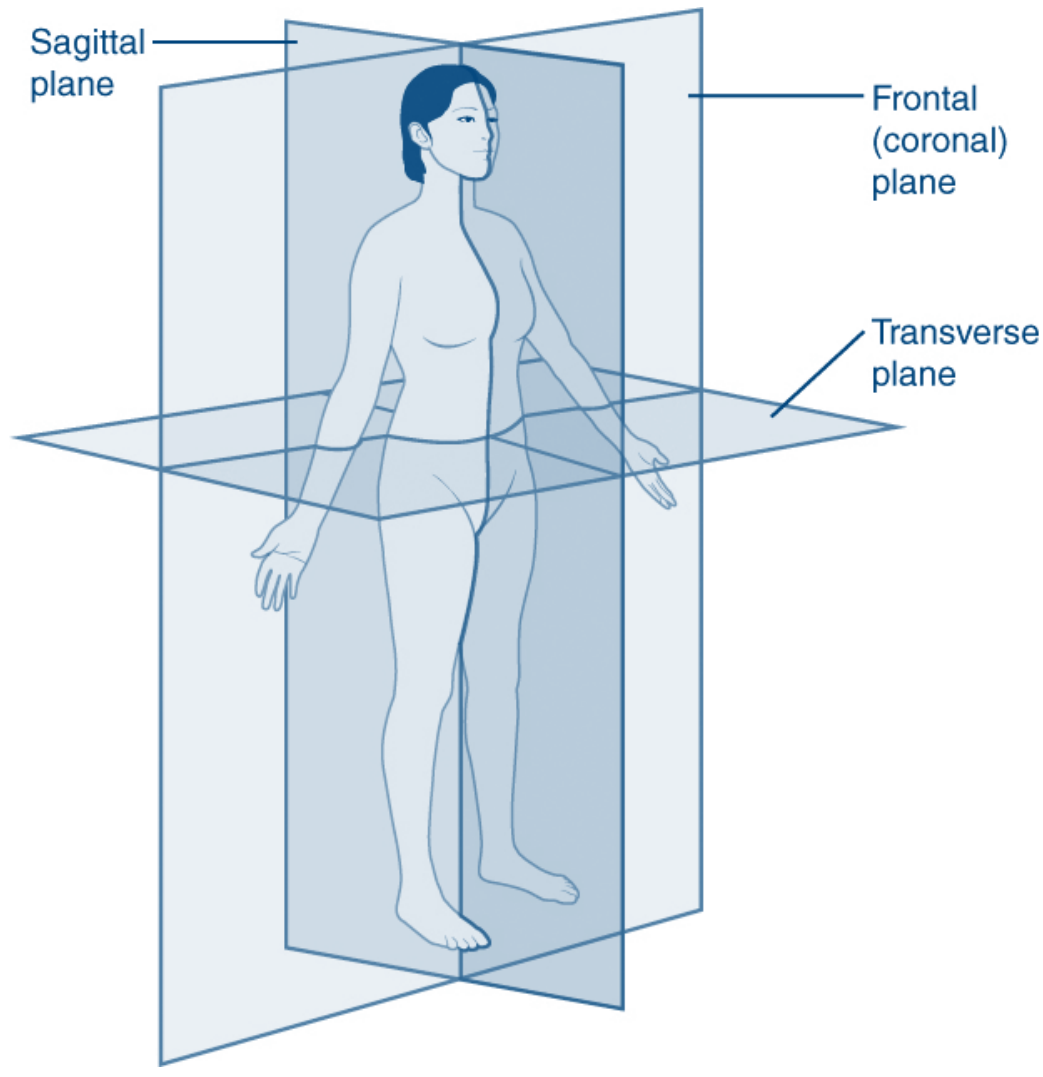

Not all patients suffering of a painful arc will express the same amount of pain. During the course of disease further reduction of pain can occur with a painful arc still present. Based on these observations and observations of persistent painful arc irrespective of reduction in pain, we believe that the severity of a painful arc could be of interest for the course of disease.

In this study we describe a gradation of the painful arc.

This description is based on clinical observations concerning pain and movement. We have classified the painful arc accordingly into four categories. From grade 0 in which no pain or abnormal movement is observed to grade 3 in which a painful drop is observed. 
In this study, which was part of a randomized controlled trial in which the effectiveness of subacromial injections was evaluated, we classified the observed painful arc into one of the four categories. ${ }^{(13)}$ The results of this gradation were compared to primary and secondary outcome measures of the RCT like the VAS score, Constant Murley score, the Functional Mobility Test, the Shoulder Disability Questionnaire and the Shoulder Pain Score. ${ }^{(14-18)}$.

We postulated that with a reduction in pain during the course of disease and provided treatment the classification of the painful arc would change accordingly.(i.e. lower pain score on VAS, lower grade of painful arc)

\section{Patients and methods}

For this study results were used of a RCT in which patients were treated for subacromial impingement. ${ }^{(13)}$ At the start of the study, before treatment, all patients included had a painful arc. A total of 159 patients were included in this study including 75 men and 84 women with a mean age range of 53 years (range 20-87). Patients did not receive prior injection treatment by their general practitioners for their current episode of shoulder pain. Patients were randomised into three treatment groups and were blinded for their respective treatment. Treatment consisted of a subacromial injection with either a mixture of $8 \mathrm{ml}$ lidocaine $1 \%$ and $2 \mathrm{ml}$ hyaluronic acid (Ostenil) TRB Chemedica, Haar / München, Germany); a mixture of $8 \mathrm{ml}$ lidocaine $1 \%$ with $2 \mathrm{ml}$ triamcinolone acetonide $10 \mathrm{mg} / \mathrm{ml}$; or a mixture of $8 \mathrm{ml}$ lidocaine $1 \%$ with $2 \mathrm{ml}$ of $\mathrm{NaCl} 0.9 \%$ (placebo group). The subacromial injections were repeated up to three times if necessary, after three and six weeks. Outcome measurements were assessed at baseline and during the course of the study. Follow up measures were taken at three, six, 12 and 26 weeks.

At baseline, before subacromial injection, a physical examination was performed. During the physical examination the painful arc was observed during active movement and categorized. For this categorization the amount of perceived pain as well as the scapulothoracic and glenohumeral movement was observed. All physical examinations and observations of the painful arc were carried out by the same physician. 


\section{Classification of painful arc}

We have classified the painful arc as being grade 0 when there is no pain during completely normal scapulothoracic and glenohumeral motion during elevation in the frontal plane.

We classify the painful arc as grade 1 in case of normal scapulothoracic and glenohumeral motion during elevation in the frontal plane with a limited amount of pain during motion.

In case of a disturbed glenohumeral and scapulothoracic motion accompanied with pain we classify the painful arc as grade 2 .

In case of disturbed glenohumeral and scapulothoracic motion accompanied with pain and followed by a painful drop during active lowering of the arm we classify the painful arc as grade three. (Table 1)

All of the used primary and secondary outcome measures that were obtained for follow up purposes of the RCT, were used for comparison with the gradation of the painful arc.

The primary outcome measure of the RCT was pain as measured on a horizontal 10 $\mathrm{cm}$ visual analogue scale (VAS) (0, no pain to 10 , severe pain). ${ }^{(18)}$

The Constant shoulder score is a validated system with subjective (pain and daily activities) and objective (range of movement and power) assessments in a ratio of 35\%:65\%. It is designed to provide a full functional assessment applicable to different shoulder conditions. ${ }^{(14)}$

The functional Mobility Test is a standardized motor test in patients with painful shoulder joint disorders. ${ }^{(15)}$

The Shoulder Disability Questionnaire is a functional questionnaire for pain and/ or limitation of movement of the shoulder. The past 24 hours are assessed through 16 questions that can be answered with either yes, no, or not applicable. ${ }^{(16)}$

The Shoulder Pain score consists of six questions about pain and uses a 101 numerical rating scale (NRS 101). It has proved useful for following the course of disorder of the shoulder over time and giving an indication of when the patient is cured. ${ }^{(17)}$ 


\section{Table 1 - Gradation of painful arc}

\begin{tabular}{|ll|}
\hline grade & description \\
\hline 0 & No pain, normal glenohumeral and scapulothoracic movement \\
\hline 1 & pain, but normal glenohumeral and scapulathoracic movement \\
\hline 2 & Pain with a disturbed glenohumeral and scapulothoracic movement \\
\hline 3 & $\begin{array}{l}\text { Pain with a disturbed glenohumeral and scapulothoracic movement followed by a painful drop during } \\
\text { lowering of the arm }\end{array}$ \\
\hline
\end{tabular}

\section{Statistical analysis}

First data were tested for normality. Frequencies were calculated for the consecutive follow up moments at 3, 6, 12 and 26 weeks. Missing values were treated by the Last observation carried forward (LOCF) method in case of loss to follow up or withdrawal. For all other missing data a mean trend substitution was performed. A Linear regression analysis was performed for comparison of the painful arc to the primary and secondary outcome measures. The $\mathrm{p}$-value was set at $<0,05$.

\section{Results}

All of the 159 included patients received the first allocated injection. The second and third allocated injections were received by 150 patients. Nine patients (6\%) did not receive the second and third injection, 3 in each of the groups. In the hyaluronic acid group reasons for not receiving the allocated injections were: withdrawn because of malignancy $(n=1)$, lost to follow up $(n=1)$ and not wishing to continue $(n=1)$. In the triamcinolone acetonide group reasons for not receiving the allocated treatment were: withdrawn because of too much pain $(n=1)$, lost to follow up $(n=1)$ and complete relieve of pain after 2 injections $(\mathrm{n}=1)$. In the $\mathrm{NaCl}$ injection group reasons for not receiving the allocated treatment consisted of too much pain $(n=2)$ and lost to follow up $(\mathrm{n}=1)$.

A total of 22 of the 159 patients (13.8\%) withdrew from the study, with no further or incomplete follow-up. Reasons for withdrawal consisted of malignancy (2), too much pain (5), not wishing to continue (1) and loss to follow-up (14). Of the 14 patients lost to follow-up, ten could not be contacted; the other four did not wish to continue the 
study. All patients who withdrew from the study were included in the statistical analysis according to the intention-to-treat principle, in which the last observation carried forward principle was used. ${ }^{(13)}$ (Fig 2)

All data was normally distributed. At baseline, before treatment, no grade 0 was observed in the evaluation of the painful arc. Grade 1 was observed in $26 \%(n=41)$, grade 2 in $43 \%(n=69)$ and grade 3 in $31 \%(n=49)$. After three weeks, at first follow up, grade 0 was observed $3 \%(n=4)$, grade 1 in $31 \%(n=49)$, grade 2 in $40 \%(n=64$ and grade 3 in $26 \%$ $(\mathrm{n}=42)$. At final follow up at 26 weeks grade 0 was observed in $23 \%(n=36)$, grade 1 in $40 \%(n=63)$, grade 2 in $21 \%(n=33)$ and grade 3 in $17 \%(n=27)$. (Table 2, fig 3$)$

Linear regression analysis of the VAS score and the gradation of the painful arc was positively correlated at all follow up measurements.

In table 3 the results of the linear regression analysis for secondary outcome measures are displayed. The results show that with a higher gradation of the painful arc the result in the constant score is worse. In case of the functional mobility test the results are in a same direction. As the painful arc shows a higher grade, results on the functional mobility test are worse.

For the shoulder disability questionnaire a higher grade of the painful arc resulted in a higher and thus worse score in the Shoulder disability Questionnaire. The same result was found for the shoulder pain score. (table 3)

Table 2 - Frequency of painful arc in time

\begin{tabular}{|c|cccc|}
\hline week & grade 0 & grade 1 & grade 2 & grade 3 \\
\hline 0 & 0 & 41 & 69 & 49 \\
\hline 3 & 4 & 49 & 64 & 42 \\
\hline 6 & 10 & 66 & 52 & 30 \\
\hline 12 & 26 & 66 & 38 & 29 \\
\hline 26 & 36 & 63 & 33 & 27 \\
\hline
\end{tabular}


Figure 1 - Randomisation of patients and patiënt flow in the trial

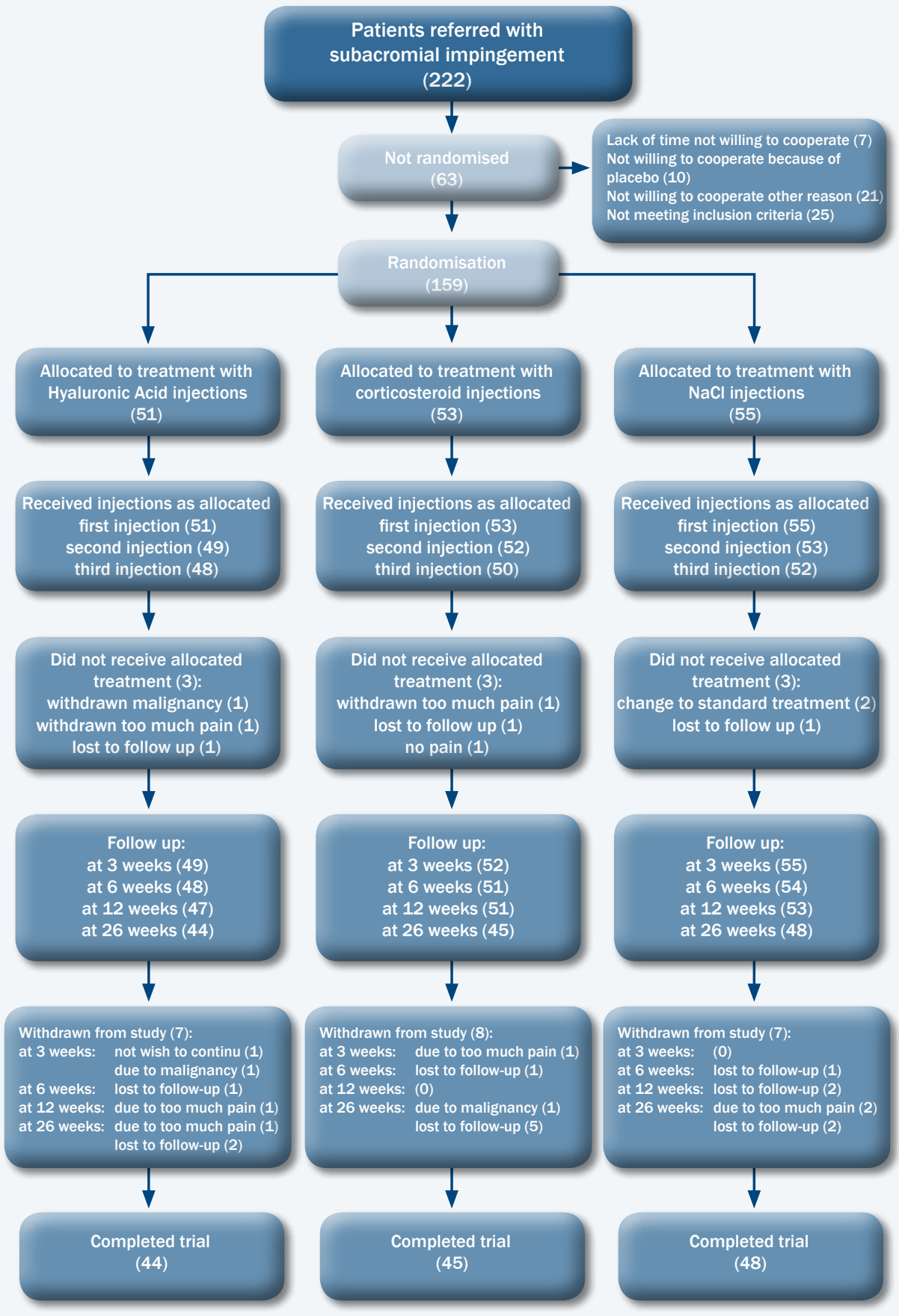


Table 3 - Linear regression analysis

\begin{tabular}{|c|c|c|c|c|c|c|c|}
\hline & & Grade 1 & & Grade 2 & & GR 3 & \\
\hline & & B & sign. & B & sign. & B & sign. \\
\hline \multirow[t]{4}{*}{ baseline } & constant score & 2,334 & 0,25 & - & - & $-15,76$ & 0 \\
\hline & FMT & $-2,373$ & 0 & _ & _ & 4,419 & 0 \\
\hline & SDQ & $-3,995$ & 0,254 & _ & _ & 7,099 & 0,033 \\
\hline & SP & $-1,232$ & 0,139 & _- & _ & 1,447 & 0,067 \\
\hline \multirow[t]{4}{*}{3 weeks } & constant score & $-12,087$ & 0,035 & $-19,656$ & 0,001 & $-38,512$ & 0 \\
\hline & FMT & 1,189 & 0,45 & 4,375 & 0,006 & 9,631 & 0 \\
\hline & SDQ & 35,378 & 0,001 & 56,951 & 0 & 65,937 & 0 \\
\hline & SP & 6,536 & 0,008 & 10,234 & 0 & 13,917 & 0 \\
\hline \multirow[t]{4}{*}{6 weeks } & constant score & $-10,352$ & 0,004 & $-20,258$ & 0 & $-39,333$ & 0 \\
\hline & FMT & 2,591 & 0,004 & 6,212 & 0 & 11,433 & 0 \\
\hline & SDQ & 32,111 & 0 & 54,898 & 0 & 62,499 & 0 \\
\hline & SP & 3,067 & 0,05 & 8,224 & 0 & 11,3 & 0 \\
\hline \multirow[t]{4}{*}{12 weeks } & constant score & $-9,752$ & 0 & $-19,247$ & 0 & $-39,822$ & 0 \\
\hline & FMT & 1,793 & 0,003 & 5,518 & 0 & 10,842 & 0 \\
\hline & SDQ & 41,12 & 0 & 54,798 & 0 & 63,936 & 0 \\
\hline & SP & 6,657 & 0 & 8,2 & 0 & 12,212 & 0 \\
\hline \multirow[t]{4}{*}{26 weeks } & constant score & $-10,381$ & 0 & $-18,545$ & 0 & $-35,556$ & 0 \\
\hline & FMT & 2,595 & 0 & 6,157 & 0 & 10,278 & 0 \\
\hline & SDQ & $-10,62$ & 0,096 & $-2,979$ & 0,684 & 7,209 & 0,352 \\
\hline & SP & $-2,341$ & 0,055 & $-0,914$ & 0,513 & 1,5 & 0,31 \\
\hline
\end{tabular}


Figure 1 - Frequency of painful arc in time

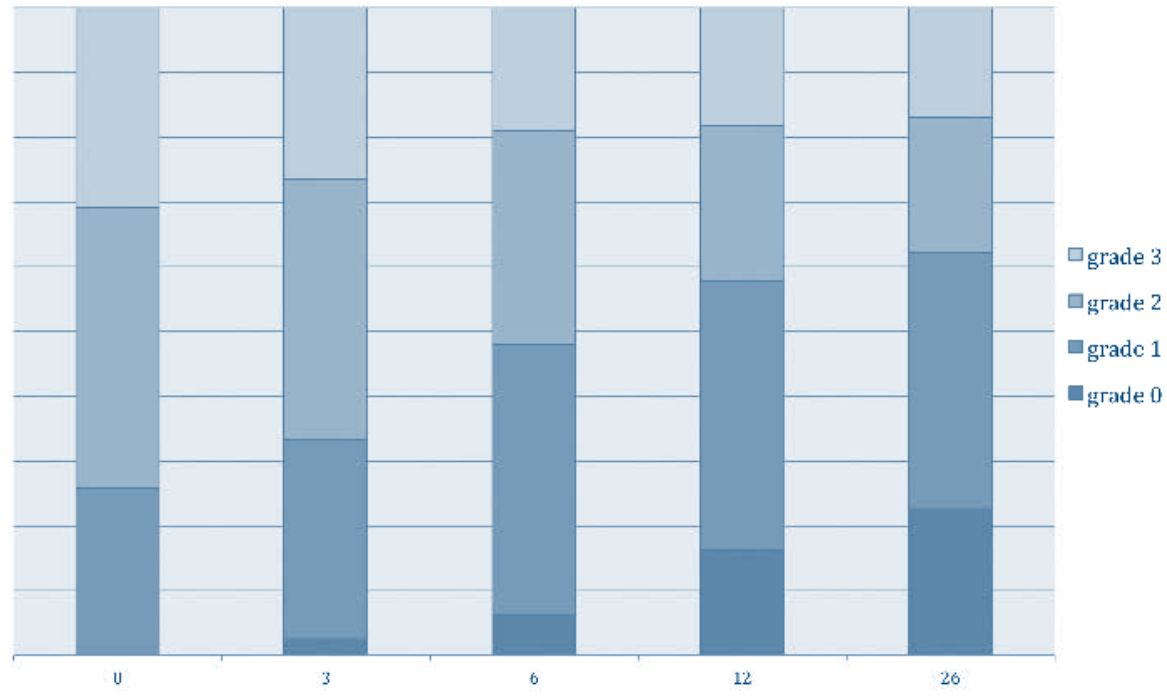

\section{Discussion}

In this study we have described a gradation of the painful arc in subacromial disorders. The gradation was based on observations of patient perceived pain and glenohumeral and scapulothoracic motion. The study was part of a RCT in which the effectiveness of subacromial injections was evaluated. At all follow up occasions the painful arc was graded according to the proposed classification. For this study we explored the usefulness of a classification of the painful arc. We found the classification of the painful arc to be complementary to observations of subacromial disorders. The observed gradation went in the same direction as all other outcome measures. (i.e. in case of improvement of complaints we found a lower grade of the painful arc). As far as we know there have been no other studies that have tried to grade the painful arc before. We are aware of the limitations of this study. The study was performed with a single observation and single observer and therefore we are not able to present inter and intra observer ratings. However, based on the observations carried out for this study we believe that the gradation of the painful as presented is of use for clinical decision making. Further research is needed for investigation of reproducibility and validation of the gradation of the painful arc. 


\section{References}

1. DBC Onderhoud. 2015; Available from: http://www.dbcinformatiesysteem.nl/.

2. Huisstede, B.M., et al., Multidisciplinary consensus on the terminology and classification of complaints of the arm, neck and/or shoulder. Occup Environ Med, 2007. 64(5): p. 313-9.

3. van der Heijden, G.J., Shoulder disorders: a state-of-the-art review. Baillieres Best Pract Res Clin Rheumatol, 1999. 13(2): p. 287-309.

4. Juel, N.G. and B. Natvig, Shoulder diagnoses in secondary care, a one year cohort. BMC Musculoskelet Disord, 2014. 15: p. 89.

5. Scibek, J.S. and C.R. Carcia, Assessment of scapulohumeral rhythm for scapular plane shoulder elevation using a modified digital inclinometer. World J Orthop, 2012. 3(6): p. 87-94.

6. Kessel, L. and M. Watson, The painful arc syndrome. Clinical classification as a guide to management. J Bone Joint Surg Br, 1977. 59(2): p. 166-72.

7. Neer, C.S., 2nd, Anterior acromioplasty for the chronic impingement syndrome in the shoulder: a preliminary report. J Bone Joint Surg Am, 1972. 54(1): p. 41-50.

8. Neer, C.S., 2nd, Impingement lesions. Clin Orthop Relat Res, 1983(173): p. 70-7.

9. Diercks, R., et al., Guideline for diagnosis and treatment of subacromial pain syndrome: a multidisciplinary review by the Dutch Orthopaedic Association. Acta Orthop, 2014. 85(3): p. 314-22.

10. Michener, L.A., P.W. McClure, and A.R. Karduna, Anatomical and biomechanical mechanisms of subacromial impingement syndrome. Clinical Biomechanics, 2003. 18(5): p. 369-379.

11. Keener, J.D., et al., A Prospective Evaluation of Survivorship of Asymptomatic Degenerative Rotator Cuff Tears. Vol. 97. 2015. 89-98.

12. McFarland, E.G., et al., Impingement is not impingement: the case for calling it "Rotator Cuff Disease". Muscles Ligaments Tendons J, 2013. 3(3): p. 196-200.

13. Penning, L.I.F., R.A. de Bie, and G.H.I.M. Walenkamp, The effectiveness of injections of hyaluronic acid or corticosteroid in patients with subacromial impingement: A three-arm randomised controlled trial. Journal of Bone \& Joint Surgery, British Volume, 2012. 94B(9): p. 1246-1252.

14. Constant, C.R. and A.H. Murley, A clinical method of functional assessment of the shoulder. Clin Orthop, 1987(214): p. 160-4. 
15. Westerberg, C.E., E. Solem-Bertoft, and I. Lundh, The reliability of three active motor tests used in painful shoulder disorders. Presentation of a method of general applicability for the analysis of reliability in the presence of pain. Scand J Rehabil Med, 1996. 28(2): p. 63-70.

16. van der Heijden, G.J., P. Leffers, and L.M. Bouter, Shoulder disability questionnaire design and responsiveness of a functional status measure. J Clin Epidemiol, 2000. 53(1): p. 29-38.

17. Winters, J.C., et al., A shoulder pain score: a comprehensive questionnaire for assessing pain in patients with shoulder complaints. Scand J Rehabil Med, 1996. 28(3): p. 163-7.

18. Huskisson, E.C., Visual Analogue Scales, in Pain Measurement and Assessment, R. Melzack, Editor. 1983, Raven Press: New York. p. 33-37. 


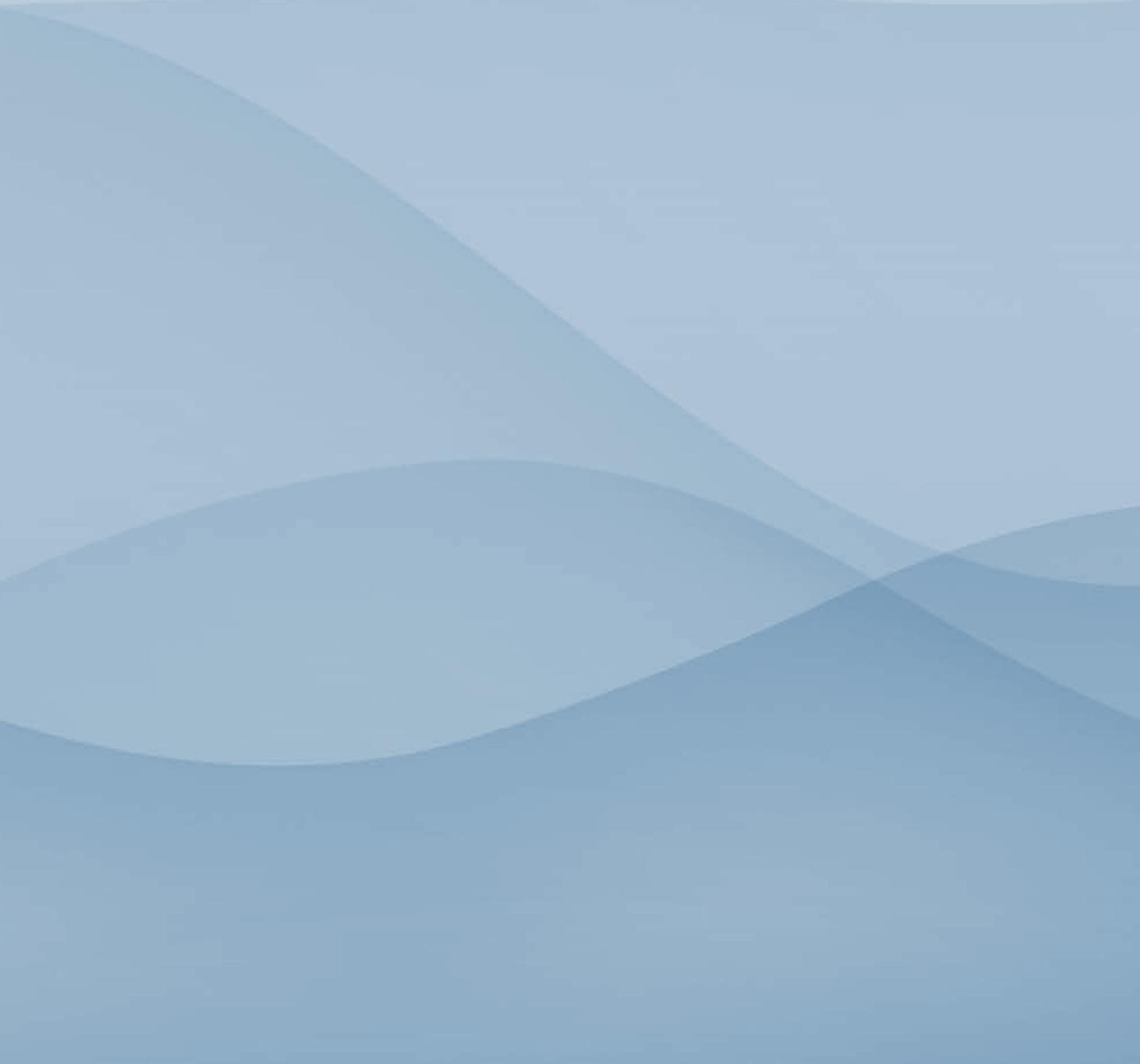




\section{Chapter 6}

Reliability study of the sonographic measurement of the acromiohumeral distance in symptomatic patients

Pijls B.G.

Kok F.P.

Penning L.I.F.

Guldemond N.A.

Arens H.J.

J Clin Ultrasound. 2010 Mar-Apr;38(3):128-34. 


\section{Abstract}

Background: The purpose of this study was to evaluate the inter- and intraobserver reliability and accuracy of sonographic (US) acromiohumeral distance (AHD) measurement for both experienced and novice operators in US in patients suffering from subacromial impingement syndrome.

Method: A total of 43 patients (50 shoulders) diagnosed with subacromial impingement syndrome were recruited from an orthopedic outpatient clinic. The US measurement of AHD was obtained consecutively in a neutral position and in a $60^{\circ}$ abduction position. A total of 300 blinded measurements were taken.

Result: In the neutral abduction group the intraobserver interclass correlation coefficient (ICC) was 0.94 for the experienced operator and 0.92 for the novice operator. The inter-observer ICC was 0.70 and the accuracy was $1.1 \mathrm{~mm}$. In the $60^{\circ}$ abduction group, the intra-observer ICC was 0.90 for the experienced operator and 0.87 for the novice operator. The interobserver ICC was 0.64 and the accuracy was $1.4 \mathrm{~mm}$. All ICCs were significant at a level of $\mathrm{p}<0.0001$.

Conclusion: The inaccuracy of the method was $1 \mathrm{~mm}$ regardless of the experience of the observer. US AHD measurement in patients with shoulder complaints is not as accurate as reported in healthy subjects. This may have important implications for the clinical use of this parameter. ${ }^{\circledR} 2010$ Wiley Periodicals, Inc. J Clin Ultrasound 38:128-134, 2010; Published online in Wiley InterScience (www.interscience.wiley. com). DOI: $10.1002 /$ jcu.20674VV

Keywords: ultrasonography; shoulder; shoulder impingement syndrome; acromiohumeral distance; subacromial space; musculoskeletal system 
The acromiohumeral distance (AHD) has been studied in literature mainly through standard X-rays of the shoulder. The AHD is influenced by rotator cuff disease such as tears, muscle fatty degeneration, and atrophy. Hence, it can be used to diagnose rotator cuff tears, fatty degeneration, and atrophy. ${ }^{(1,2)}$ Fatty degeneration is of prognostic value in reconstructive rotator cuff surgery. ${ }^{(3)}$ Progressive fatty degeneration of the rotator cuff is associated with poor surgical outcome. ${ }^{(3)}$ Recently, AHD has been associated with shoulder function (Constant Score) in patients suffering from subacromial impingement syndrome (SIS). ${ }^{(4)}$ Accurate AHD measurement is therefore of clinical importance. The AHD is a 3-dimensional distance. ${ }^{(5)}$ Radiographic assessment can only measure 2-dimensional displacement. Another problem with radiographic AHD measurement is that the AHD is affected by both patient positioning and beam direction. ${ }^{(6,7)}$

Researchers have used sonography (US) to measure the AHD. ${ }^{(8-12)}$ Real-time US enables the radiologist to dynamically look for the smallest AHD in various patient positions. Comparison with the contralateral shoulder can also be readily performed without exposing the patient to additional radiation. Contrary to healthy subjects, the reliability and accuracy of US AHD measurement has not been investigated in patients with shoulder complaints. ${ }^{(10)}$ The purpose of this study was to evaluate the inter- and intraobserver reliability and accuracy of US AHD measurements by both experienced and novice operators in symptomatic patients.

\section{Materials and Methods}

Institutional review board approval was obtained and written informed consent was obtained from the patients. Patients were recruited from an orthopedic outpatient clinic. Inclusion criteria were a SIS diagnosed by an orthopedic surgeon, requiring a referral for US of the rotator cuff, and complaints for a period of more than 6 months without response to nonsurgical treatment. Exclusion criteria were shoulder complaints other than SIS such as shoulder instability, adhesive capsulitis or pathology of the acromioclavicular joint, a history of systemic musculoskeletal disorders, fracture of the upper extremity, or surgery of the affected shoulder.

Measurements were conducted on 50 shoulders in 43 patients, equally divided in a neutral position group and a $60^{\circ}$ abduction group. No randomization was performed. 
Measurements took place in a consecutive manner. After completion of the neutral position cohort, the $60^{\circ}$ abduction group followed.

In the neutral position group, there were 9 men and 12 women (4 patients with bilateral SIS) with a mean $+/$ - SD age of $51+/-11$ years (range, 34-74 years). The mean $+/$ - SD height of the patients was $174+/-9 \mathrm{~cm}$ (range, 162-193 cm). There were 9 right and 16 left shoulders.

In the $60^{\circ}$ abduction group, there were 10 men and 12 women ( 3 patients with bilateral SIS) with a mean +/- SD age of $52+/-10$ years (range, 34-68 years). The mean +/- SD height was $172+/-7 \mathrm{~cm}$ (range, $160-186 \mathrm{~cm}$ ). There were 9 right and 16 left shoulders.

Two observers, an experienced musculoskeletal radiologist with 6 years of experience in US of the shoulder and an orthopedic resident novice in shoulder US, independently measured the AHD in the same set of patients. These 2 observers of different experience levels were chosen to evaluate the effect of experience with US, because this has been shown to be of importance in US of the rotator cuff. ${ }^{(13)}$ Both the experienced and the novice operator practiced the technique on several patients (not included in this series) until they were familiar with it and felt confident they could obtain reproducible results. Each observer was blinded to the other's as well as his own measurements. The measurement of the AHD displayed in the left lower corner of the monitor was masked and the cover remained in place throughout the entire session. All measurements of a given patient, performed by both the experienced and the novice operator, were obtained and recorded in a single session. During the measurements, the experienced and novice operators were never together in the same room, so that measurements were obtained independently. The recorded AHD measurements could only be viewed when the session was finished.

\section{Neutral Position of the Shoulder (No Abduction)}

The US examinations were carried out on a HDI 5000 scanner using a 5- to $12-\mathrm{MHz}$ linear array transducer, and a center frequency of 7.5 MHz (Philips Ultrasound, Bothell, WA). We aimed to standardize and control the patient position as much as possible. The patients were therefore positioned on a chair with the arms hanging at the side, while holding an anti-rotation rod in supination (Figure 1). This rod also prevented unintended abduction. The arm was placed at $0^{\circ}$ anteflexion and this was monitored throughout the examination. 
Figure 1 - Photograph shows the positioning of the patient for measurement of AHD in neutral $\left(0^{\circ}\right)$ abduction position. The rotation in the shoulder joint is controlled by the placement of the hands on the bar.

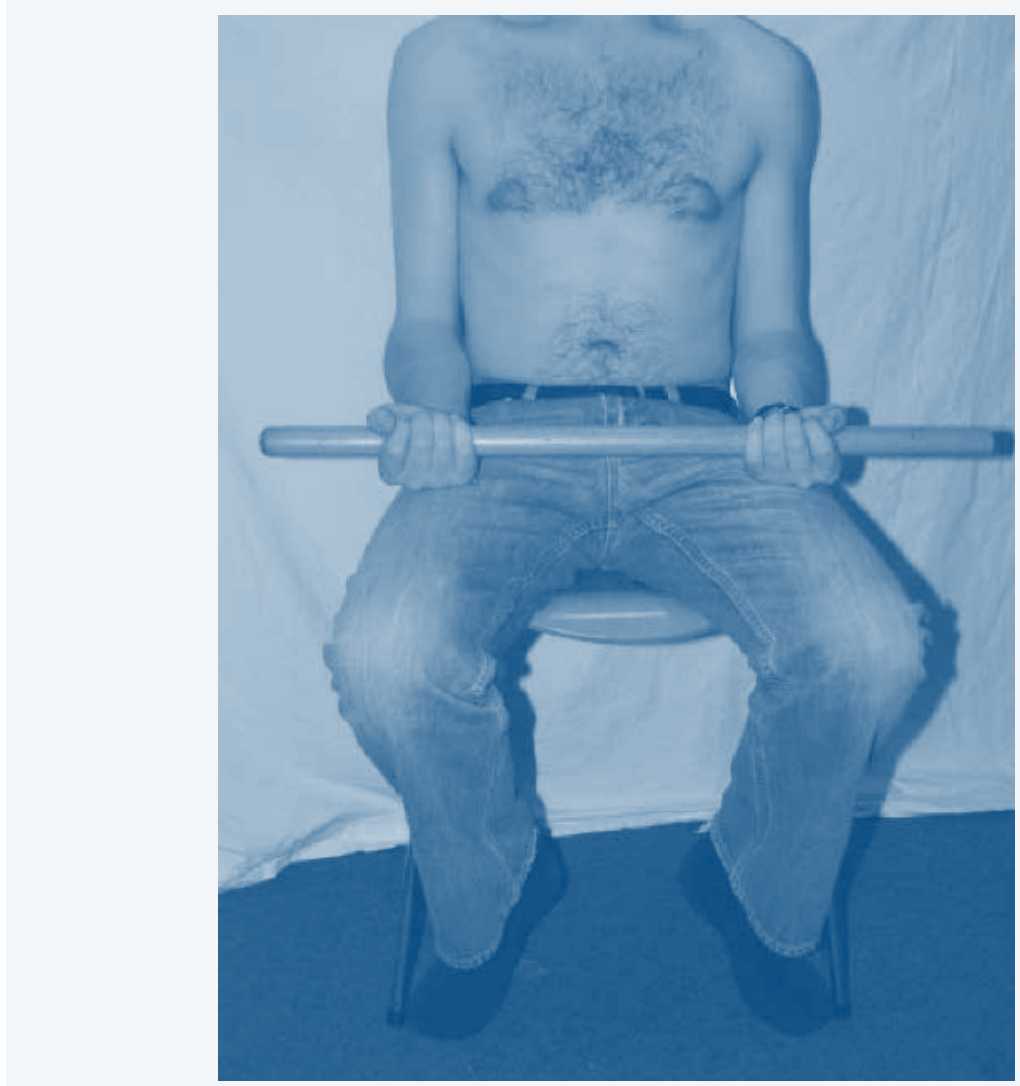

The AHD is defined as the shortest distance between the acromion and the most superior aspect of the humerus (Figure 2). ${ }^{(10)}$ It was measured at the inlet of the subacromial space by holding the transducer longitudinally with respect to the supraspinatus tendon as described in literature. ${ }^{(10,14)}$ The transducer was slightly moved around to find the smallest AHD, which was then measured and recorded in millimeters. Each operator took 3 independent, blinded measurements. In total 6 measurements were taken for each shoulder, accounting for a total of 150 measurements in the neutral abduction group. 


\section{Figure 2 - US measurement of AHD in neutral position of the shoulder}

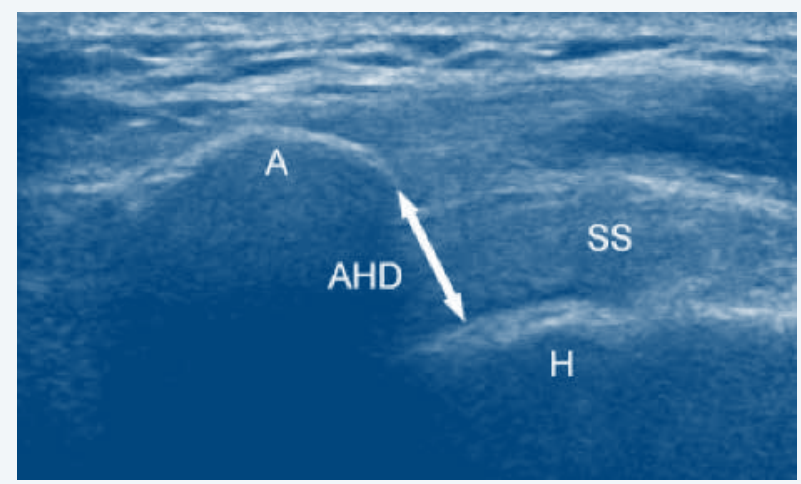

US measurement of AHD in neutral position of the shoulder. The ADH was measured at the inlet of the subacromial space by holding the transducer along the suprapinatus tendon. The transducer was moved to find the smallest AHD, which was then measured and recorded in millimeters $(\mathrm{mm})$. A, acromion; AHD, acromiohumeral distance; $\mathrm{H}$, humerus; $\mathrm{SS}$, supraspinatus tendon.

\section{$60^{\circ}$ Abduction}

The measurement of the AHD at $60^{\circ}$ abduction is similar to AHD measurement in the neutral abduction group. Instead of an anti-rotation rod, an abduction chair and a custom designed dynamic goniometer were used to allow for controlled abduction (Figure 3). The abduction chair was designed to only allow abduction in the scapular plane while restricting both forward and backward flexion. Internal and external rotation was monitored throughout the examination by keeping the elbow of the patient level. Before the study started, the dynamic goniometer was tested and found to be accurate within 1.5 degree. Again both the experienced and the novice operators took 3 independent, blinded measurements. In total 6 measurements were taken for each shoulder at $60^{\circ}$ abduction, accounting for a total of 150 measurements in the $60^{\circ}$ abduction group (Figure 4 ).

\section{Reproducibility}

The 3 measurements, taken by each observer in each abduction group, were used for determining the inter- and intra-observer reliability. We were also interested in the effect of the actual AHD measurement (placing-the-dots on the US image) on the overall reproducibility. Therefore we took blank US images during the neutral and $60^{\circ}$ abduction measuring protocol. We selected 25 of these images randomly for each group. Subsequently, the AHD was determined separately by both operators in these images. Accordingly, the effect of subtle changes in patient position or transducer placement was eliminated, so that the separate effect of the actual AHD measurement (placing- 


\section{Figure 3 - Photographs show positioning of subjects for measurement of AHD in $60^{\circ}$ abduction position.}

the-dots on the US image) on the total reproducibility could be determined. After a period of more than 6 months had elapsed, both operators were given the same 25 images previously used for measuring the AHD and they repeated the measurements blinded for the original measurements.

\section{Statistical Analysis}

Statistical analysis included the interclass correlation coefficient (ICC) for intra - and inter-observer agreement, nonparametric tests for comparing means, and a Bland-Altman analysis. ${ }^{(15)}$ All the measurements of a shoulder were taken at practically the same moment. Therefore, any influence of patient or disease characteristics on the AHD has been ruled out. The measured difference between 2 measurements by the same observer in the same shoulder therefore reflects the inaccuracy of US AHD measurement, which depends on patient positioning, visualizing the acromial inlet, and placing the calibers. Statistical analysis was carried out using SPSS statistical software (Version 12, SPSS Inc, Chicago, IL).
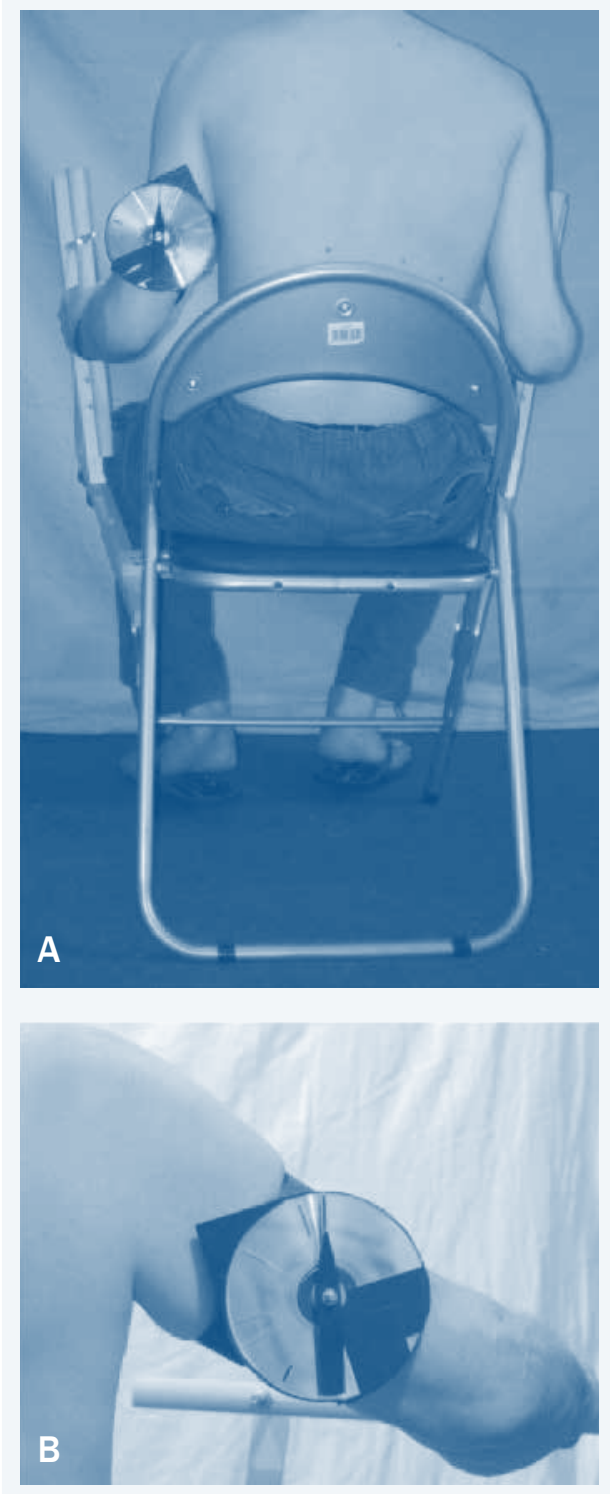

Note the use of the abduction chair (A) and dynamic goniometer (B) for controlled abduction. Measurements were performed at $60^{\circ}$ abduction. 


\section{Figure 4 - US measurement of AHD in $60^{\circ}$ abduction position}

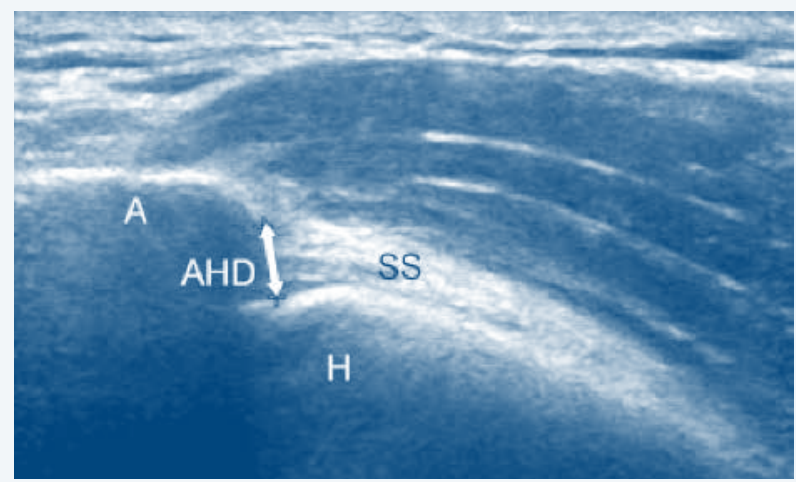

A, acromion; AHD,

acromiohumeral distance; $\mathrm{H}$, humerus; SS, supraspinatus tendon.

\section{Results}

In total, 300 AHD measurements were performed on 50 shoulders in 43 patients. In neutral position, the average AHD was $9.3+/-1.7 \mathrm{~mm}$ (range, 6.1-12.7 $\mathrm{mm}$ ) for the experienced operator and $9.0+/-1.4 \mathrm{~mm}$ (range, 6.4-12.0 $\mathrm{mm}$ ) for the novice operator $(\mathrm{p}$ $>0.05$ Wilcoxon signed-rank test). The difference between the average of 3 measurements in neutral position by the experienced operator and the average of the 3 measurements by the novice operator was $0.3+/-1.1 \mathrm{~mm}$ (range, $1.8-1.8 \mathrm{~mm}$ ).

At $60^{\circ}$ abduction, the mean AHD was $6.7+/-1.7 \mathrm{~mm}$ (range, $4.0-10.6 \mathrm{~mm}$ ) for the experienced operator and $6.7+/-1.4 \mathrm{~mm}$ (range, $5.1-11.0 \mathrm{~mm}$ ) for the novice operator $(\mathrm{p}$ $>0.05$ Wilcoxon signedrank test). The difference between the average of 3 measurements in $60^{\circ}$ abduction by the experienced operator and by the novice operator was $0.05+/-1.3$ $\mathrm{mm}$ (range, $22.8-2.5 \mathrm{~mm}$ ).

The mean AHD in neutral position was $2.5 \mathrm{~mm}$ greater than the mean AHD at $60^{\circ}$ $(9.2+/-1.4 \mathrm{~mm}$ versus $6.7+/-1.4 \mathrm{~mm}$, respectively; $\mathrm{p}<0.0001$ Mann-Whitney $\mathrm{U}$ test $)$. Means between and within observers were not significantly different.

ICCs are shown in Table 1.

ICCs for the actual AHD measurement (placing-the-dots on the US image) are shown in Table 2.

Figure 5 shows that consecutive measurements on the same patient by the same 
observer (novice operator in this case) have an accuracy of approximately $1.1 \mathrm{~mm}(95 \%$ CI $0.7-1.5 \mathrm{~mm}$ ) in neutral position. At $60^{\circ}$ abduction, the accuracy was approximately $1.4 \mathrm{~mm}$ (95\% CI 0.8-2.0 mm). The Bland-Altman plots for the experienced operator (not shown) were very similar to those of the novice operator.

Table 1 - Intra- and Interobserver Reliability for US Measurement of AHD in the Neutral and in the $60^{\circ}$ Abduction Positions

\begin{tabular}{|c|c|c|c|c|}
\hline & \multicolumn{2}{|c|}{$\begin{array}{l}\text { Intra-observer } \\
\text { ICC }\end{array}$} & \multirow{2}{*}{$\begin{array}{l}\text { Interobserver } \\
\text { ICC }\end{array}$} & \multirow[b]{2}{*}{ Overall ICC } \\
\hline & A & B & & \\
\hline Neutral position & $\begin{array}{c}0.94 \\
(0.89-0.97)\end{array}$ & $\begin{array}{c}0.92 \\
(0.85-0.96)\end{array}$ & $\begin{array}{c}0.70 \\
(0.43-0.86)\end{array}$ & $\begin{array}{c}0.78 \\
(0.65-0.88)\end{array}$ \\
\hline $\begin{array}{l}60^{\circ} \text { Abduction } \\
\text { position }\end{array}$ & $\begin{array}{c}0.90 \\
(0.82-0.95)\end{array}$ & $\begin{array}{c}0.87 \\
(0.77-0.94)\end{array}$ & $\begin{array}{c}0.64 \\
(0.33-0.82)\end{array}$ & $\begin{array}{c}0.71 \\
(0.52-0.88)\end{array}$ \\
\hline
\end{tabular}

A, Experienced operator; B, novice operator; ICC, interclass correlation coefficient; (95\% Cl), 95\% confidence interval. All ICCs were significant at a level of $p<0.0001$.

Table 2 - Intra- and Interobserver Reliability for the Actual AHD Measurement (placing-the-dots on the sonogram) in Neutral and $60^{\circ}$ Abduction Positions, Using Unmarked Sonograms

\begin{tabular}{|c|c|c|c|c|}
\hline & \multicolumn{2}{|c|}{$\begin{array}{l}\text { Intra-observer } \\
\text { ICC }\end{array}$} & \multirow{2}{*}{$\begin{array}{l}\text { Interobserver } \\
\text { ICC }\end{array}$} & \multirow[b]{2}{*}{ Overall ICC } \\
\hline & A & B & & \\
\hline Neutral position & $\begin{array}{c}0.56 \\
(0.22-0.77)\end{array}$ & $\begin{array}{c}0.57 \\
(0.24-0.78)\end{array}$ & $\begin{array}{c}0.50 \\
(0.26-0.68)\end{array}$ & $\begin{array}{c}0.52 \\
(0.32-0.71)\end{array}$ \\
\hline $\begin{array}{l}60^{\circ} \text { Abduction } \\
\text { position }\end{array}$ & $\begin{array}{c}0.82 \\
(0.61-0.91)\end{array}$ & $\begin{array}{c}0.85 \\
(0.69-0.93)\end{array}$ & $\begin{array}{c}0.77 \\
(0.64-0.87)\end{array}$ & $\begin{array}{c}0.82 \\
(0.70-0.90)\end{array}$ \\
\hline
\end{tabular}

A, Experienced operator; B, novice operator; ICC, interclass correlation coefficient; (95\% Cl), 95\% confidence interval. All ICCs were significant at a level of $p<0.0001$. 
Figure 5 - Bland-Altman plots show the difference between measurements of AHD (in $\mathrm{cm}$ ) in neutral position (A) and in $60^{\circ}$ abduction position (B) plotted against their mean for the novice operator.
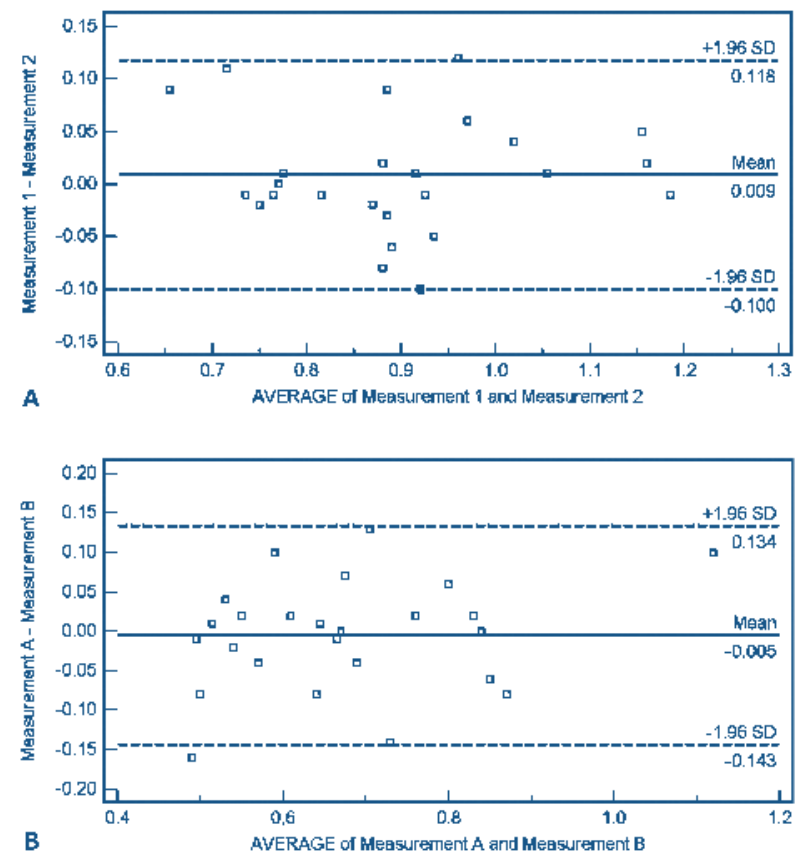

Bland-Altman plots show the difference between measurements of AHD (in $\mathrm{cm}$ ) in neutral position $(A)$ and in $60^{\circ}$ abduction position (B) plotted against their mean for the novice operator. The limits of agreement in neutral and $60^{\circ}$ abduction positions are +/- $1.1 \mathrm{~mm}(95 \%$ $\mathrm{Cl}$ 0.7-1.5 mm) and +/- 1.4 $\mathrm{mm}$ (95\% Cl 0.8-2.0 mm), respectively. Bland-Altman plots for the experienced operator (not shown) were similar to those of the novice operator.

\section{Discussion}

We evaluated the inter- and intra-observer reliability and accuracy of US measurement of AHD for 1 experienced and 1 novice operator in patients suffering from SIS. In general the reliability of the experienced operator was slightly better than that of the novice operator. The intraobserver reliability was better than the inter-observer reliability. AHD measurement at neutral position was more reproducible than at $60^{\circ}$ abduction. The intra-observer reliability was excellent at neutral position and $60^{\circ}$ abduction for both the experienced and the novice operators. The inter-observer reliability was good for neutral position and fair for $60^{\circ}$ abduction.

The ICC's between the experienced and the novice operators were similar (Table 1). This indicates that the level of experience does not substantially impact the reliability of 
the measurements in terms of individual consistency for a given operator. In other words, this technique can be easily learned even by clinicians with limited experience in US. However, there were some inconsistencies between observers as indicated by the interobserver ICCs of 0.64 and 0.70 . These inter-observer ICCs were lower compared with the values of $0.86-0.92$ found by Desmeules et al. ${ }^{(10)}$ We believe this may be due to the fact that Desmeules et al used healthy, young (average, 34 years of age) subjects, while in our study, patients suffering from SIS were older (average, 52 years). For neutral position, the difference between the 3 measurements of the experienced observer and those of the novice operator were up to $1.8 \mathrm{~mm}$ and for the $60^{\circ}$ abduction it was up to $2.8 \mathrm{~mm}$. This means that the AHD can vary up to $1.8 \mathrm{~mm}$ in neutral position and up to $2.8 \mathrm{~mm}$ in $60^{\circ}$ abduction when measured by a different observer. This should, however, not be confused for the reliability of each individual observer's measurements. Both the experienced and the novice operators repetitive measurements of the same shoulder fell within $1.1 \mathrm{~mm}$ in $95 \%$ of the time for neutral position and $1.4 \mathrm{~mm}$ for $60^{\circ}$ abduction.

Interestingly, when AHD measurements on blank US images were compared with re-measurements on the same image by the same observer more than 6 months after the initial measurement (Table 2), the ICCs for neutral position were rather poor. The ICCs for $60^{\circ}$ abduction, however, were good. Apparently, the dynamic properties of US are needed for determining where the acromial and humeral borders are at neutral abduction. In our experience, the acromial border was the most difficult of the 2 borders to identify and we believe this may explain the lack of reliability. The reason the lower border of the acromion is difficult to recognize is due to the inflammatory reaction of the soft tissues in patients suffering from SIS. ${ }^{(16)}$ In addition, attachment of the coracoacromial ligament to the inferior edge of the acromion ${ }^{(17)}$ and fibrous changes and calcifications in the deltoid fibers make identification of the inferior acromial edge difficult. Also, acoustic shadowing from the edge of the acromion limits the visualization of the inferior edge of the acromion.

The Bland-Altman plots visualize the difference between 2 consecutive measurements on the same patient in the same session by the same observer. We wanted to know whether the $2^{\text {nd }}$ measurement was different from the $1^{\text {st }}$ measurement. This is illustrated by the limits of agreement shown in Figure 5 . For the neutral position group, the $2^{\text {nd }}$ measurement lies within $1.1 \mathrm{~mm}(95 \%$ CI $0.7-1.5 \mathrm{~mm})$ of the $1^{\text {st }}$. For the $60^{\circ}$ abduction group, that difference is $1.4 \mathrm{~mm}(95 \%$ CI $0.8-2.0 \mathrm{~mm})$. In other words, when repeating the measurement by the same observer in the same session, there could be an inaccuracy 
of 1.1 and $1.4 \mathrm{~mm}$ for the neutral position and $60^{\circ}$ abduction groups, respectively. This is acceptable when applying a threshold value of $7 \mathrm{~mm}$ to define the normal AHD. Using MRI, Mayerhoefer et al have found a clinically significant difference in shoulder function (18.5 points Constant Score) in patients suffering from SIS utilizing this threshold. ${ }^{(4)}$ The inaccuracy, however, is rather large compared with the magnitude of difference in AHD measured by US reported in literature, which ranges from 0.3 to $2.1 \mathrm{~mm} \cdot{ }^{(8-11)}$ Although there is an excellent intra-observer ICC for both the experienced and the novice operators, the inaccuracy is large compared with the reported AHD values in the literature, unless a threshold, such as the $7 \mathrm{~mm}$ used by Mayerhoefer et al, is used. ${ }^{(4)}$

US measurement of the AHD has enabled dynamic evaluation of shoulder pathology with easy and fast contralateral comparison. Cholewinski et al compared the US AHD (acromion apex to greater tuberosity distance in their protocol) between both shoulders in patients suffering from SIS and in healthy controls. ${ }^{(9)}$ On average the difference in AHD between symptomatic and asymptomatic shoulders was $2.1 \mathrm{~mm}$ larger in SIS patients than the difference between left and right shoulders in healthy controls. ${ }^{(9)}$

Overhead athletes, such as basketball-, baseball-, football-, tennis players, and swimmers, place enormous repetitive loads on several shoulder structures, which can result in secondary SIS. ${ }^{(18)}$ Girometti et al found AHD narrowing $(<7 \mathrm{~mm})$ in young overhead athletes (professional basketball players) to be an early sign of SIS. ${ }^{(11)}$ Azzoni et al showed that AHD measured by US correlates well to AHD measured on radiographs. (8) They also found that the AHD measurements differed between healthy controls, patients with tendonitis, and patients with rotator cuff tear. ${ }^{(8)}$ Desmeules et al found a nonsignificant $0.3 \mathrm{~mm}$ decrease in AHD in SIS patients. ${ }^{(10)}$ In a reliability study on healthy subjects by the same investigators, the inter-observer reliability of US measurements of AHD at various abduction angles was good. ${ }^{(10)}$ We were unable to confirm this reliability in symptomatic patients.

US is ideal for dynamic AHD measurement, because it is not restricted to a fixed plane. It is also fast, easy, and available in almost every hospital and comparison of the contralateral shoulder can be readily performed. However, dynamic evaluation and comparison of the contralateral shoulder require at least 2 measurements. The inaccuracy of the difference between these 2 measurements can therefore be as high as twice the inaccuracy of a single measurement. 
Furthermore it is noteworthy to realize that the AHD is also affected by amount of abduction, ${ }^{(19,20)}$ flexion, ${ }^{(21)}$ adduction, ${ }^{(5)}$ presence of cuff tear, ${ }^{(1,2)}$ fatty infiltration, ${ }^{(1,2)}$ patient position (laying or upright), ${ }^{(22)}$ height, ${ }^{(23)}$ gender, ${ }^{(24)}$ and muscle activity. ${ }^{(5,25)}$ In radiographic AHD measurement the upward migration index (UMI) was introduced to overcome the influence of the patient's height. ${ }^{(26,27)}$ This index is calculated by dividing the distance from the inferior border of the acromion to the center of the humeral head by the radius of the humeral head. ${ }^{(26)}$ The UMI cannot be used in US AHD measurement, because the radius of the humeral head cannot be determined by US. The radius of the humeral head is correlated to length of the humerus. ${ }^{(28,29)}$ The length of the humerus is correlated to height. ${ }^{(30,31)}$ An US alternative to the radiographic UMI could be the ratio of AHD over the patient's height.

In conclusion, the data and analysis from this study show that US measurement of AHD in patients with shoulder complaints is not as accurate and reliable as those reported in healthy subjects, ${ }^{(9)}$ with an inaccuracy of $1 \mathrm{~mm}$ regardless of the experience of the observer, and with the AHD varying as much as $1.8 \mathrm{~mm}$ between 2 operators when scanning a shoulder in neutral position. This has important implications for the interpretation of studies using US to measure AHD as well as for the clinical use of this parameter. We recommend that future studies on US measurement of AHD take the advantages and limitations of this technique into consideration.

\section{Acknowledgments}

We would like to express our gratitude to the orthopaedic surgeons of the Elkerliek hospital for their expertise and assistance with patient inclusion. 


\section{References}

1. Nove-Josserand L, Edwards TB, O'Connor DP, et al. The acromiohumeral and coracohumeral intervals are abnormal in rotator cuff tears with muscular fatty degeneration. Clin Orthop Relat Res 2005;433:90.

2. Saupe N, Pfirrmann CW, Schmid MR, et al. Association between rotator cuff abnormalities and reduced acromiohumeral distance. AJR Am J Roentgenol 2006;187:376.

3. Goutallier D, Postel JM, Gleyze P, et al. Influence of cuff muscle fatty degeneration on anatomic and functional outcomes after simple suture of full-thickness tears. J Shoulder Elbow Surg 2003;12: 550.

4. Mayerhoefer ME, Breitenseher MJ, Wurnig C, et al. Shoulder impingement: relationship of clinical symptoms and imaging criteria. Clin J Sport Med 2009;19:83.

5. Graichen H, Hinterwimmer S, von Eisenhart-Rothe R, et al. Effect of abducting and adducting muscle activity on glenohumeral translation, scapular kinematics and subacromial space width in vivo. J Biomech 2005;38:755.

6. Fehringer EV, Rosipal CE, Rhodes DA, et al. The radiographic acromiohumeral interval is affected by arm and radiographic beam position. Skeletal Radiol 2008;15:15.

7. Nagels J, Verweij J, Stokdijk M, et al. Reliability of proximal migration measurements in shoulder arthroplasty. J Shoulder Elbow Surg 2008;17:241.

8. Azzoni R, Cabitza P, Parrini M. Sonographic evaluation of subacromial space. Ultrasonics 2004;42: 683 .

9. Cholewinski JJ, Kusz DJ, Wojciechowski P, et al. Ultrasound measurement of rotator cuff thickness and acromio-humeral distance in the diagnosis of subacromial impingement syndrome of the shoulder. Knee Surg Sports Traumatol Arthrosc 2008;16:408.

10. Desmeules F, Minville L, Riederer B, et al. Acromio- humeral distance variation measured by ultrasonography and its association with the outcome of rehabilitation for shoulder impingement syndrome. Clin J Sport Med 2004;14:197.

11. Girometti R, De Candia A, Sbuelz M, et al. Supraspinatus tendon US morphology in basketball players: correlation with main pathologic models of secondary impingement syndrome in young overhead athletes. Preliminary report. Radiol Med (Torino) 2006;111:42. 
12. Silva RT, Hartmann LG, Laurino CF, et al. Clinical and ultrasonographic correlation between scapular dyskinesia and subacromial space measurement among junior elite tennis players. Br J Sports Med 2008;8:8.

13. O'Connor PJ, Rankine J, Gibbon WW, et al. Interobserver variation in sonography of the painful shoulder. J Clin Ultrasound 2005;33:53.

14. Hashimoto BE, Kramer DJ, Wiitala L. Applications of musculoskeletal sonography. J Clin Ultrasound 1999;27:293.

15. Bland JM, Altman DG. Statistical methods for assessing agreement between two methods of clinical measurement. Lancet 1986;1:307.

16. Voloshin I, Gelinas J, Maloney MD, et al. Proinflammatory cytokines and metalloproteases are expressed in the subacromial bursa in patients with rotator cuff disease. Arthroscopy 2005;21: 1076 .

17. Gagey N, Ravaud E, Lassau JP. Anatomy of the acromial arch: correlation of anatomy and magnetic resonance imaging. Surg Radiol Anat 1993; 15:63.

18. Wilk KE, Meister K, Andrews JR. Current concepts in the rehabilitation of the overhead throwing athlete. Am J Sports Med 2002;30:136.

19. Bey MJ, Brock SK, Beierwaltes WN, et al. In vivo measurement of subacromial space width during shoulder elevation: technique and preliminary results in patients following unilateral rotator cuff repair. Clin Biomech (Bristol, Avon) 2007;22:767.

20. Graichen H, Bonel H, Stammberger T, et al. Three-dimensional analysis of the width of the subacromial space in healthy subjects and patients with impingement syndrome. AJR Am J Roentgenol 1999;172:1081.

21. Hebert LJ, Moffet H, Dufour M, et al. Acromiohumeral distance in a seated position in persons with impingement syndrome. J Magn Reson Imaging 2003;18:72.

22. Railhac JJ, Sans N, Rigal A, et al. Strict anteroposterior radiography of the shoulder: value of the assessment of rotator cuff tears. J Radiol 2001;82: 979.

23. Anetzberger H, Putz R. The scapula: principles of construction and stress. Acta Anat (Basel) 1996; 156:70.

24. Graichen H, Bonel H, Stammberger T, et al. Sexspecific differences of subacromial space width during abduction, with and without muscular activity, and correlation with anthropometric variables. J Shoulder Elbow Surg 2001;10:129. 
25. Chen SK, Simonian PT, Wickiewicz TL, et al. Radiographic evaluation of glenohumeral kinematics: a muscle fatigue model. J Shoulder Elbow Surg 1999;8:49.

26. Hirooka A, Wakitani S, Yoneda M, et al. Shoulder destruction in rheumatoid arthritis. Classification and prognostic signs in 83 patients followed 5-23 years. Acta Orthop Scand 1996;67:258.

27. van de Sande MA, Rozing PM. Proximal migration can be measured accurately on standardized anteroposterior shoulder radiographs. Clin Orthop Relat Res 2006;443:260.

28. Steele DG, McKern TW. A method for assessment of maximum long bone length and living stature from fragmentary long bones. Am J Phys Anthropol 1969;31:215.

29. Wright LE, Vasquez MA. Estimating the length of incomplete long bones: forensic standards from Guatemala. Am J Phys Anthropol 2003;120:233.

30. Dupertuis CW, Hadden JA, Jr. On the reconstruction of stature from long bones. Am J Phys Anthropol 1951;9:15.

31. Telkka A. On the prediction of human stature from the long bones. Acta Anat (Basel) 1950;9:103. 


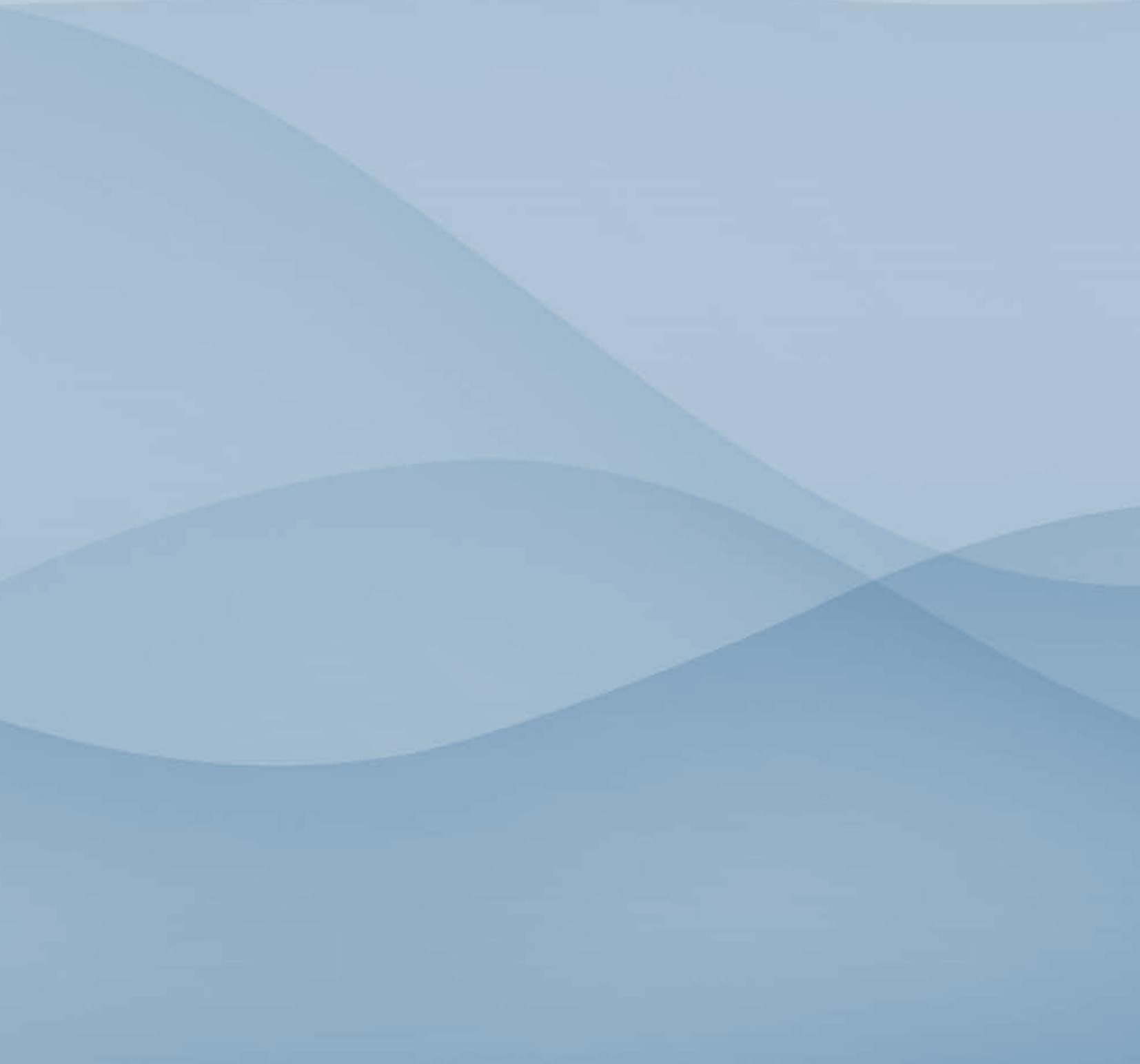




\section{Chapter 7}

Reproducibility of a

3-dimensional gyroscope

in measuring shoulder

anteflexion and abduction

Penning L.I.F.

Guldemond N.A.

de Bie R.A.

Walenkamp G.H.I.M.

BMC Musculoskelet Disord. 2012 Jul 30;13:135. 


\section{Abstract}

Background: Few studies have investigated the use of a 3-dimensional gyroscope for measuring the range of motion (ROM) in the impaired shoulder. Reproducibility of digital inclinometer and visual estimation is poor. This study aims to investigate the reproducibility of a tri axial gyroscope in measurement of anteflexion, abduction and related rotations in the impaired shoulder.

Methods: Fifty-eight patients with either subacromial impingement (27) or osteoarthritis of the shoulder (31) participated. Active anteflexion, abduction and related rotations were measured with a tri axial gyroscope according to a test retest protocol. Severity of shoulder impairment and patient perceived pain were assessed by the Disability of Arm Shoulder and Hand score (DASH) and the Visual Analogue Scale (VAS). VAS scores were recorded before and after testing.

Results: In two out of three hospitals patients with osteoarthritis $(\mathrm{n}=31)$ were measured, in the third hospital patients with subacromial impingement $(n=27)$.

There were significant differences among hospitals for the VAS and DASH scores measured before and after testing. The mean differences between the test and retest means for anteflexion were -6 degrees (affected side), 9 degrees (contralateral side) and for abduction 15 degrees (affected side) and 10 degrees (contralateral side).

Bland \& Altman plots showed that the confidence intervals for the mean differences fall within -6 up to 15 degrees, individual test - retest differences could exceed these limits.

A simulation according to 'Generalizability Theory' produces very good coefficients for anteflexion and related rotation as a comprehensive measure of reproducibility. Optimal reproducibility is achieved with 2 repetitions for anteflexion. 
Conclusions: Measurements were influenced by patient perceived pain. Differences in VAS and DASH might be explained by different underlying pathology. These differences in shoulder pathology however did not alter the reproducibility of testing. The use of a tri axial gyroscope is a simple non invasive and reproducible method for the recording of shoulder anteflexion and abduction. Movements have to be repeated twice for reproducible results.

Keywords: Reproducibility, Shoulder, Tri axial gyroscope, Range of motion, Shoulder function, Generalizability theory 


\section{Background}

Range of motion (ROM) active and passive is an essential measure in the diagnosis and evaluation of shoulder impairments ${ }^{(1)}$. The reproducibility of estimated ROM however, is under discussion and depends on the method used for measurement ${ }^{(2,3)}$. Several methods have been developed for the measurement of ROM. The techniques range from visual estimation and goniometric measurements to electromagnetic tracking systems, accelerometers and invasive techniques, with sensors mounted on the scapula ${ }^{(4-10)}$. Most of these measurement techniques have to be performed in a laboratory setting and consist of the placement of multiple sensors on bony landmarks. Placement of sensors on bony landmarks lack a direct bony contact because of overlying tissue and thus could affect the reproducibility of results ${ }^{(11)}$. The accurate evaluation of ROM of the shoulder is important for clinical decision making and thus should be reproducible. Most exact measurement techniques are time consuming and therefore cannot be performed in the outpatient clinic. Reproducibility of digital inclinometer and visual estimation of range of motion is poor $^{(12,13)}$. The technique of a tri axial gyroscope could be a quick and simple method for the recording of three-dimensional shoulder movements. In this study we investigated the reproducibility of a tri axial gyroscope to assess active anteflexion and abduction movements in patients with shoulder complaints. Anteflexion and abduction consist of a combined upward movement and related rotation in either frontal or sagital plane. Using the tri axial gyroscope we were able to measure both flexion or abduction and related rotations during movement. The focus of the study was directed on the assessment of the clinical reproducibility in impaired shoulders, caused by different underlying pathology. The main research questions consisted of the reproducibility of measurement through use of an over- the-counter and the number of times measurements have to be repeated.

\section{Methods}

\section{Setting and participants}

From May 2007 until October 2007 a comprehensive reproducibility study was performed among fifty eight patients suffering from shoulder complaints. Patients were 
recruited in three hospitals. The underlying shoulder pathology consisted either of subacromial impingement syndrome $(n=27)$ or osteoarthritis $(n=31)$. In one hospital patients with subacromial impingement were measured in the other two hospitals patients with osteoarthritis. All patients were awaiting surgery for their complaints. Nine patients suffered from bilateral complaints. The dominant side of these patients was presumed to be the affected side. Patients underwent examination with a Minimod ${ }^{\otimes}$ device (Mc Roberts, The Hague, Netherlands) (Figure 1) for both active anteflexion and abduction and related rotations of their shoulder. The reproducibility of the test was examined according to a test - retest protocol. The local Ethics Committee approved the study protocol and the study was carried out according to the Declaration of Helsinki. Informed consent was obtained of patients preceding the study.

Figure 1 - Fixation of Minimod device on upper arm with neoprene strap

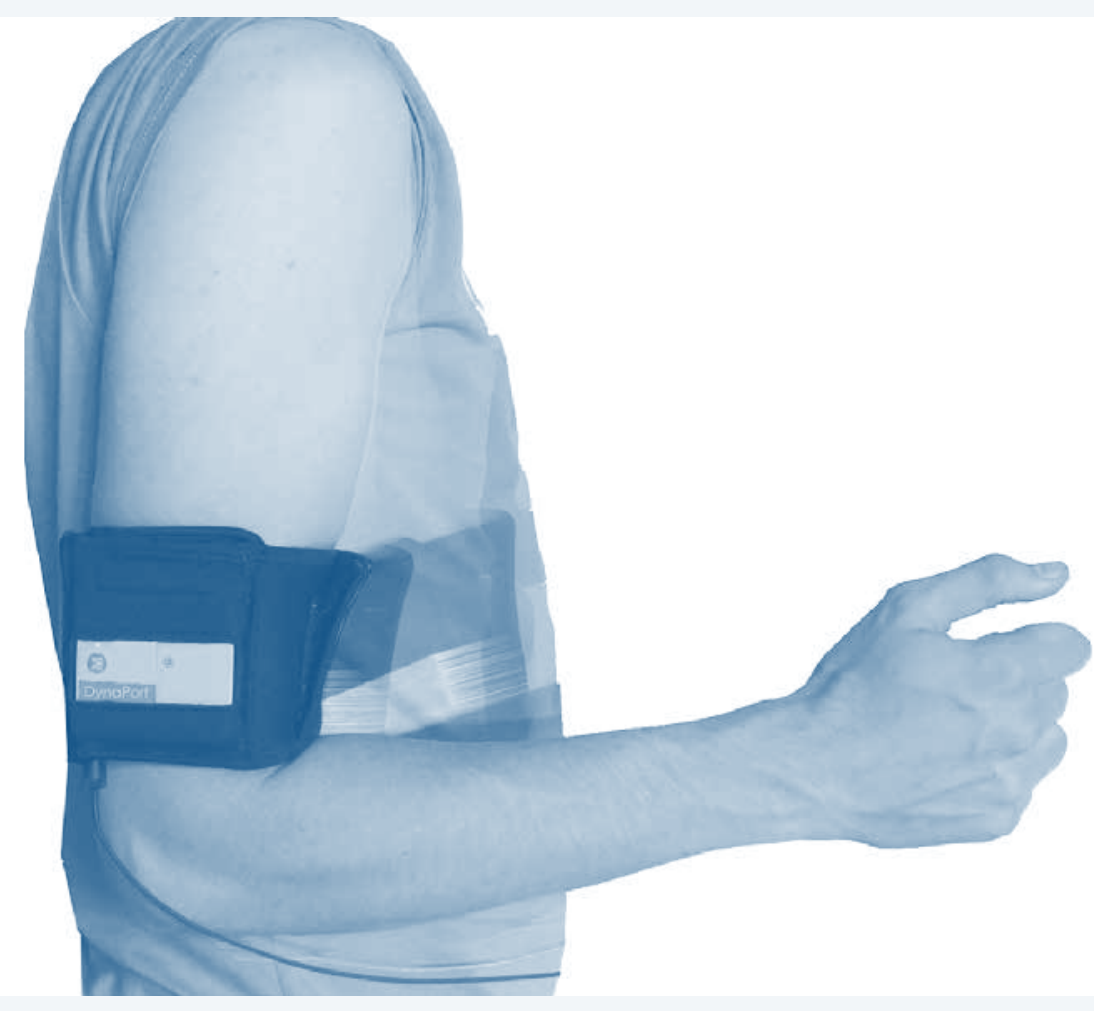




\section{Measurement techniques}

The Minimod 3-dimensional gyroscope is a small box (62 x 41 x $18 \mathrm{~mm}, 53$ grams) containing three gyroscopic sensors. A gyroscope is a device for measuring or maintaining orientation, based on the principles of conservation of an angular momentum ${ }^{(14)}$. Data are collected and stored on a Secure Digital (SD) card. In this study both maximum active anteflexion and abduction and related rotations of the shoulder were measured according to a pre defined test protocol.

In order to prevent influence of thoracic spine movement during measurement, the patient was placed with the opposite shoulder against a wall. The Minimod device was fixed with a neoprene strap to the lateral middle part of the upper arm of the patient. (Figure 1) Preceding the actual measurement the Minimod was calibrated for abduction and anteflexion movement. For the calibration the device was fixed with the neoprene strap. The arm of the patient was first slowly moved in an anteflexion direction by the researcher up to 45 degrees, this movement was recorded with the minimod device. After the anteflexion movement an abduction movement was performed in the same way. The calibration was used for setting of the $\mathrm{x} y$ and $\mathrm{z}$ axis needed for further calculation. Each test consisted of five consecutive movements. The start and end of each test was marked by pressing a switch connected to the device. Calibration was performed before each test. After this calibration patients were asked to perform a maximal possible active anteflexion movement for five times. A new calibration was performed before measurement of the abduction movement. Patients were now asked to perform a maximal active abduction for five times, than the contralateral side was measured in the same way for both anteflexion and abduction. During a break of approximately 30 minutes patients completed the DASH score, than a retest was performed for anteflexion and abduction in the affected and contralateral side. A total of 40 (20 per shoulder) movements were recorded for each patient. In order to assess the effect of patient perceived pain on movements, VAS scores were recorded immediately before and after measurement of the test and the retest. Measurements were performed in 3 hospitals by one local (trained) outcome assessor. 


\section{Analysis}

Demographic data were collected on age, sex, dominance, length and weight. (Table 1)

\section{Table 1 - Patient characteristics}

\begin{tabular}{|c|c|c|c|c|c|c|c|}
\hline & $\begin{array}{l}\text { Hospital } \\
1(n=9)\end{array}$ & SD & $\begin{array}{c}\text { Hospital } \\
2 \\
(n=22)\end{array}$ & SD & $\begin{array}{l}\text { Hospital } \\
\quad 3 \\
(n=27)\end{array}$ & SD & p-value \\
\hline Age & 55,9 & 15,8 & 55,5 & 4,1 & 52,4 & 7,9 & 0,70 \\
\hline Lenght & 1,7 & 0,1 & 1,7 & 0 & 1,7 & 0,1 & 0,24 \\
\hline Weight & 80,1 & 10,6 & 74,8 & 3,5 & 75,6 & 14,6 & 0,66 \\
\hline BMI & 26,4 & 3,3 & 24,7 & 0,8 & 26,5 & 4,2 & 0,27 \\
\hline DASH & 36,3 & 23,5 & 27,1 & 5,2 & 48,4 & 20,6 & 0,01 \\
\hline Male & 4 & & 13 & & 10 & & 0,40 \\
\hline Female & 5 & & 9 & & 17 & & 0,40 \\
\hline Affected side left & 3 & & 7 & & 8 & & 0,82 \\
\hline Affected side right & 6 & & 15 & & 19 & & 0,40 \\
\hline Affected side both & 1 & & 6 & & 2 & & 0,38 \\
\hline Dominant side left & 1 & & 0 & & 1 & & 0,55 \\
\hline Dominant side right & 8 & & 22 & & 26 & & 0,55 \\
\hline \multicolumn{8}{|l|}{ Affected side } \\
\hline Mean VAS score before test & 2,74 & 2,35 & 3,20 & 2,98 & 5,16 & 3,19 & 0,03 \\
\hline Mean VAS score after test & 2,97 & 2,39 & 3,57 & 3,22 & 6,07 & 3,36 & 0,01 \\
\hline Mean VAS score before retest & 3,47 & 2,89 & 3,18 & 3,00 & 5,33 & 3,37 & 0,05 \\
\hline Mean VAS score after retest & 3,41 & 2,49 & 3,53 & 3,19 & 6,61 & 3,04 & 0,00 \\
\hline Mean difference VAS score test & 0,22 & 0,51 & 0,37 & 0,62 & 0,91 & 1,44 & 0,13 \\
\hline Mean difference VAS score retest & $-0,06$ & 1,45 & 0,35 & 0,78 & 1,28 & 1,57 & 0,01 \\
\hline \multicolumn{8}{|l|}{ Contralateral side } \\
\hline Mean VAS score before test & 0,54 & 0,56 & 0,56 & 1,03 & 1,69 & 2,2 & 0,04 \\
\hline Mean VAS score after test & 0,63 & 0,55 & 0,58 & 1,06 & 2,01 & 2,3 & 0,01 \\
\hline Mean VAS score before retest & 0,60 & 0,57 & 0,66 & 1,32 & 1,71 & 2,1 & 0,06 \\
\hline Mean VAS score after retest & 0,56 & 0,55 & 0,74 & 1,37 & 2,35 & 2,4 & 0,01 \\
\hline Mean difference VAS score test & 0,03 & 0,13 & 0,01 & 0,12 & 0,32 & 0,89 & 0,20 \\
\hline Mean difference VAS score retest & $-0,04$ & 0,05 & 0,08 & 0,33 & 0,64 & 1,41 & 0,08 \\
\hline
\end{tabular}


Primary outcome measurements in this study are the data collected with the Minimod. The data collected with the Minimod consist of the accelerations in (meter/second squared) measured by seismic acceleration sensors in three axis. . The raw signals stored on the SD card were exported to ASCI files through use of the MiRA (MiniMod Read and Acquire) software. ASCI files were send to McRoberts, among with a list of the order in which abduction and anteflexion were performed, for further analysis using $\mathrm{Matlab}^{\oplus}$ and calculating range of motion in degrees of anteflexion, abduction and related rotations using matrix algebra and goniometric operations. For the sake of company confidentiality we cannot further explain the method of analysis in Matlab.

Secondary outcome measurements are the VAS scores (Visual Analogue Scale) and the DASH. (Disability of Arm Shoulder and Hand) ${ }^{(15)}$. The VAS scores were recorded preceding and immediate following each time the Test or Retest was performed. VAS scores were used to examine possible bias in test results caused by patient perceived pain performing the test. Following the first assessment the DASH questionnaire was filled out.

The Visual Analogue Scale is a line of $10 \mathrm{~cm}$ in length, which is taken to represent the continuum of experienced pain. It has been proved to be a simple, sensitive and reproducible instrument that enables the patients to express their pain in such a way that it can be given a numerical value ${ }^{(16)}$.

\section{Statistical analysis}

The results of individual movements were expressed in degrees of maximum achieved anteflexion or abduction and related rotations. For the analysis of primary outcome results of Test and Retest, the mean of five consecutive movements was calculated, together with the Standard Deviation (SD) and $95 \%$ confidence intervals.

Mean differences in degrees between mean results of Test and Retest were calculated.

Bland Altman plots were used to show the level of agreement for Testing and Retesting for the different hospitals. (MedCalc ${ }^{\oplus}$ version 11.3.1.0)

A simulation according to the 'Generalizability Theory' was performed for the Test and Retest by combining either anteflexion or abduction and related rotation in a 1 -faceted crossed design $\left(\mathrm{P}^{\star} \mathrm{F} 1\right)$. $\mathrm{P}$ represents the total number of persons and $\mathrm{F} 1$ represents the 10 level 1 -faceted design. The results of this simulation are expressed as generalizability- 
coefficient (g-coefficient): range 0-1. A g-coefficient of 0,8 is generally accepted as a good reliability ref Shavelson R., Webb N.M. Generalizability Theory: a primer. Measurement methods for the social sciences series 1. Vol. XIII, 1991.

After performing a G-study (generalizability study) also a D-study (decision-study) was performed. By performing a D-study the number of repetitions of measurement for a reliable result can be calculated ${ }^{(17,18)}$.

For the secondary outcome results, DASH and recorded VAS scores before and after testing of the affected side were analyzed using an ANOVA (SPSS 17.0).

\section{Results}

The recruited 58 patients performed a total of 10 movements for each Test. Measuring both affected and contralateral side in a Test and Retest, this resulted in a total of 1160 recordings of anteflexion and 1160 recordings of abduction. The matrix algebra and goniometric operations performed by Mc Roberts resulted in 4640 calculated measures of range of motion, depicted in degrees of anteflexion, abduction and related rotations.

In hospital 1 and 2 patients with osteoarthritis were measured, in hospital 3 patients with subacromial impingement. The recorded patient characteristics were significantly different concerning the DASH score. The score of hospital 3 was significantly higher than the score of hospital 2 these differences can be explained because of different shoulder pathology in the groups. The VAS scores measured preceding and following each test showed significant differences between the participating hospitals for the VAS scores measured before and after the test and after the retest of both affected and contra lateral sides. The mean difference between pre and post test VAS score was significantly different for the retest, VAS scores measured for the contra lateral side did not show significant differences between mean differences of pre and post test VAS scores. (Table 1)

The mean differences between the test and retest means for anteflexion were -6 degrees (affected side), 9 degrees (contralateral side) and for abduction 15 degrees (affected side) and 10 degrees (contralateral side). (Table 2) 
Table 2 - Mean and mean differences between test and retest means

\begin{tabular}{|c|c|c|c|c|c|c|c|c|}
\hline \multirow[b]{2}{*}{ affected } & \multicolumn{2}{|c|}{ Anteflexion } & \multicolumn{2}{|c|}{ Anteflexion rotation } & \multicolumn{2}{|c|}{ Abduction } & \multicolumn{2}{|c|}{ Abduction rotation } \\
\hline & test & retest & test & retest & test & retest & test & retest \\
\hline mean & 149,35 & 140,37 & 57,61 & 51,19 & 128,75 & 118,05 & $-46,43$ & $-46,42$ \\
\hline SD & 25,61 & 27,41 & 37,52 & 33,33 & 31,03 & 35,23 & 55,10 & 53,43 \\
\hline $\begin{array}{l}\text { mean difference } \\
\text { between test and } \\
\text { retest (SD) }\end{array}$ & $-6,21$ & $(45,16)$ & $-4,89$ & $(41,39)$ & 15,10 & $(33,60)$ & $-1,38$ & $(39,82)$ \\
\hline \multicolumn{9}{|l|}{ contralatera } \\
\hline mean & 135,94 & 128,73 & 48,65 & 51,96 & 118,13 & 103,45 & $-34,82$ & $-34,47$ \\
\hline SD & 40,68 & 32,10 & 42,22 & 25,80 & 37,43 & 40,83 & 52,64 & 51,49 \\
\hline $\begin{array}{l}\text { mean difference } \\
\text { between test and } \\
\text { retest (SD) }\end{array}$ & 9,41 & $(29,55)$ & 8,01 & $(35,66)$ & 10,27 & $(36,41)$ & 1,02 & $(35,37)$ \\
\hline
\end{tabular}

The Bland - Altman plots show individual differences between test and retest measurement regarding anteflexion and abduction for each centre. The confidence intervals for the overall mean differences fall within -6 up to 15 degrees, but individual test-retest differences (prediction interval) could exceed these limits. (Figures 2, 3 and 4)

The simulation according to the "Generalizability Theory' resulted in g-coefficients for the test in anteflexion of 0,99 (affected side), 0,96 (contralateral side), abduction 0,99 (affected side), 0,99 (contralateral side) and for the retest anteflexion: 0,99 (affected side) 0,98 (contralateral side) and abduction 0,99 (affected side), 0,99 (contralateral side) respectively.

The performed D-study resulted in g-coefficients of 0,97 after 2 repetitions (anteflexion affected side), 0,91 after 2 repetitions (anteflexion contralateral side), 0,99 after 2 repetitions (abduction affected side), 0,97 after 2 repetitions (abduction contralateral side), 0,98 after 2 repetitions (anteflexion retest affected side), 0,96 after 2 repetitions (anteflexion retest contralateral side) and 0,98 after 2 times for both affected and contralateral side in the retest of abduction. (Figure 5a) Analysis of the combination of anteflexion and related rotations in a simulation of the generalizability theory resulted in less good reproducibility coefficients. In particular the reproducibility of abduction was largely influenced by the related rotations. (Figure $5 b$ ) 
Figure 2 - Bland Altman plot anteflexion
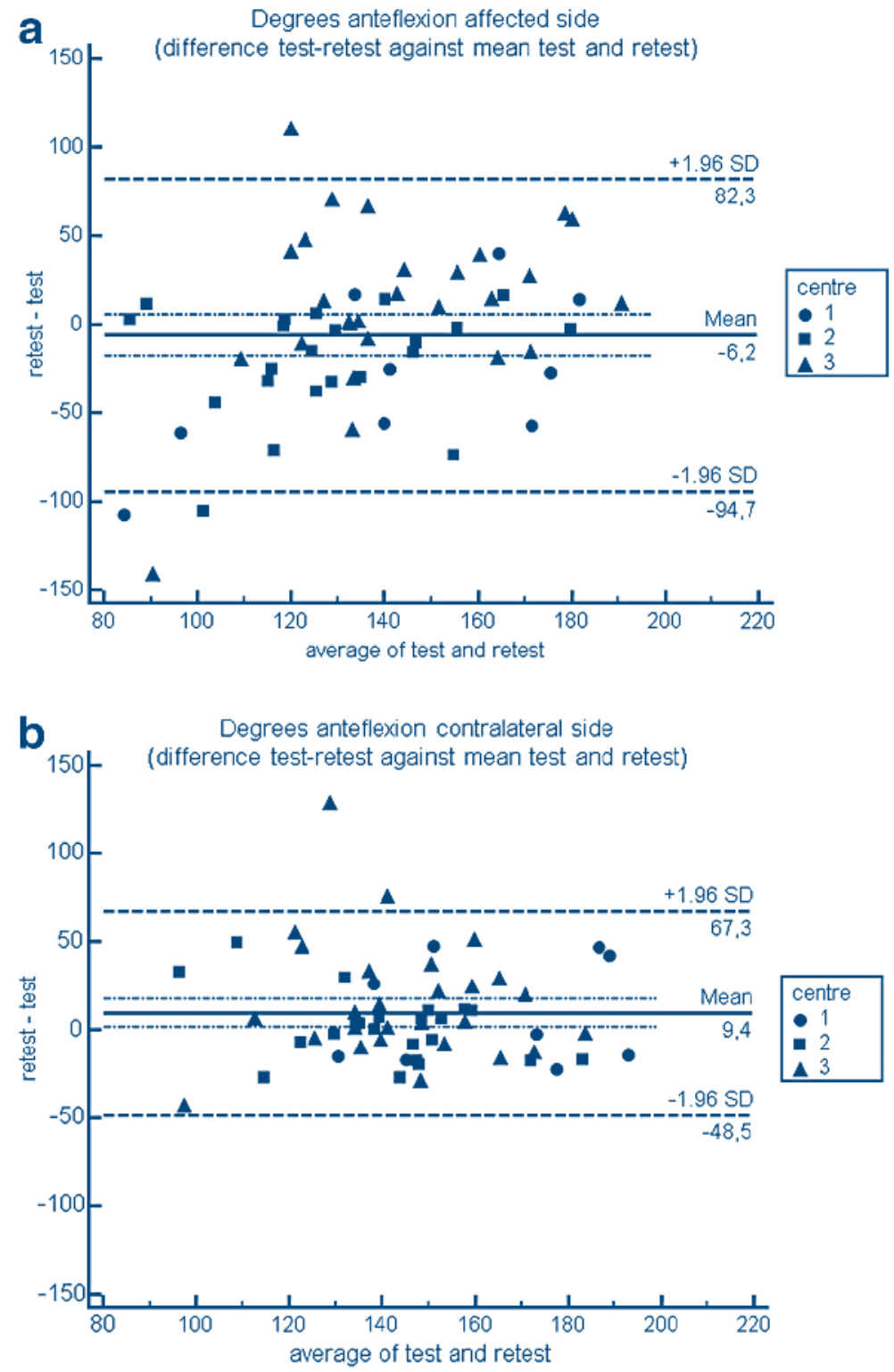
Figure 3 - Bland Altman plot abduction
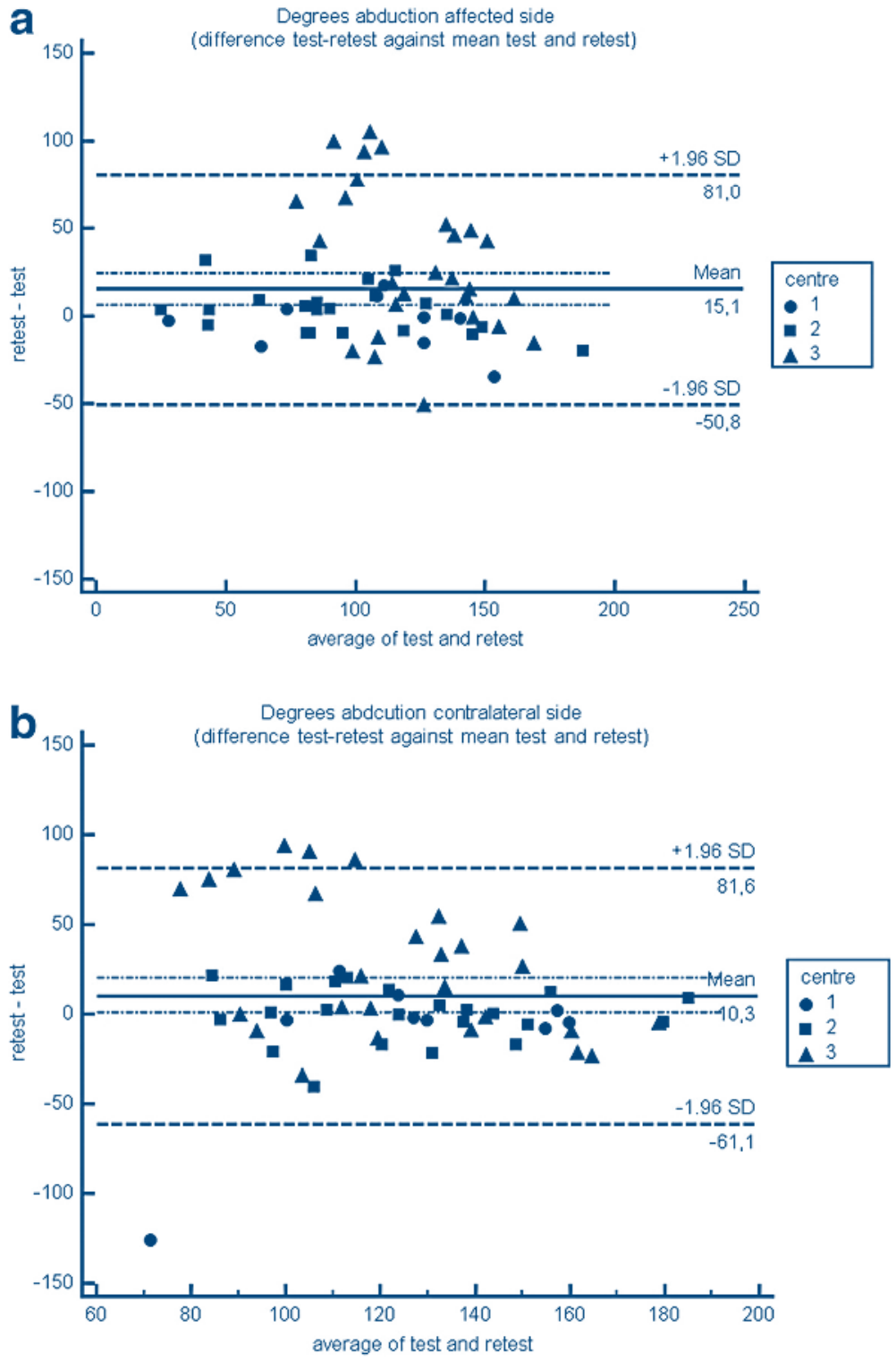
Figure 4 - D study results

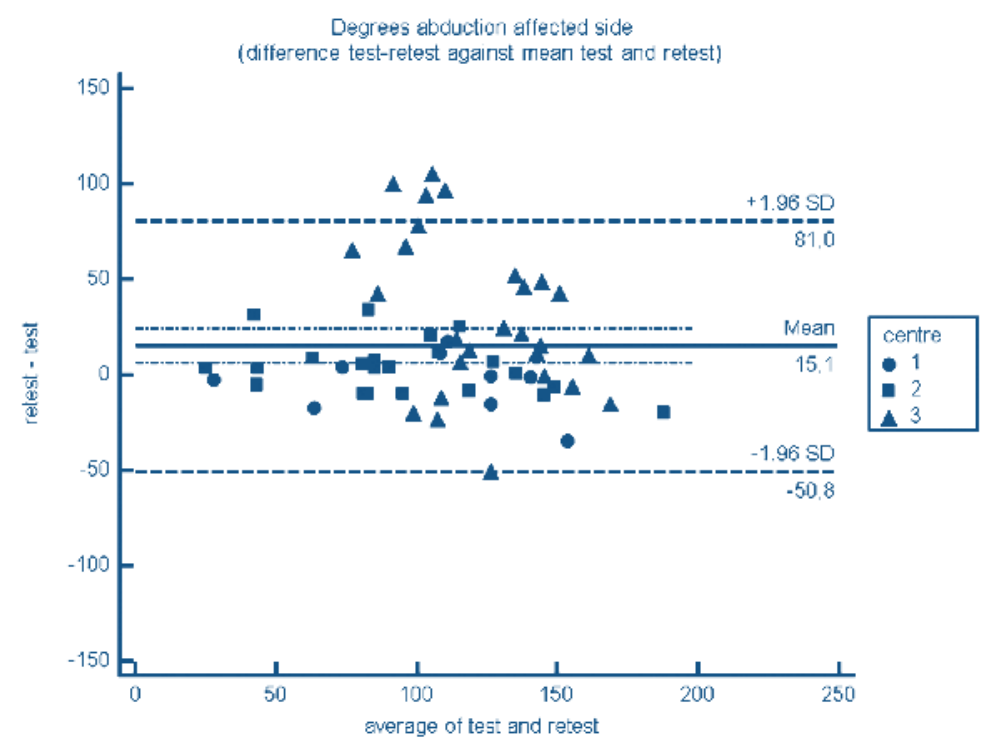


Figure 5 - D study results with related rotations

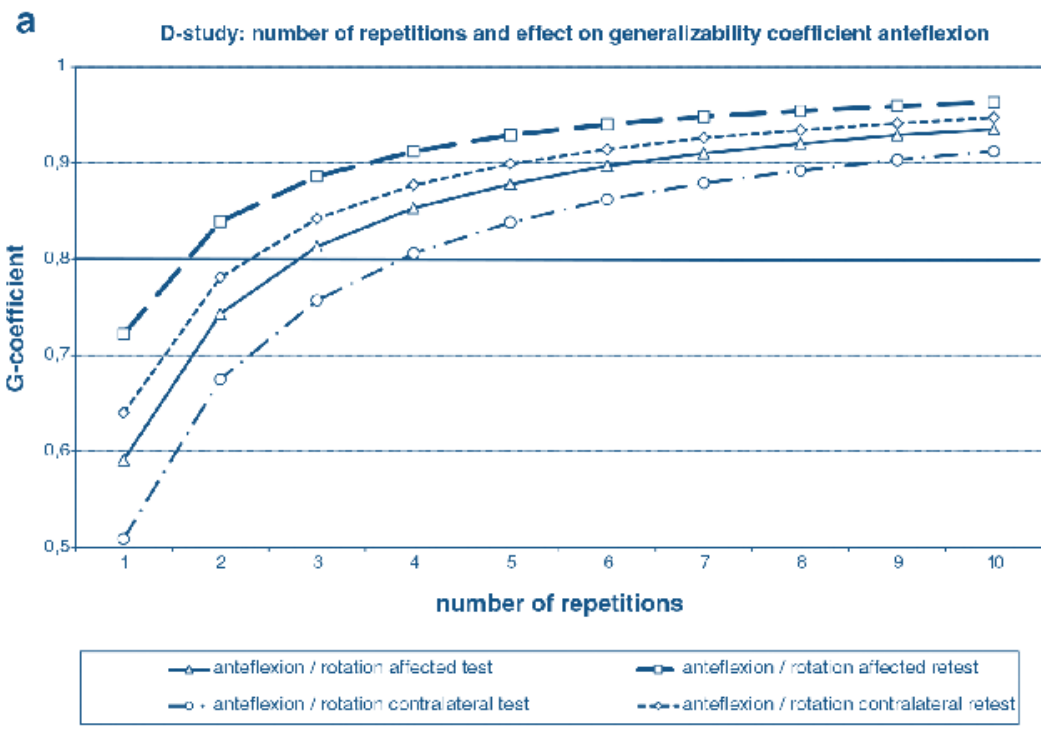

b D-study: number of repetitions and effect on generalizability coefficient abduction

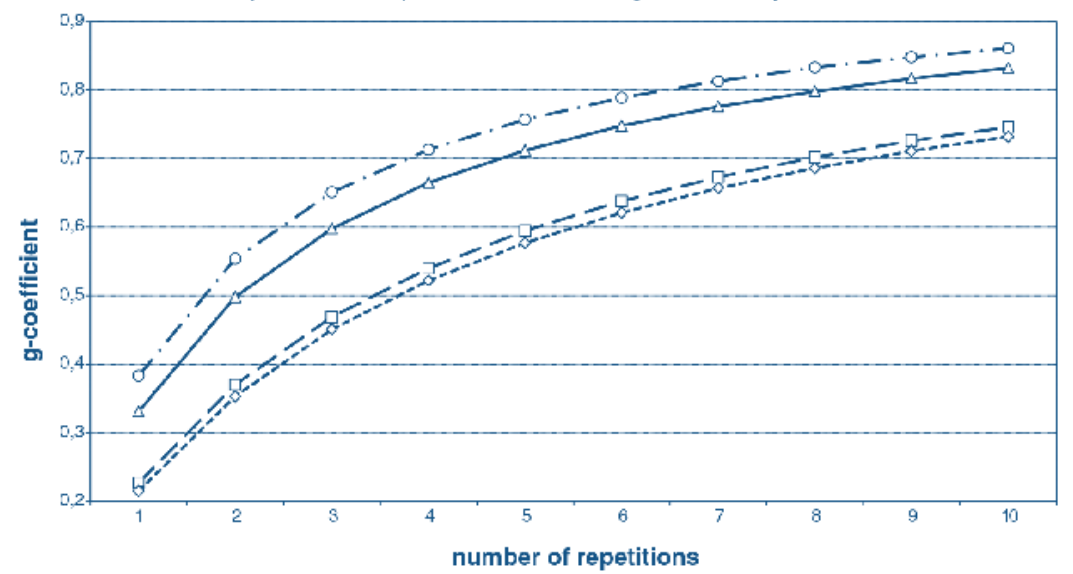




\section{Discussion}

The three-dimensional gyroscope under study showed good to excellent reproducibility for measuring anteflexion and abduction. An average of 2 repetitions was needed for a sound reproducibility of anteflexion and abduction measurement, In case the related rotations were imputed in the generalizability analysis, 2 up to 4 repetitions were needed for anteflexion movement, where 7-10 repetitions were needed for abduction. These differences might be explained by the fact that there is more variability in rotation during abduction compared to anteflexion. Mean differences for anteflexion and abduction between test and retest were -6 degrees (affected side), 9 degrees (contralateral side) and 15 degrees (affected side), 10 degrees (contralateral side) respectively. Bland Altman plots showed a level of agreement with a confidence interval for overall mean differences of -6 up to 15 degrees.

Accordingly to El-Zayat et al., the device related measurement error (based on $95 \%$ prediction intervals) could vary between -0.77 and 2.25 degrees depending on velocity of motion and the distance of the device to the centre of rotation. Because of the repeated measurements for each trial, we considered the possible effect of sensor error on the results as negligible ${ }^{(14)}$.

A clinical anteflexion movement consists of a movement in the frontal plane with accompanying rotations of the humerus. The abduction movement consists of a movement in the sagital plane with accompanying movement of the humerus. With the acquired data we were able to calculate rotational movement during anteflexion and abduction. We therefore were able to assess the combined effect of movement in the frontal and sagital plane with accompanying rotations in a generalizability theory model.

In our study we focused on the reproducibility of testing. The results of testing were displayed in degrees; the validity of these results however needs further study.

During the study data had to be sent to Mc Roberts (Meanwhile the procedure has been improved and results can be processed in the outpatient clinic).

The reproducibility coefficients found in our study ranging from 0,96 to 0,99 are excellent compared to other measurement techniques, taking into account that the tests were performed in patients with different underlying shoulder pathology $(3,6,8,12,13,19)$. 
In this study we could prove that the tri-axial gyroscope is a reproducible instrument in the measurement of shoulder anteflexion and abduction in patients with different underlying pathologies.

\section{Conclusions}

$\mathrm{ROM}$ is an essential measure in the diagnosis of shoulder impairments ${ }^{(1)}$. Several methods have been developed for the measurement of $\operatorname{ROM}^{(2,3)}$. These methods have poor reproducibility ${ }^{(12,13)}$. The technique of a tri axial gyroscope could be a quick and simple method for the recording of three-dimensional shoulder movements. Our findings support the excellent reproducibility of a tri axial gyroscope for measurement of shoulder anteflexion and abduction.

In our study patient perceived pain showed to be of influence on the measurements carried out. The differences in VAS and DASH score might be explained by difference of underlying pathology, osteoarthritis and subacromial impingment, between groups. The differences in shoulder pathology however did not alter the reproducibility of testing.

Simulation according to the "Generalizabilty Theory" showed in a D-study that measurements only have to be repeated twice for reproducible results.

\section{Competing interests}

The authors declare that they have no competing interests.

\section{Authors' contributions}

LIFP participated in the design of the study carried out the data collection and measurement, performed the statistical analysis and drafted the manuscript. NAG, RAdB and GHIMW participated in the design of the study and helped to draft the manuscript. All authors read and approved the final manuscript.

\section{Authors' information}

LIFP is currently positioned at the Sint Maartenskliniek, Nijmegen, The Netherlands, as an orthopedic surgeon specialized in upper extremity. 
NAG is positioned at Delft University, Delft, The Netherlands as Program Director Health.

RAdB is positioned at the Department of Epidemiology of Maastricht University, Maastricht, The Netherlands as Professor of Physiotherapy.

GHIMW is Emeritus Professor in Orthopedic Surgery, Orthopaedic surgeon.

\section{Acknowledgements}

The authors thank Mr. C. Visser, MD PhD and Mr. A. van Noort, MD PhD for the collection of the data in hospital 1 and 2, Mr. R. van Lummel (McRoberts) for providing the Minimod device and processing of raw data and Ms. R. Mertens, student of the Faculty of Health, Medicine and Life sciences, Maastricht University, for her assistance during the outpatient clinic visits of patients.

Written consent for publication was obtained from the patients. 


\section{References}

1. Inman V, Saunders J, Abbott L: Observations on the function of the shoulder joint. J Bone Joint SurgBr 1944, 26(1): 1-30.

2. van de Pol RJ, van Trijffel E, Lucas C: Inter-rater reliability for measurement of passive physiological range of motion of upper extremity joints is better if instruments are used: a systematic review. Aust JPhysiother 2010, 56(1):7-17.

3. Tveita EK, Ekeberg OM, Juel NG, Bautz-Holter E: Range of shoulder motion in patients with adhesive capsulitis; intra-tester reproducibility is acceptable for group comparisons. BMC Musculoskelet Disord 2008, 9:49.

4. Karduna AR, McClure PW, Michener LA, Sennett B: Dynamic measurements of threedimensional scapular kinematics: a validation study. J Biomech Eng 2001, 123(2):184- 190.

5. Wagner JM, Rhodes JA, Patten C: Reproducibility and minimal detectable change of three-dimensional kinematic analysis of reaching tasks in people with hemiparesis after stroke. Phys Ther 2008, 88(5):652-663.

6. Nadeau S, Kovacs S, Gravel D, Piotte F, Moffet H, Gagnon D, Hebert LJ: Active movement measurements of the shoulder girdle in healthy subjects with goniometer and tape measure techniques: a study on reliability and validity. Physiother Theory Pract 2007, 23(3):179-187.

7. Shimomura Y, Iwanaga K, Harada H, Katsuura T: Development and evaluation of the measurement system for the human shoulder joint based on the 6 DOF kinematic modelling. JPhysiol Anthropol Appl Hum Sci 2000, 19(1):43-51.

8. Triffitt PD, Wildin C, Hajioff D: The reproducibility of measurement of shoulder movement. Acta Orthop Scand 1999, 70(4):322-324.

9. Vermeulen HM, Stokdijk M, Eilers PH, Meskers CG, Rozing PM, Vliet Vlieland TP: Measurement of three dimensional shoulder movement patterns with an electromagnetic tracking device in patients with a frozen shoulder. Ann Rheum Dis 2002, 61(2): 115-120.

10. Illyes A, Kiss RM: Shoulder joint kinematics during elevation measured by ultrasoundbased measuring system. J Electromyogr Kinesiol 2007, 17(3):355-364.

11. Langenderfer JE, Rullkoetter PJ, Mell AG, Laz PJ: A multi-subject evaluation of uncertainty in anatomical landmark location on shoulder kinematic description. Comput Methods Biomech BiomedEngin 2009, 12(2):211-216. 
12. de Winter AF, Heemskerk MA, Terwee CB, Jans MP, Deville W, van Schaardenburg DJ, Scholten RJ, Bouter LM: Inter-observer reproducibility of measurements of range of motion in patients with shoulder pain using a digital inclinometer. BMC Musculoskelet Disord 2004, 5:18.

13. Terwee CB, de Winter AF, Scholten RJ, Jans MP, Deville W, van Schaardenburg D, Bouter LM: Interobserver reproducibility of the visual estimation of range of motion of the shoulder. Arch Phys MedRehabil 2005, 86(7): 1356-1361.

14. El-Zayat BF, Efe T, Heidrich A, Wolf U, Timmesfeld N, Heyse TJ, Lakemeier S, FuchsWinkelmann S, Schofer MD: Objective assessment of shoulder mobility with a new 3D gyroscope-a validation study. BMC Musculoskelet Disord 2011, 12:168.

15. Hudak PL, Amadio PC, Bombardier C, Beaton D, Cole D, Davis A, Hawker G, Katz JN, Makela M, Marx RG, et al: Development of an upper extremity outcome measure: The DASH (disabilities of the arm, shoulder, and head). Am JIndMed 1996, 29(6):602-608.

16. Huskisson EC, Donnelly S: Hyaluronic acid in the treatment of osteoarthritis of the knee. Rheumatology (Oxford) 1999, 38(7):602-607.

17. G2.sps ss: flash.lakeheadu.ca/ boconno2/gtheory/gtheory.html (downloaded 201005-16) 2010 .

18. Mushquash C, O'Connor BP: SPSS and SAS programs for generalizability theory analyses. BehavResMethods 2006, 38(3):542-547.

19. Jordan K, Dziedzic K, Jones PW, Ong BN, Dawes PT: The reliability of the threedimensional FASTRAK measurement system in measuring cervical spine and shoulder range of motion in healthy subjects. Rheumatology 2000, 39(4):382-388. 


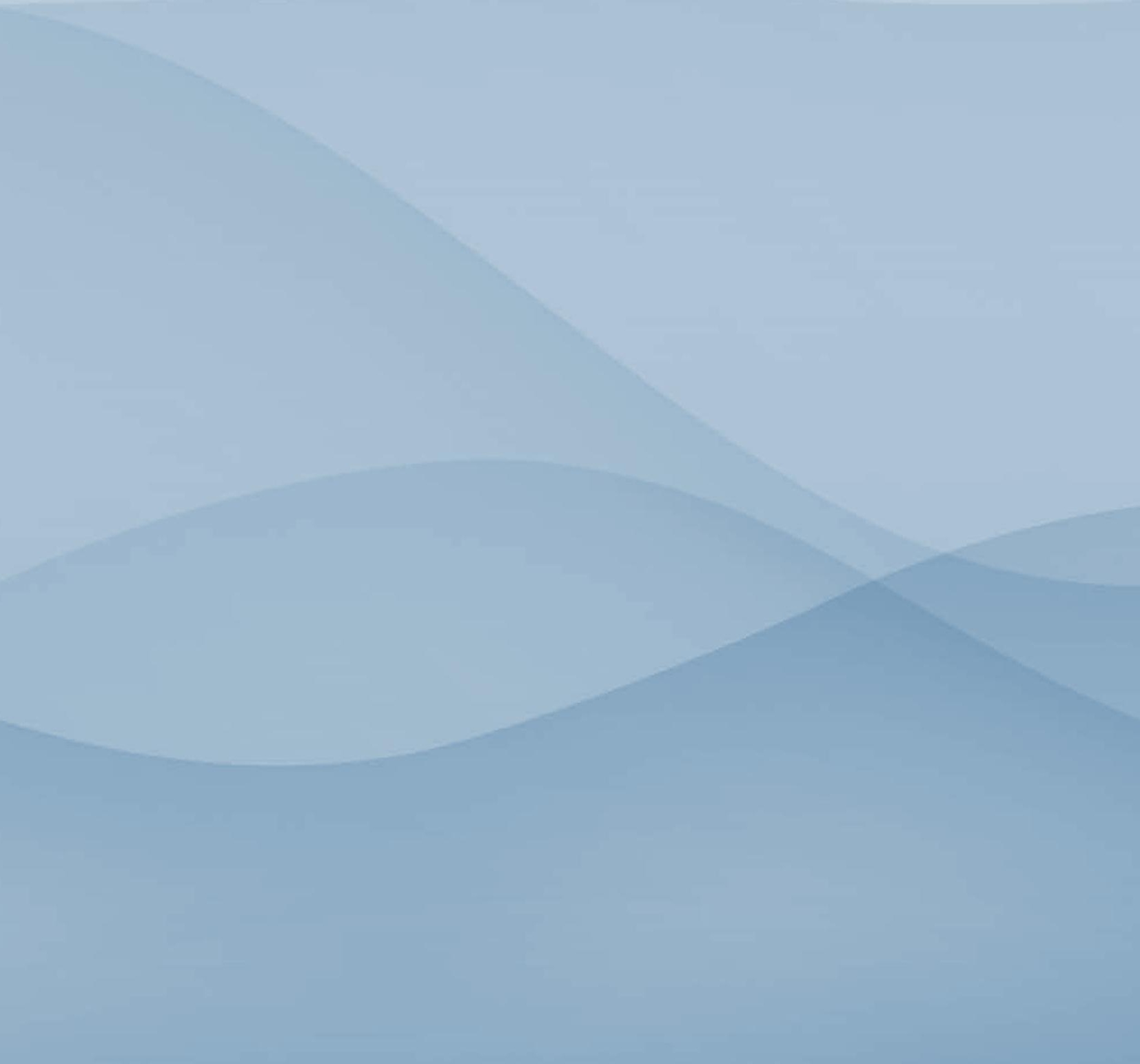


Chapter 8

General discussion 


\section{General discussion}

In this thesis we have addressed a number of research questions as posed in the general introduction concerning therapy and diagnosis in subacromial shoulder complaints. In this chapter we will focus on the research questions, the obtained answers and new questions that have appeared.

\section{Therapy}

1. What is the effectiveness of subacromial injections in subacromial impingement with respect to patient perceived pain, disability and function and is there a difference between corticosteroids and hyaluronic acid?

In the results of the RCT (chapter 2, results section) we found that injections are effective in reduction of pain and improvement of function in subacromial impingement. After 26 weeks we could not show a significant difference between groups of hyaluronic acid, corticosteroids and placebo, but we found that corticosteroids and placebo were more effective on patient perceived pain than hyaluronic acid. At short term, until 12 weeks, corticosteroids had a significantly better effect on patient perceived pain than placebo injections. In literature short term effects are described at four and six weeks after start of injection therapy. ${ }^{(1-10)}$

Concerning improvement in function and disability, we found equal results. Al secondary outcome measures used for assessment of function and disability went in the same direction as did the pain related outcome measures.

Only at 26 weeks there was some reduction in pain and improvement in function in the hyaluronic acid group although this can be explained by the natural course of the disease. In the literature some studies have shown an improvement in pain and function after injection of subacromial hyaluronic acid. ${ }^{(11-13)}$ Funk et al. used the same type of hyaluronic acid $\left(\right.$ Ostenil $\left.^{\circledR}\right)$, however, this study was published as a poster presentation at the 10th World congress on Osteoarthritis, we therefore were not able the further explore the differences in outcome. 
As depicted in Figure 1, reduction in pain in the placebo group may be seen as the natural course of disease. Although we were only able to discover a reduction in pain in the first weeks after injection of corticosteroids and not any more after 26 weeks, this is yet an important beneficial effect of the corticosteroid injections. Faster recovery in pain will restore the shoulder function quicker, and prevent the development of capsular limitations.

2. Do injections with a combination of hyaluronic acid and lidocaine give a better reduction in pain, disability and function than injections in which a placebo is combined with lidocaine?

In our trial we could not prove a significant improvement in pain and function after hyaluronic acid injections compared to placebo injections. (chapter 2, results section) At twelve weeks, the opposite was shown. The placebo group had a significant lower VAS score than the hyaluronic acid group. The hyaluronic acid group reported more disability than the placebo group. One reason for investigating the effectiveness of hyaluronic acid in the trial was the assumption that injections with hyaluronic acid could lead to a reduction in inflammation. We were however not able to prove this assumption. Published studies have stated varying effects of hyaluronic acid for different indications e.g. osteoarthritis of large joints, knee, hip, shoulder. ${ }^{(14,15)}$ A recent review states a conflict of interest in assessment of hyaluronic acid injections for osteoarthritis of the knee. Industry funded research was less likely to report negative results. ${ }^{(16)}$ In our study there was no funding of any kind.

In renal and pulmonary disease it has been shown that large molecular strands of hyaluronic acid are broken down in inflamed tissue. The presence of an inflamed bursa might therefore reverse the effectiveness of hyaluronic acid by breakdown of these large molecular strands into smaller ones. Strands of low molecular hyaluronic acid are believed to induce inflammation. ${ }^{(17)}$ 
3. Do injections with a combination of a corticosteroid and lidocaine give a better reduction in pain, disability and function than injections in which a placebo is combined with lidocaine?

In the RCT (chapter 2) we could prove a better and faster reduction in pain, function and disability in the corticosteroid group compared to the placebo group until twelve weeks after start of the injection therapy.

Lidocaine was added in all combined injections in all groups. For blinding purposes we choose to compare the additions (hyaluronic acid, corticosteroid and saline), Therefore, each injection consisted of $8 \mathrm{ml}$ of lidocaine $1 \%$ and an additional $2 \mathrm{ml}$ of study regimen. For comparability reasons we did not choose to compare with a placebo group consisting of $10 \mathrm{ml}$ lidocaine $1 \%$. As far as we know, saline does not have a therapeutic effect. We therefore choose saline as the placebo addition. By means of this addition we could compare the added saline hyaluronic acid and corticosteroid. The total amount of $10 \mathrm{ml}$ as well as the type of used needle for injection 19 Gauche (1.5 inch) was chosen to prevent sensation of difference in viscosity. Before start of the trial this was blindly tested on an orange. There was no difference in the experienced resistance during injection.

\section{Is there an accumulative effect of repeated injections with corticosteroids?}

In the RCT all patients were asked to complete a pain diary after each of the administered injections for a time period of three weeks. With the obtained data we were able to analyze the day by day results in the first 9 weeks of the trial.(Chapter 3, results section) Based on clinical experience and supported by literature on the effectiveness of injections in lateral epicondylitis of the elbow ${ }^{(18,19)}$ we suspected that the course of pain after a subacromial corticosteroid injection would give a rise in pain during the first days with an increased need for escape medication, followed by pain reduction. ${ }^{(20)}$ Analysis of our data however did not show such an increase in pain. On the contrary, we could show an immediate reduction in pain. This reduction lasted for approximately $8-10$ days. After these 10 days we found a slight increase in pain. In order to prove a cumulative effect of repeated corticosteroid injections we explored data of documented VAS scores after the second and third corticosteroid injection - see Figure 2. In the analysis of data we could show an accumulative effect of corticosteroid injections. After each of the three injections there was a further reduction in pain. 


\section{What is the optimum number of repetitions of subacromial injections?}

With the results of the pain diaries we were able to show a reduction in pain after each of the three corticosteroid injections.(Chapter 3 , results section) The reduction in pain was large after the first and second injection. After the third injection there was only a slight reduction in pain compared to the first and second corticosteroid injection - see Figure 2.

As far as we know there are no guidelines that state the minimum or maximum amount of subacromial injections for subacromial complaints based on studies after the effectivity of corticosteroids. Most guidelines advice to limit the number of injections based on fear for deterioration of cuff tissue. An animal study has shown the reversibility of effects of corticosteroids after three weeks. ${ }^{(21)}$ There is little data available on the incidence of cuff ruptures caused by subacromial corticosteroid injection. ${ }^{(22)}$

Our study showed that there is only a sparse effect after the third corticosteroid injection. Therefore, we would like to propose to limit the number of corticosteroid injections for an episode of subacromial bursitis to the maximum of two injections.

\section{Diagnosis}

6. Can the diagnostic and clinical value of the empty can and drop arm test for cuff disorders be improved by combining these tests with a subacromial injection containing corticosteroid and lidocaine?

The empty can and drop arm test were developed to detect cuff ruptures. In case of a subacromial impingement or bursitis the results of these tests presumably will be influenced by the perceived pain of the patient. Influence of pain therefore could lead to a higher number of false positive test results. In order to improve the test result of the drop arm and empty can test, we studied the effect of a subacromial injection with corticosteroid and lidocaine and investigated the combined test result of the empty can and drop arm test. Corticosteroids were added to the injection for treatment purposes, although there is some evidence that pain will increase after corticosteroid injection in the first hours and days after administration ${ }^{(13,20)}$, we could not prove this in the RCT 
(Chapter 3, results section) and therefore assumed this effect to be limited. The effect of the lidocaine, a supposed immediate relief of pain, was used for pain reduction and therefore used to improve the true positive interpretation of both single and combined application of the empty can and drop arm test.

We found a positive Neer test in $69 \%$ of our study population $(n=49)$. The results of the study showed an improvement in the specificity of both the empty can and drop arm test to respectively $67 \%$ and $95 \%$, combining the tests resulted in an improved specificity of $98 \%$ and loss of sensitivity of $44 \%$ after injection.(Chapter 4 , results section) Compared to literature our results showed lower sensitivity and specificity of the empty can test. ${ }^{(23,24)}$ For the drop arm test we found similar results. ${ }^{(25)}$ This is possibly explained because of a rather small study group and low number of cuff ruptures $(n=6)$ in the study population.

7. What is the diagnostic value of a gradation of the painful arc in subacromial impingement?

The painful arc in subacromial impingement is largely influenced by the amount of perceived pain and disturbance of glenohumeral and scapulothoracic motion. Based on clinical observations of a painful arc we found different degrees of pain and limitation of motion. We therefore proposed a classification of the painful arc. In the classification the painful arc was graded according to the amount of pain and observed motion. As far as we know no other attempts have been made to classify the painful arc in this way.

As part of the RCT described in chapter 2 patients were assessed for a painful arc. The painful arc was graded according to the proposed classification. In chapter 5 we describe the results of this classification.

At baseline all patients had a painful arc, during the course of the study there was a shift in the observed gradation. We found a positive correlation between the observed gradation of the painful arc and other observed outcome measures for pain (VAS score) and function. All observations of the painful arc and the grading of this observations were performed once and were carried out by the same physician. The study therefore has its limitations in respect to inter and intra observer variability ratings. The observed correlation with the other primary and secondary outcome measures however seems to be of use for clinical decision making. 


\section{To what extent differ the observations of the acromio-humeral distance on ultrasound} between experienced and non-experienced observers?

Narrowing of the acromio humeral distance (AHD) is an indicator for the subacromial impingement syndrome. In this study the AHD was investigated under different angles of measurement in abduction.(Chapter 6) We could prove that performance of the test in neutral and 60 degrees of abduction gave an inaccuracy of 1.1 and $1.4 \mathrm{~mm}$ respectively. This is acceptable when applying a threshold of $7 \mathrm{~mm}$. Ultrasound measurement has an advantage compared to X-ray examination because of fast and easy bilateral comparability. The difference however between the experienced and novice observer make this measurement of limited use in symptomatic patients compared to observations among healthy subjects.

9. What is the reproducibility of measuring anteflexion and abduction with a 3 dimensional gyroscope?

In this study we focused on the reproducibility of testing in symptomatic patients. We did not validate measurements of abduction and anteflexion. The 3 dimensional gyroscope showed reproducibility coefficients ranging from 0.96 to 0.99 , these results are excellent compared to other measurement techniques. ${ }^{(26)}$ (Chapter 7) We could prove that the 3 dimensional gyroscope is a reproducible instrument for measurement of shoulder anteflexion and abduction. A limitation in the use of this instrument was that data had to be sent to the manufacturer of the gyroscope, where data had to be processed (meanwhile this procedure has been improved). In the research setting this instrument could be of use. The group of El Zayat has validated the instrument for shoulder anteflexion and abduction in a laboratory setting. ${ }^{(27)}$

10. What could be a new strategy for the diagnosis and treatment of subacromial complaints based on the studies performed for this thesis?

In this thesis we investigated several aspects of subacromial impingement, focusing on diagnosis and injection therapy. There is a need for a simple and practically feasible strategy in the diagnosis and treatment of subacromial complaints for both first and 
second line healthcare, which is not expensive and easy to applicate. We therefore propose an algorithm based on the results in this thesis for the diagnosis and treatment of subacromial shoulder disorders. See figure 3.

We propose a flow diagram in which after standard noninvasive treatment, patients are examined by a physician. We propose to apply this algorithm to both first and second line healthcare.

In case of failure or limited effect of the applied physiotherapy and NSAIDs, the examination by the physician has the purpose to rule out an existing cuff rupture and Frozen shoulder. A pragmatic approach for this is to combine the subacromial injection with the empty can and drop arm test. The specificity of testing is improved and the treatment itself has started as well. After the evaluation of the effect of the injection, the decision should be made whether to repeat the injection or to expand the examination e.g. with an ultrasound examination. In case of a good result after subacromial injection we propose to repeat the injection, in case of bad result, no result or worsening we propose to have an ultrasound made. In case of effectiveness of the subacromial injection the treatment is ended, in case of persisting complaints surgical treatment could be considered. 


\section{Figures:}

Figure 1 - Mean VAS scores after injection at 0, 3 and 6 weeks (Derived from Chapter 2)

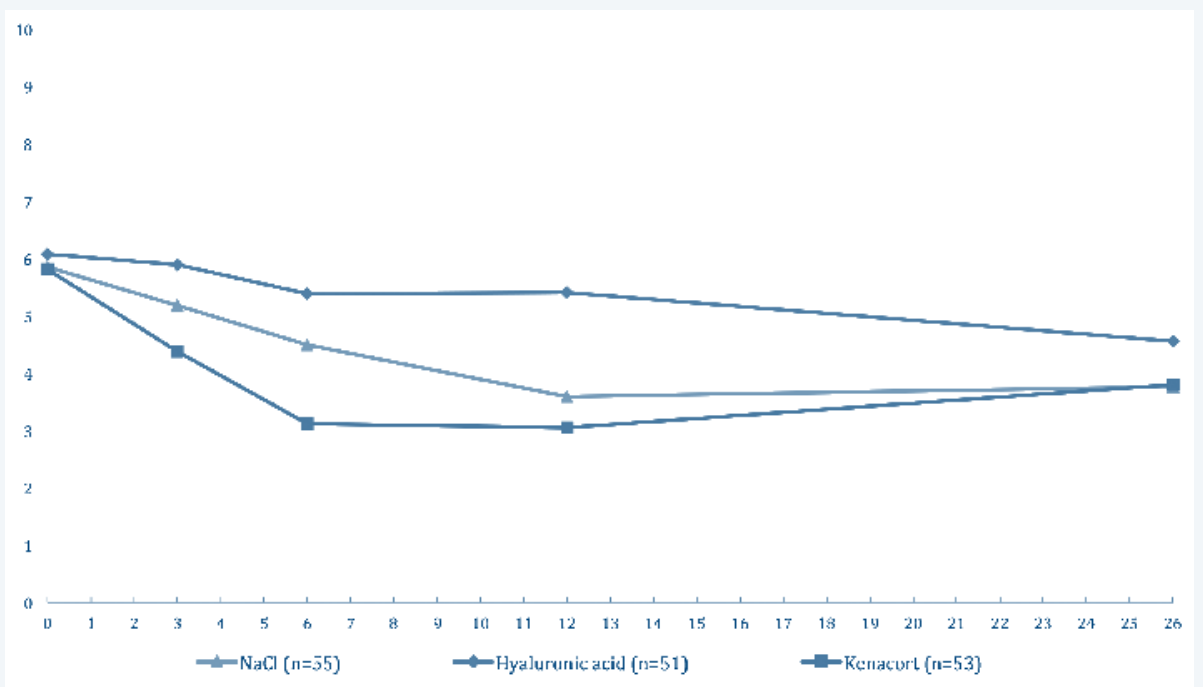

Figure 2 - Mean VAS scores in pain diary for Kenacort (Derived from chapter 3)

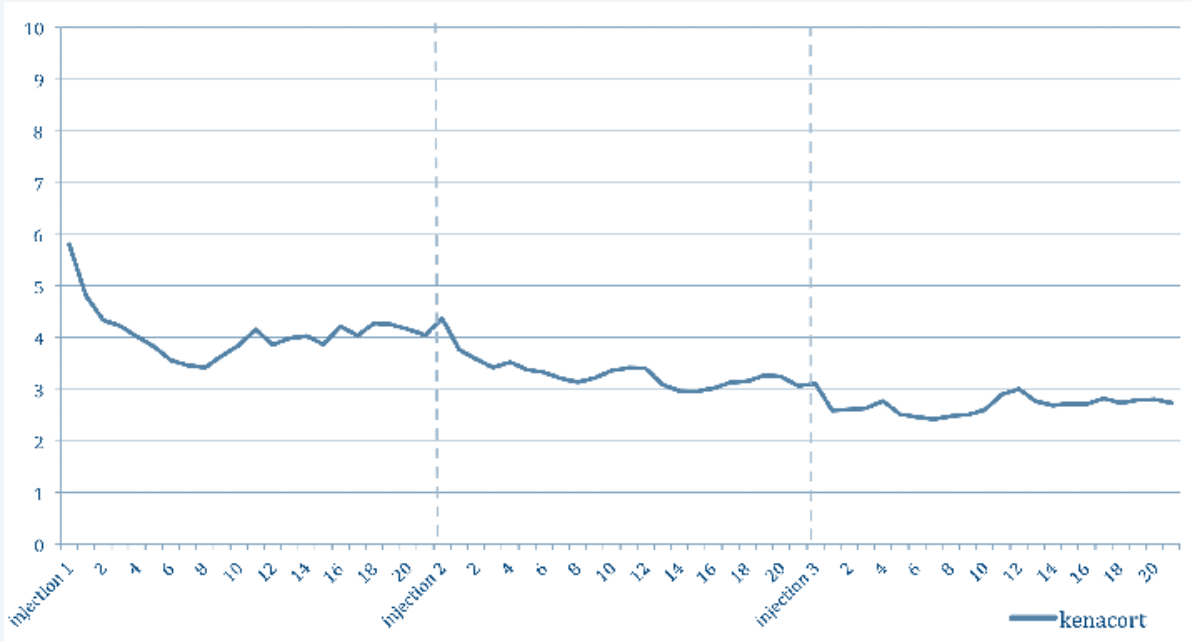


Figure 3 - treatment algorithm for subacromial disorders

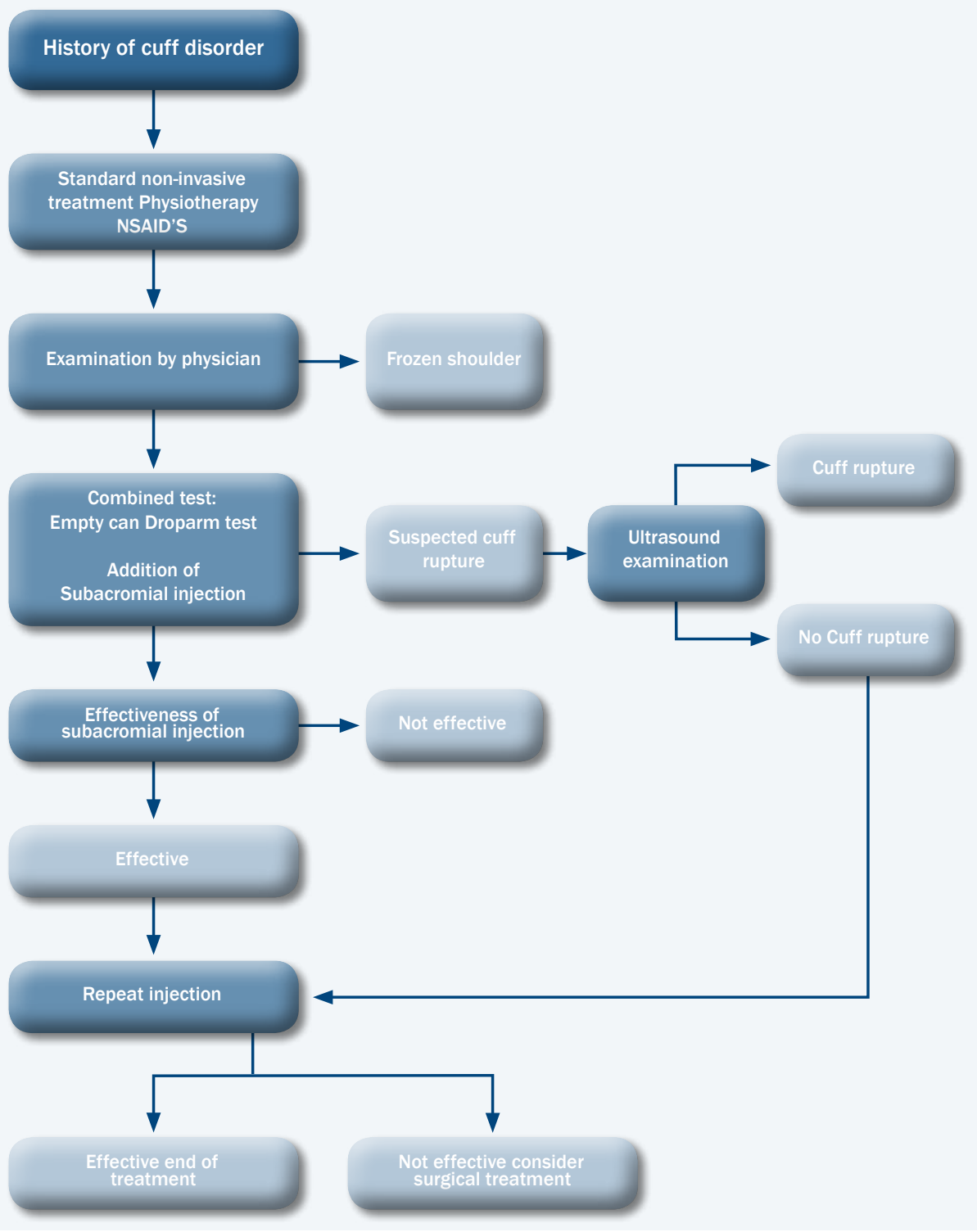




\section{References}

1. Buchbinder, R., S. Green, and J.M. Youd, Corticosteroid injections for shoulder pain. Cochrane Database Syst Rev, 2003(1): p. CD004016.

2. Dogu, B., et al., Blind or ultrasound-guided corticosteroid injections and short-term response in subacromial impingement syndrome: a randomized, double-blind, prospective study. Am J Phys Med Rehabil, 2012. 91(8): p. 658-65.

3. Kim, Y.S., et al., Does hyaluronate injection work in shoulder disease in early stage? A multicenter, randomized, single blind and open comparative clinical study. J Shoulder Elbow Surg, 2012. 21(6): p. 722-7.

4. Johansson, K., et al., Subacromial corticosteroid injection or acupuncture with home exercises when treating patients with subacromial impingement in primary care--a randomized clinical trial. Fam Pract, 2011. 28(4): p. 355-65.

5. Ekeberg, O.M., et al., Subacromial ultrasound guided or systemic steroid injection for rotator cuff disease: randomised double blind study. BMJ, 2009. 338: p. a3112.

6. Crawshaw, D.P., et al., Exercise therapy after corticosteroid injection for moderate to severe shoulder pain: large pragmatic randomised trial. Bmj. 340: p. c3037.

7. Alvarez, C.M., et al., A prospective, double-blind, randomized clinical trial comparing subacromial injection of betamethasone and xylocaine to xylocaine alone in chronic rotator cuff tendinosis. Am J Sports Med, 2005. 33(2): p. 255-62.

8. Akgün, K., M. Birtane, and Ü. Akarırmak, Is local subacromial corticosteroid injection beneficial in subacromial impingement syndrome? Clinical Rheumatology, 2004. 23(6): p. 496-500.

9. Naredo, E., et al., A randomized comparative study of short term response to blind injection versus sonographic-guided injection of local corticosteroids in patients with painful shoulder. J Rheumatol, 2004. 31(2): p. 308-14.

10. Hay, E.M., et al., A pragmatic randomised controlled trial of local corticosteroid injection and physiotherapy for the treatment of new episodes of unilateral shoulder pain in primary care. Ann Rheum Dis, 2003. 62(5): p. 394-9.

11. Itokazu, M. and T. Matsunaga, Clinical evaluation of high-molecular-weight sodium hyaluronate for the treatment of patients with periarthritis of the shoulder. Clin Ther, 1995. 17(5): p. 946-55. 
12. Shibata, Y., et al., Clinical evaluation of sodium hyaluronate for the treatment of patients with rotator cuff tear. J Shoulder Elbow Surg, 2001. 10(3): p. 209-16.

13. Funk, P153 Hyaluronan vs. steroid injection for subacromial impingement of the shoulder. Osteoarthritis and Cartilage, 2005. 13: p. S80.

14. van den Bekerom, M.P., et al., What is the evidence for viscosupplementation in the treatment of patients with hip osteoarthritis? Systematic review of the literature. Arch Orthop Trauma Surg, 2008. 128(8): p. 815-23.

15. van der Weegen, W., et al., No Difference Between Intra-Articular Injection of Hyaluronic Acid and Placebo for Mild to Moderate Knee Osteoarthritis: A Randomized, Controlled, Double-Blind Trial. J Arthroplasty, 2014.

16. Printz, J.O., et al., Conflict of interest in the assessment of hyaluronic acid injections for osteoarthritis of the knee: an updated systematic review. J Arthroplasty, 2013. 28(8 Suppl): p. 30-33 e1.

17. Noble, P.W., Hyaluronan and its catabolic products in tissue injury and repair. Matrix Biology, 2002. 21(1): p. 25-29.

18. Verhaar, J.A., et al., Local corticosteroid injection versus Cyriax-type physiotherapy for tennis elbow. J Bone Joint Surg Br, 1996. 78(1): p. 128-32.

19. Sims, S.E., et al., Non-surgical treatment of lateral epicondylitis: a systematic review of randomized controlled trials. Hand (N Y), 2014. 9(4): p. 419-46.

20. Lewis, M., et al., Local steroid injections for tennis elbow: does the pain get worse before it gets better?: Results from a randomized controlled trial. Clin J Pain, 2005. 21(4): p. 330-4.

21. Mikolyzk, D.K., et al., Effect of Corticosteroids on the Biomechanical Strength of Rat Rotator Cuff Tendon. The Journal of Bone \& Joint Surgery, 2009. 91(5): p. 1172-1180.

22. Bhatia, M., et al., Correlation between rotator cuff tears and repeated subacromial steroid injections: a case-controlled study. Ann R Coll Surg Engl, 2009. 91(5): p. 414-6.

23. Alqunaee, M., R. Galvin, and T. Fahey, Diagnostic accuracy of clinical tests for subacromial impingement syndrome: a systematic review and meta-analysis. Arch Phys Med Rehabil, 2012. 93(2): p. 229-36.

24. Itoi, E., et al., Which is more useful, the "full can test" or the "empty can test," in detecting the torn supraspinatus tendon? Am J Sports Med, 1999. 27(1): p. 65-8.

25. Birtane, M., M. Calis, and K. Akgun, The diagnostic value of magnetic resonance imaging in subacromial impingement syndrome. Yonsei Med J, 2001. 42(4): p. 418-24. 
26. Penning, L.I., et al., Reproducibility of a 3-dimensional gyroscope in measuring shoulder anteflexion and abduction. BMC Musculoskelet Disord, 2012. 13: p. 135.

27. El-Zayat, B.F., et al., Objective assessment of shoulder mobility with a new 3D gyroscope-a validation study. BMC Musculoskelet Disord, 2011. 12: p. 168. 


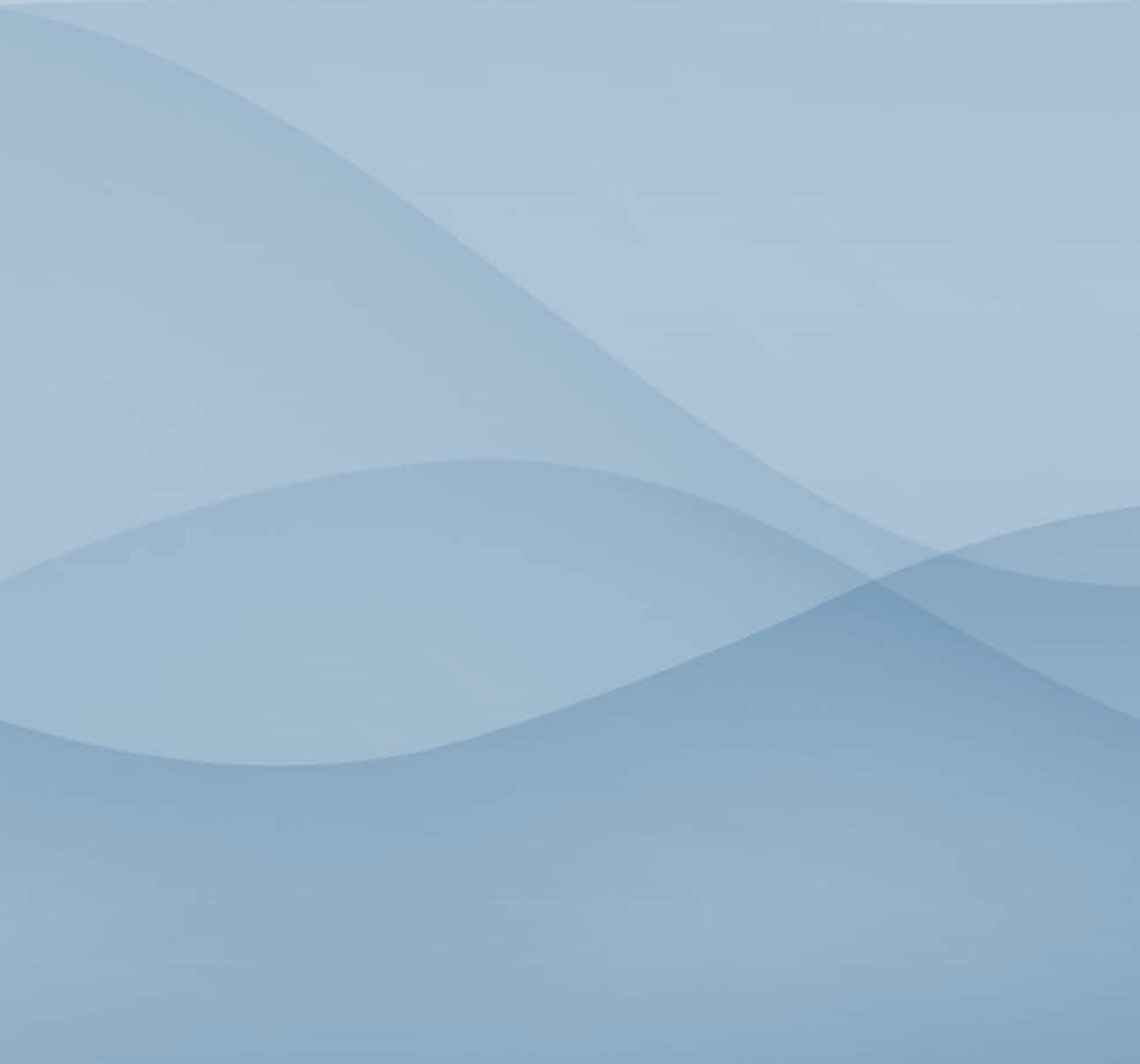




\section{Chapter 9}

\section{Summary}

Nederlandse samenvatting 


\section{Summary}

\section{Chapter 1}

Shoulder disorders are frequently encountered in first and second line healthcare. In this chapter we give an outline of different causes and sources of shoulder disorders. An overview is given on common used conservative treatment strategies in first line health care. We address the limitations of currently available physical diagnostic tests for cuff disorders.

In case of failure of conservative treatment there is a tendency to administer subacromial corticosteroid injections. We describe the use, effect and possible side effects of corticosteroid injections. Next to corticosteroid injections use of hyaluronic acid injections for shoulder disorders is described.

We give an overview of this thesis in respect to the performed RCT, the studies we have performed to improve clinical testing in shoulder disorders and the aim to develop a simple diagnostic and treatment strategy in shoulder disorders for both first and second line healthcare.

The chapter is closed with an outline of the aims and questions addressed in this thesis.

\section{Chapter 2}

In this chapter we describe the results of an RCT investigating the effectiveness of subacromial injections with hyaluronic acid an corticosteroids compared to saline (placebo) injections. We give a short overview of the Guideline used by the Dutch General Practioners (NHG). For the trial 159 patients were included and randomized over three treatment groups. In these groups patients were treated with $8 \mathrm{ml}$ lidocaine and either $2 \mathrm{ml}$ of corticosteroid, hyaluronic acid or saline. We postulated a reduction in pain of $70 \%$ after 26 weeks for the groups treated with hyaluronic acid and corticosteroid and a reduction in pain of $50 \%$ in the saline group.

Both patients and investigating physician were blinded for the treatment group, the analysis of data was performed blinded as well. Patients received up to three injections.

The primary outcome measure consisted of pain measured on a VAS score, secondary outcome consisted of pain full arc, range of motion, Constant shoulder score, patient 
specific disability, Shoulder disability questionnaire, shoulder pain score and the functional mobility test.

Corticosteroid injections gave a better reduction in pain than did hyaluronic acid and saline injections during the first 12 weeks of the trial. At 26 weeks there were no significant differences between groups. The mean reduction in pain at 26 weeks was $20 \%$ for the corticosteroid group, $15 \%$ for the hyaluronic acid group and $21 \%$ for the Saline group. We therefore were not able to prove the postulated reduction in pain of $70 \%$ and $50 \%$ respectively.

The results of the trial did not support the clinical use of hyaluronic acid for subacromial impingement. The corticosteroid injections proved to be effective at short term.

\section{Chapter 3}

In the study described in this chapter we investigated the effect of subacromial injections during the first days after injection. All patients of the in chapter 2 described RCT were asked to fill out a pain diary. Primary outcome consisted of pain on a VAS score during the 21 days after injection. Secondary outcome consisted of the number of taken escape medication and adverse effects.

The corticosteroid group showed the largest reduction in pain during the first week after injection compared to hyaluronic acid and saline. The effect of the corticosteroid injections was best after the first injection. Administration of a second corticosteroid injection gave a further reduction in pain, although the effect was not as large as the effect of the first injection. The third corticosteroid injection only gave a slight further reduction in pain. Only the corticosteroid group showed the above described booster effect after repeated subacromial injection. Based on the results of this study, where the best reduction in pain was achieved after two corticosteroid injections we questioned whether more than two subacromial corticosteroid injections should be administered in case of subacromial impingement.

\section{Chapter 4}

Shoulder disorders are common in the general population. Cuff disorders are a frequent cause of shoulder disorders. The clinical accuracy of shoulder tests for cuff 
disorders is still limited. In this chapter we describe the results of a study performed to improve clinical accuracy of individual tests, the drop arm and empty can test, by combining them and adding a subacromial injection. For this study 49 patients were prospectively assessed. All patients were diagnosed with subacromial impingement. The empty can and drop arm test were performed before and after subacromial injection. Ultrasound was used as reference test in this study.

Data were analyzed for both individual tests and combined test results. The combined test results were obtained after applying a rule for parallel testing. Accordingly at least one of the combined individual tests had to be positive for a positive result of the combined test.

The ultrasound found six cuff ruptures. Specificity improved and sensitivity decreased after subacromial injection. Combining of test results led to an improvement in sensitivity and specificity without subacromial injection.

\section{Chapter 5}

A rather typical feature of subacromial complaints is the painful and disturbed glenohumeral and scapulothoracic movement in the frontal plane described as a painful arc. In this chapter we propose a classification and grading system for the painful arc based on the amount of patient perceived pain and disturbance of glenohumeral and scapulothoracic motion. As a part of the RCT described in chapter 2 all patients were scored for a painful arc and all painful arc observations were graded according to the proposed classification. Data were compared in a linear regression analysis to VAS scores and secondary outcome measures of the RCT. We found a positive correlation between the gradation of the painful arc and the observed outcome measures.

\section{Chapter 6}

The acromiohumeral distance (AHD) is a three dimensional distance and is influenced by rotator cuff tears, fatty degeneration and atrophy of the cuff. Radio graphical assessment of the AHD is limited to two dimensions and affected by patient positioning and beam direction. In this chapter we describe a reliability study performed to assess the ultrasound measurement of AHD in symptomatic patients. A total of 43 patients suffering from subacromial impingement were recruited for this study. The ultrasound measurements were performed in neutral and 60 degrees abduction position. 
Two observers with different experience in ultrasound performed the assessment. The inter and intra observer reliability of ultrasound AHD measurement in subacromial impingement was slightly better in the experienced observer. The intra observer reliability was excellent in neutral position, the inter observer reliability was good. The results of this study showed that ultrasound AHD measurements were less accurate in patients with subacromial impingement as in those reported in healthy subjects.

\section{Chapter 7}

Reproducible measurement of active and passive range of motion (ROM) is essential in diagnosis and evaluation of shoulder disorders. Several techniques have been developed for measurement of range of motion varying from visual estimation to placement of multiple sensors on bony landmarks. In this chapter we present the results of the reproducibility of range of motion measurements with a three dimensional gyroscope. 58 patients participated in this multicenter study, they suffered either from subacromial impingement or had been diagnosed with osteoarthritis of their shoulder. Active anteflexion and abduction were measured with a three dimensional gyroscope according to a test and retest protocol. Measurements were taken of the affected and contralateral side.

The three dimensional gyroscope showed good to excellent reproducibility for measurement of anteflexion and abduction. An average of two repetitions was needed for sound reproducibility.

\section{Chapter 8}

In this chapter we address the questions as posed in the general introduction. They handle issues concerning therapy and diagnosis in shoulder complaints.

Corticosteroid injections have a significantly better effect on patient perceived pain and function than hyaluronic acid and placebo injections during the first three months. We could not prove a significant effect of hyaluronic acid injections on patient perceived pain or function compared to placebo injections. We were not able to prove the assumption that hyaluronic acid injections would lead to a reduction of inflammation.

We were able to show an accumulative effect of repeated corticosteroid injections. After two repeated injections of corticosteroids the optimum effect is reached, further repetition of corticosteroid injection only showed a sparse effect. 
For the diagnosis of cuff disorders detection of cuff ruptures is essential. The empty can and drop arm tests have shown improved sensitivity and specificity when their individual test results are combined. Addition of a subacromial anesthetic leads to an improvement of the specificity of individual tests.

The proposed classification for the painful arc showed a positive correlation with other observed outcome measures concerning pain and function.

Measuring the acromiohumeral distance on ultrasound is of limited use in symptomatic patients compared to healthy subjects.

Measurement of anteflexion and abduction with a three-dimensional gyroscope in symptomatic patients leads to excellent reproducibility coefficients compared to other measurement techniques.

Based on the results found in the conducted studies for this thesis we have proposed an algorithm for diagnosis and treatment of cuff disorders. 


\section{Nederlandse Samenvatting}

\section{Hoofdstuk 1}

Schouderklachten worden veelvuldig gezien in de eerste en tweede lijns gezondheidszorg. In dit hoofdstuk geven we een overzicht van de verschillende oorzaken van schouderklachten. We beschrijven gebruikelijke conservatieve behandelstrategieën in de eerstelijns gezondheidszorg en we benoemen de beperkingen van huidige beschikbare klinische testen voor cuff problemen.

Indien conservatieve therapie faalt wordt veelal gebruik gemaakt van subacromiale corticosteroïd injecties. We beschrijven de toepassing, de effectiviteit en eventuele bijwerkingen van corticosteroïd injecties. We beschrijven dat naast corticosteroïd injecties ook behandeling met hyaluronzuur voor schouderklachten toegepast wordt.

We geven een overzicht van het proefschrift met betrekking tot de uitgevoerde RCT en de naar optimalisatie van klinische diagnostiek uitgevoerde studies. Daarnaast beschrijven we het doel van het proefschrift om een eenvoudige behandelstrategie te ontwikkelen voor schouderklachten in de eerste en tweedelijns gezondheidszorg.

Het hoofdstuk eindigt met een opsomming van de doelen en vragen zoals beantwoord in dit proefschrift.

\section{Hoofdstuk 2}

In dit hoofdstuk beschrijven we de resultaten van een gerandomiseerde trial. In deze trial wordt de effectiviteit van injecties met hyaluronzuur of corticosteroïden vergeleken met $\mathrm{NaCl}$ (placebo). We geven een kort overzicht met betrekking tot de richtlijn van Het Nederlands Huisarts Genootschap (NHG). Voor deze trial werden 159 patiënten geïncludeerd en gerandomiseerd over 3 behandelgroepen. In deze behandelgroepen werden patiënten behandeld met $8 \mathrm{ml}$ lidocaïne en $2 \mathrm{ml}$ corticosteroïd, hyaluronzuur of $\mathrm{NaCl}$. In onze hypothese veronderstelden we een reductie in pijn van $70 \%$ voor de groepen hyaluronzuur en corticosterö̈den en een reductie in pijn van $50 \%$ bij de $\mathrm{NaCl}$ groep.

Zowel de patiënten als de arts / onderzoeker waren geblindeerd voor de behandelgroep. Ook de analyse van de data werd geblindeerd uitgevoerd. De patiënten werden met maximaal drie injecties behandeld. 
De primaire uitkomstmaat bestond uit pijn, gemeten op een VAS schaal. De secundaire uitkomstmaten bestonden uit: painful arc, bewegingsuitslagen, Constant schouder score, patiënt specifieke beperking, shoulder disability questionnaire, schouder pijn score en de functional mobility test.

Corticosteroïd injecties gaven een betere reductie van pijn gedurende de eerste 12 weken van de trial dan hyaluronzuur en $\mathrm{NaCl}$. $\mathrm{Na} 26$ weken bestond er geen significant verschil meer tussen de groepen. De gemiddelde reductie van pijn na 26 weken was $20 \%$ voor de corticosteroïdgroep, $15 \%$ voor de hyaluronzuurgroep en $21 \%$ voor de $\mathrm{NaCl}$ groep. We konden op basis hiervan de eerder gestelde hypothese van een pijnreductie van respectievelijk $70 \%$ en $50 \%$ niet bewijzen.

Op basis van de resultaten van de trial is er onvoldoende ondersteuning voor de klinische toepassing van hyaluronzuur bij subacromiaal impingement. Corticosteroïd injecties zijn bewezen effectief op korte termijn.

\section{Hoofdstuk 3}

In het onderzoek dat we in dit hoofdstuk beschrijven hebben we onderzocht wat het effect is van subacromiale injecties gedurende de eerste dagen na injectie. Alle patiënten van de in hoofdstuk 2 beschreven RCT werd gevraagd om een pijndagboek bij te houden. De primaire uitkomstmaat bestond uit de pijn op een VAS score tijdens de eerste 21 dagen na een injectie. De secundaire uitkomstmaat bestond uit de hoeveelheid extra ingenomen pijnstillers en de eventuele bijwerkingen.

De corticosteroïdgroep had de grootste vermindering van pijn gedurende de eerste week na injectie in vergelijking met de hyaluronzuur groep en de $\mathrm{NaCl}$ groep. Het effect van de corticosteroïd injecties was het grootste na de eerste injectie. Het toedienen van een tweede corticosteroïd injectie gaf een verdere vermindering van de pijn, alhoewel het effect minder groot was dan na de eerste injectie. De derde corticosteroïd injectie gaf slechts een lichte vermindering van de pijnklachten. Alleen in de corticosteroïdgroep vonden we het booster effect zoals hierboven beschreven na herhaalde corticosteroïd injecties. Op basis van de resultaten van dit onderzoek, waarbij de grootste pijnvermindering werd bereikt na 2 corticosteroïd injecties vragen we ons af of het noodzakelijk is om meer dan 2 injecties te plaatsen bij subacromiaal impingement. 


\section{Hoofdstuk 4}

Schouderklachten komen vaak voor in de bevolking. Cuff problemen zijn vaak een veroorzaker van deze schouderklachten. De klinische accuratesse van beschikbare schoudertesten is tot op heden beperkt. In dit hoofdstuk beschrijven we de resultaten van een onderzoek wat uitgevoerd is om de betrouwbaarheid van de empty can en drop arm testen te verbeteren door deze te combineren en een subacromiale injectie toe te voegen. Voor deze studie werden 49 patiënten prospectief onderzocht. Alle patiënten werden gediagnosticeerd met subacromiaal impingement. De empty can en drop arm test werden uitgevoerd voor en na een subacromiale injectie. Echografie werd als referentietest gebruikt.

De data werden zowel voor de afzonderlijke testen als voor de gecombineerde testen geanalyseerd. Voor de analyse van de gecombineerde testresultaten werd een regel voor parallel testen toegepast. Naar analogie van deze regel moest er minstens een van de gecombineerde testen een positief testresultaat hebben om tot een positief testresultaat te leiden voor de gecombineerde testen. Bij de echografie werden zes cuffrupturen gevonden. De specificiteit verbeterde en de sensitiviteit verminderde na een subacromiale injectie. Bij het gecombineerde testresultaat was er zonder injectie sprake van een verbetering van zowel de sensitiviteit als de specificiteit.

\section{Hoofdstuk 5}

Een opvallende bevinding bij subacromiale klachten is de painful arc, een pijnlijke en verstoorde scapulothoracale en glenohumerale bewegelijkheid in het frontale vlak. In dit hoofdstuk beschrijven we het voorstel voor een classificatie en graderingssysteem van de painful arc gebaseerd op de door de patiënt ervaren hoeveelheid pijn en verstoring van het glenohumerale en scapulothoracale bewegingspatroon. Als onderdeel van de in hoofdstuk 2 beschreven RCT werd bij alle patiënten de painful arc gescoord. De geobserveerde painful arc werd gegradeerd volgens de voorgestelde classificatie. De data werden in een lineaire regressie analyse vergeleken met de VAS score en de andere uitkomstmaten van de RCT. We vonden een positieve correlatie tussen de gradatie van de painful arc en de geobserveerde uitkomstmaten. 


\section{Hoofdstuk 6}

De afstand tussen humerus en acromion, ook wel acromio humerale afstand (AHA), is een driedimensionale afstand. Deze wordt beïnvloed door peesscheuren, vettige degeneratie en atrofie van de rotatoren manchet. Röntgenonderzoek van de AHA is beperkt tot 2 dimensies en wordt bepaald door patiëntpositie en de richting van de röntgenstraal. In dit hoofdstuk beschrijven we een betrouwbaarheids studie welke werd uitgevoerd om de betrouwbaarheid te onderzoeken van echografische AHA metingen bij symptomatische patiënten. In totaal werden 43 patiënten met subacromiaal impingement geïncludeerd in dit onderzoek. De echografische metingen werden zowel in neutrale als 60 graden abductiepositie uitgevoerd. Het echografisch onderzoek werd uitgevoerd door twee onderzoekers. Er bestond een verschil tussen de onderzoekers met betrekking tot de echografische ervaring. De inter en intra observer betrouwbaarheid van de echografische AHA metingen bij symptomatische patiënten was iets beter bij de meer ervaren onderzoeker. De intra observer betrouwbaarheid was excellent in neutrale positie, de inter observer betrouwbaarheid was goed. De resultaten van dit onderzoek laten minder betrouwbare echografische AHA metingen zien bij symptomatische patiënten dan bij gezonde individuen.

\section{Hoofdstuk 7}

Reproduceerbare metingen van bewegingsuitslagen zijn van essentieel belang voor de diagnose en evaluatie van schouderklachten. Er zijn verschillende technieken ontwikkeld om bewegingsuitslagen te meten. Deze variëren van visuele schatting, tot het plaatsen van sensors op benige oriëntatiepunten. In dit hoofdstuk presenteren we de resultaten van de reproduceerbaarheid van meting van bewegingsuitslagen met een driedimensionale gyroscoop. Aan dit onderzoek namen 58 patiënten deel afkomstig uit verschillende centra. Zij hadden last van subacromiaal impingement of artrose van hun schouder. Actieve anteflexie en abductie werden gemeten met een driedimensionale gyroscoop volgens een test en her-test protocol. Metingen werden zowel bij de aangedane als niet aangedane zijde verricht.

Met de driedimensionale gyroscoop werd een goede tot excellente reproduceerbaarheid gevonden bij metingen van anteflexie en abductie. Er waren gemiddeld 2 herhalingen nodig voor een goede reproduceerbaarheid 


\section{Hoofdstuk 8}

In dit hoofdstuk behandelen we de antwoorden op de vragen welke gesteld werden in de introductie van het proefschrift. De vragen betreffen issues aangaande therapie en behandeling van schouderklachten.

Corticosteroïdinjecties hebben een significant beter effect op pijn en functie dan hyaluronzuur en placebo injecties gedurende de eerste drie maanden. We konden niet aantonen dat hyaluronzuur injecties een significant beter effect hebben op pijn en functie dan placebo injecties. We waren niet in staat om de veronderstelling te bewijzen dat hyaluronzuur injecties leiden tot een vermindering van ontstekingsreactie.

We konden wel aantonen dat het herhalen van corticosteroïd injecties leidt tot een accumulatief effect. Na twee injecties lijkt het optimale effect te zijn bereikt. Het toedienen van een extra injectie geeft maar weinig extra vermindering van pijn.

Het is van essentieel belang voor de diagnose van cuff problematiek om cuff scheuren uit te sluiten.

De empty can en drop arm testen hebben een bewezen hogere sensitiviteit en specificiteit wanneer deze testen gecombineerd uitgevoerd worden. De toevoeging van een lokale verdovende subacromiale injectie leidt tot een verbetering van de specificiteit van de afzonderlijke testen.

Het voor de painful arc voorgestelde classificatiesysteem liet een positieve correlatie zien in vergelijking met de andere uitkomstmaten voor de score van pijn en functie.

Het meten van de acromio humerale afstand met behulp van echografie is van beperkte waarde gebleken bij symptomatische patiënten in vergelijking met gezonde individuen.

Het meten van de anteflexie en abductie met een drie dimensionale gyroscoop bij symptomatische patiënten geeft excellente reproduceerbaarheids coëfficiënten in vergelijking met andere meettechnieken.

Op basis van de resultaten van de onderzoeken uit dit proefschrift hebben we een voorstel geformuleerd voor een algoritme voor de diagnose en behandeling van subacromiale schouderklachten. 


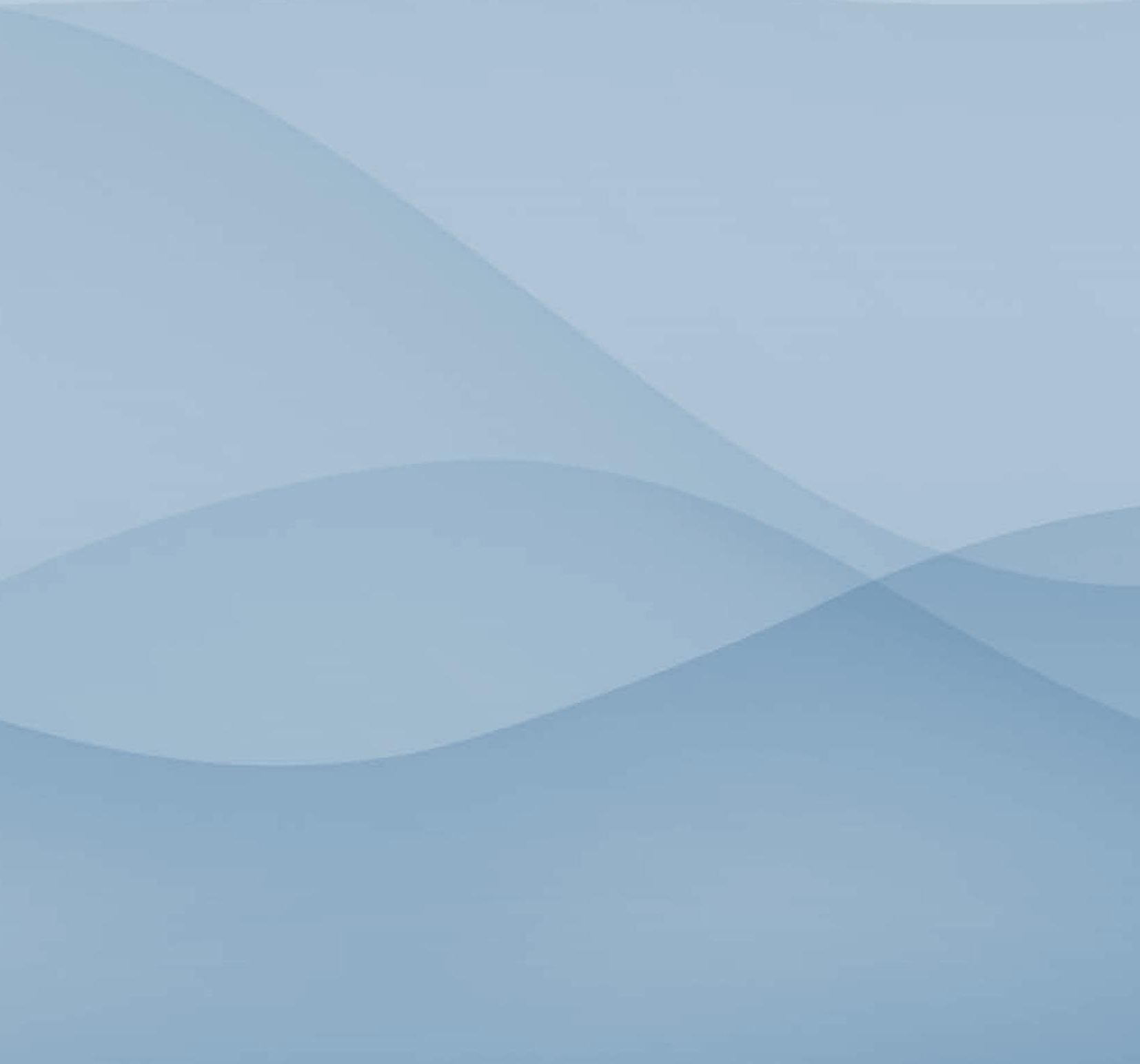


Acknowledgements

Curriculum Vitae

Valorisation 


\section{Acknowledgements}

$\mathrm{Nu}$ het proefschrift voltooid is, komt er tijd om te reflecteren op de voorbije periode. In deze aanzienlijke periode heb ik kennis gemaakt met de diverse aspecten van het uitvoeren van wetenschappelijk onderzoek. In de verschillende fases van het onderzoek ben ik door vele mensen bijgestaan, ik ben hen, wel of niet nader genoemd, hier zeer erkentelijk voor. Enkele van deze mensen zou ik in het bijzonder willen benoemen.

De leden van de leescommissie: ik ben u dankbaar voor uw bereidheid het proefschrift te willen beoordelen.

Mijn promotoren: Professor GHIM Walenkamp, beste Geert, ik ben je dankbaar voor je onvoorwaardelijke steun tijdens het promotietraject. Door je voortdurend kritische houding ten aanzien van het werk heb je me gestimuleerd om het werk tot een hoger abstractieniveau te brengen. Ik kwam daarvoor graag terug naar Maastricht.

Professor RA de Bie, beste Rob, je bent vrijwel van het eerste uur bij het project betrokken geweest, je genuanceerde houding en uitermate praktische en creatieve oplossingen hebben geleid tot een goede balans in de promotie.

De patiënten: Een gerandomiseerde klinische trial is niet uit te voeren zonder patiënten. Daar het bijzonder lastig bleek om voldoende personen te werven, ben ik de patiënten die deel hebben genomen aan de onderzoeken des te erkentelijker voor hun deelname.

De polikliniek orthopedie van het AzM: Zonder jullie was het niet gelukt om de trial geblindeerd uit te voeren. Trouw hebben jullie je gehouden aan alle regeltjes die ik had bedacht om te zorgen dat ik mijzelf niet kon de-blinderen en dat de deelnemende patiënten geblindeerd bleven. Jullie hebben alle spuiten telkens weer voor mij voorbereid en afgeplakt met tape zodat ik niet kon zien wat er in zat.

Het Trialbureau van het AzM: Liesbeth Jütten, Margareth Winants, dr. Nick Guldemond, dr. Caroline Speksnijders, dr. Ilona Punt, stuk voor stuk hebben jullie mij 
in de eerste uren van het onderzoek maar ook daarna geholpen om te leren bewegen in de jungle van het wetenschappelijk onderzoek. Liesbeth, bedankt voor het vullen van de studie enveloppen en het bewaken van de randomisatielijsten. Nick, bedankt voor je hulp bij het artikel over de 'Minimod'

Mijn Co-auteurs: Pieter Leffers, dr. René Weijers, dr. Bart Pijls, bedankt voor de samenwerking bij het uitvoeren van de onderzoeken en het schrijven van de artikelen.

Mijn Opleiders: Professor Ruud Geesink, Dr. André van Ooij, Professor Geert Walenkamp, Professor Lodewijk van Rhijn en Aart Verburg, dank jullie wel voor de wijze waarop jullie mij het orthopedisch vak hebben bijgebracht en de ruimte die jullie mij binnen de opleiding hebben geboden om te kunnen werken aan het onderzoek.

Mijn opleidersgroepen: De Maastrichtse opleidingsgroep: Dr René ten Broeke, dr. Henk Arens, Heleen Staal, Jan Geurts, dr. Pieter Emans, Joris Hermus, Peter Fezcko, Professor dr. Sjoerd Bulstra, Mike van Steijn en dr. Paul Willems. Dank jullie wel voor alle kennis die jullie mij hebben bijgebracht ten aanzien van de orthopedie.

De Sittardse opleidingsgroep: Frits Draijer, Hans van Os, dr. Nanne Kort en Pieter Tillman. Dank voor de ruimte die jullie mij in jullie drukke praktijk hebben geboden om te kunnen werken aan mijn Maastrichtse onderzoek.

Mijn collega assistenten in de Maastrichtse periode: dank jullie wel voor de hulp bij het werven van de patiënten voor de RCT en de ruimte die jullie mij gegeven hebben als ik een 'burger' dag had en bezig was met het onderzoek.

Mijn collega's in de Sint Maartenskliniek in Nijmegen: Dr. Bart Swierstra, dr. Ate Wymenga, Jan van Loon, Gijs van Hellemondt, dr. Maarten Spruit, dr. Marc Nijhof, Dick van der Schaaf, Koen Defoort, Arno ten Ham, dr. Angélique Witteveen, dr. Vincent Busch, dr. Jon Goossen, Els van der Eede, dr. Jan-Willem Louwerens, Professor dr. Marinus de Kleuver, Philip Horsting, dr. Harald de Man.

Graag wil ik jullie bedanken voor de tijd die jullie mij hebben gegeven en gegund om 
aan dit proefschrift te werken en de enthousiaste motiverende reacties die jullie gaven als ik weer een van mijn stukjes had gepubliceerd.

Mijn bovenste extremiteiten collega: Marco van der Pluijm Marco, we werken inmiddels bijna 5 jaar samen in onze bovenste extremiteitsunit. Je hebt me in het begin, tijdens mijn Fellowship de kneepjes van het BE vak bijgebracht en me daarna veel ruimte gegeven om mij verder te ontwikkelen en die ruimte geef je me nog steeds. Dank je wel daarvoor.

Het secretariaat: Wilma Muller, Caroline Lintsen en Wilma van Engelen. Dank jullie wel voor jullie ondersteuning en interesse in de voortgang van het onderzoek. Wilma Muller, dank je wel voor het bewaken van mijn agenda als ik weer eens teveel uren in een dag wilde stoppen.

Mijn Paranimfen: Remco van der Wiel. Remco, we kennen elkaar al heel lang en je hebt het hele traject van de promotie en alles wat er daarnaast plaatsvond meegemaakt, ik vind het bijzonder dat je mijn paranimf wilde zijn en ben je dankbaar voor onze vriendschap.

(Oom) Theodoor van Boven, Theodoor, dank je wel dat je mijn paranimf wilde zijn. Ik weet zeker dat Opa Jan het zou hebben weten te waarderen en kon je grap ten aanzien van de letterlijke uitleg van een 'rok' kostuum wel waarderen.

Vrienden: Rinus en Fifi, Rob en Gaby, Marie-France, Bas en de vrienden van "de Kaar vaan Mestreech", jullie waren wel weer in voor een feestje, dus dat komt er!

Mijn ouders en broer, Arie, Berdien en Roald, jullie hebben mij altijd gesteund bij de keuzes die ik gemaakt heb, ook al was dat telkens aan de andere kant van Nederland. Lieve Arie en Berdien door jullie kritische maar nuancerende opvoeding heb ik mij op vele vlakken kunnen ontwikkelen. Ik ben jullie dankbaar voor alle steun door de jaren heen. Lieve Roald, we hebben vaak discussies gehad over het leven, hoewel we daar ieder onze eigen kijk op hadden heeft het ons wel gebracht waar we nu staan, dank je wel daarvoor. 
Mijn (schoon)familie, Giel en Toos Dijk en (zwager en schoonzus) Sander en Annet, dank jullie wel voor de voortreffelijke wijze waarop jullie mij kennis hebben laten maken met de Maastrichtse traditie en gebruiken. Ik dacht dat ik Maastricht kende, maar er was nog veel meer! Dank ook voor de voortdurende interesse in mijn onderzoek en de voortgang van het promotietraject.

Mijn kinderen: Lieve Sjuul en Felice, in jullie nog relatief korte leventje hebben jullie mij tot nu toe niet anders gekend als af en toe wat humeurig omdat het niet opschoot met het onderzoek. Het was dan ook zeer ontroerend toen jullie begrepen wat er moest gebeuren voor het boekje. Jullie begonnen als bezetenen te tekenen, zelfs dubbelzijdig, want dan was het boekje eerder af en konden we een Legostad gaan bouwen. Inmiddels is het boekje af en wachten er weer andere uitdagingen, maar een ding is zeker, we gaan nog veel (lego) bouwen samen.

Mijn lieve vriendin en partner: Barbara, toen we elkaar leerden kennen was ik al bezig met het onderzoek en het heeft al die tijd als een telkens terugkerende rode draad door ons leven heen gelopen. Ik heb veel respect voor het geduld wat je daarvoor opgebracht hebt. Je steun is onvoorwaardelijk geweest en je hebt me telkens weer gestimuleerd als het even tegenzat. Dank je wel lieve schat. 


\section{Curiculum Vitae}

Ludo Ivar Folmer Penning was born on the 1th of August 1975 in Voorburg. After graduation from high school ( VWO, Haags Montessori Lyceum) in 1993, he studied medicine at Maastricht University. During the second year of the curriculum his first interest in scientific research was born during the block "with trial and error", He was introduced to the orthopedic surgery by Dr Eric Hoorntje and started with a retrospective study on the effect of lateral ligament releases in retropatellar chondropathy under supervison of prof dr Sjoerd K. Bulstra. During the internships research was further continued at the Maastricht orthopedic department on the treatment of congenital dysplasia of the hip, early versus late treatment. In 1999 he completed his medicine studies.

After obtaining his medical degree, the orthopedic career was started. Under supervision of professor dr. Geert Walenkamp the basis was made for this thesis. In 2000 he was accepted for the orthopedic training program, he was subsequently trained in the Diaconessen Ziekenhuis Eindhoven, Maastricht University Medical Center and Orbis Medical Center. Starting in 2003 until finishing his training in 2010, the orthopedic training was combined with the conduction of studies, subject of this thesis and a Master Epidemiology.

In 2010 he started a Fellowship Upper extremity under supervision of Marco van der Pluijm at the Sint Maartenskliniek, Nijmegen. He now lives in the north of Limburg, with his girlfriend Barbara and their two children Sjuul and Felice. After the Fellowship he continued working as a consultant orthopedic surgeon specialized in Upper extremity at the Sint Maartenskliniek, Nijmegen. 


\section{Valorisation}

\section{Introduction}

In this valorisation chapter we describe the innovative aspects of the studies conducted for this thesis. The results of the performed studies have generated knowledge on aspects of treatment and diagnostics in cuff disorders. This new knowledge is of value for science, but also has socioeconomic implications.

\section{Innovation}

In this thesis we have studied the effectiveness of injections in cuff disorders. We investigated the effectiveness of hyaluronic acid as a novel medicine for this type of shoulder complaints. We have shown that hyaluronic acid has unsatisfactory effectiveness in the treatment of cuff disorders and was less effective than corticosteroid injections. We could prove that corticosteroid injections work rather fast and are significantly more effective up to 12 weeks after injection.

In our search for the effectiveness of repeated subacromial corticosteroid injections, we discovered a booster effect of repeated injections. As far as we know this has not been described before in the treatment of cuff disorders. The repetition of an injection leads to an increased reduction in pain after corticosteroid injections as compared to hyaluronic acid and saline injections.

At present there are no strict guidelines stating the maximum number of repeated corticosteroid injections. The advice is to repeat when effective. Based on animal studies numbers of injection repetition up to six times a year are suggested. ${ }^{(1)}$

In the study described in chapter three we found a booster effect of the first and second injection, resulting in a decrease in pain during the first eight to ten days after injection. A third injection did not result in a further decrease in pain. Based on these results we propose a maximum of 2 corticosteroid injections. 
A single physical examination test for shoulder disorders has a rather low sensitivity and specificity. Combining tests has been proven to result in a higher reliability. ${ }^{(2,3)}$

For this thesis we have combined the empty can and drop arm test, two tests, examining pain and motor function, with a subacromial injection. With this combination we were able to show an improved specificity after injection as compared to a single test without subacromial injection.

Reproducible measurement of shoulder abduction and anteflexion was investigated with a novel test design using a three dimensional gyroscope. We could prove good to excellent reproducibility with this test design.

\section{Social and economic relevance}

Shoulder related sick leave accounts for an incidence of approximately $16-18 \%{ }^{(4)}$ Most patients will suffer from complaints between six to twelve months. ${ }^{(5)}$

In this thesis we have shown that a positive result can be achieved after subacromial corticosteroid injections at the short and intermediate term (six months). Although not part of the research for this thesis, this positive effect can lead to earlier return to work. Especially since half of the medical cost of shoulder complaints in the first six months are generated by sick-leave. ${ }^{(6)}$

In this thesis we have presented the limited effect of repetition of subacromial corticosteroid injections more than two times. We also proposed a treatment algorithm in which test results and corticosteroid injections are combined. Change of the current therapeutic and diagnostic approach, based on these results and the proposed algorithm can lead to a faster diagnostic track and subsequently better therapeutic results.

Reduction of corticosteroid injection by means of reducing the number of repeated injections will only give limited change on a macroeconomic level.

\section{Target Group}

The results of this thesis are relevant for health care workers in primary and secondary care. 
In primary care large numbers of patients suffering from shoulder complaints are treated. Many family doctors are able to treat with corticosteroid injections, but at present the diagnostic tools in the Dutch setting might be improved The results presented in this thesis provide another and novel diagnostic approach in which effectiveness of injections and physical examination are combined.

In secondary care patients suffering from shoulder complaints generally are treated by Rheumatologists and Orthopedic Surgeons. In the setting of secondary care more diagnostic resources are available compared to primary care. Nevertheless, the basic approach in which the effectiveness of a subacromial injection is combined with results from physical examination is applicable in secondary care as it is in primary care. Improvement of diagnostics and injection therapy might result in less use of costly hightech tools as MRI.

Given the positive results of subacromial administered corticosteroid injections, they tend to be repeated too often in both primary and secondary care. The results presented in this thesis show these repetitions in a different perspective, and should be limited. This could result to shorter treatments.

\section{Future research}

In this thesis we gave a description of a classification of the painful arc. Based on the available data we were not able to prove the reproducibility and validity of this classification. Future research could explore this.

Future research also should focus on the cost-effectiveness of the treatment of cuff disorders. 


\section{References}

1. Diercks, R., et al., Guideline for diagnosis and treatment of subacromial pain syndrome: a multidisciplinary review by the Dutch Orthopaedic Association. Acta Orthop, 2014. 85(3): p. 314-22.

2. Biederwolf, N.E., A proposed evidence-based shoulder special testing examination algorithm: clinical utility based on a systematic review of the literature. Int J Sports Phys Ther, 2013. 8(4): p. 427-40.

3. Hanchard, N.C., et al., Physical tests for shoulder impingements and local lesions of bursa, tendon or labrum that may accompany impingement. Cochrane Database Syst Rev, 2013. 4: p. CD007427.

4. Luime, J.J., et al., High incidence and recurrence of shoulder and neck pain in nursing home employees was demonstrated during a 2-year follow-up. J Clin Epidemiol, 2005. 58(4): p. 407-13.

5. Kuijpers, T., et al., Clinical prediction rules for the prognosis of shoulder pain in general practice. Pain, 2006. 120(3): p. 276-85.

6. Kuijpers, T., et al., Costs of shoulder pain in primary care consulters: a prospective cohort study in The Netherlands. BMC Musculoskelet Disord, 2006. 7: p. 83. 

